和

-

Hing

14.

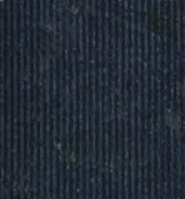

H.m.

(1)
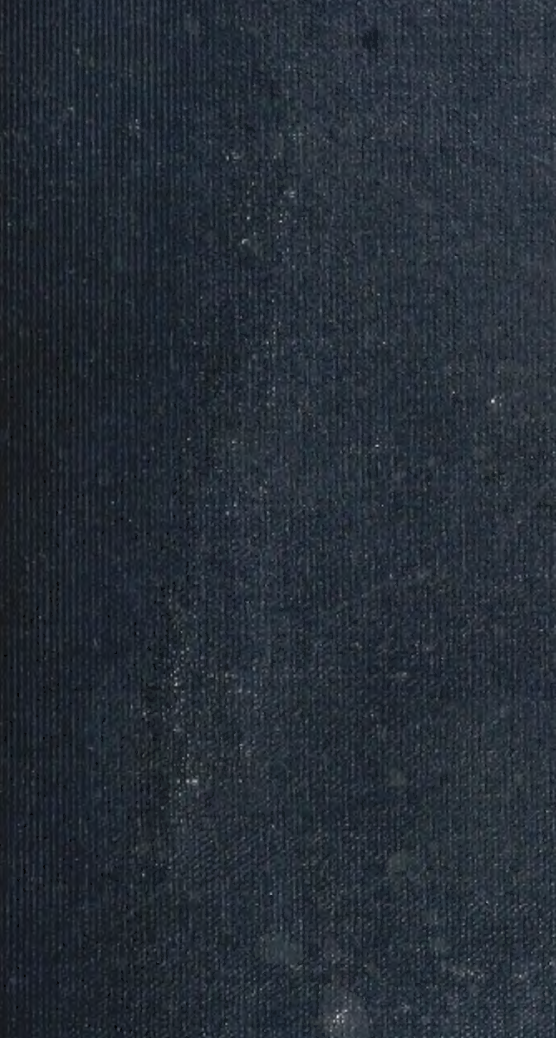

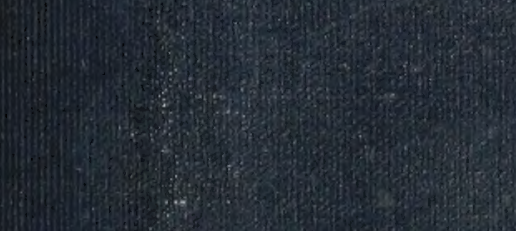

(4)

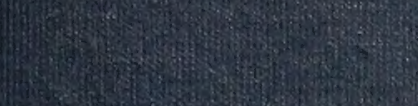




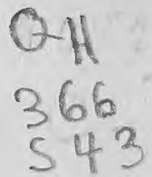

\section{OTrnell Alniurratu Tithrary}

BOUGHT WITH THE INCOME OF THE

SAGE ENDOWMENT FUND

THE GIFT OF

Henry W. Sage

I89I

A. 369349

$28 / \pi / 7$ 


\section{$x=$}

\section{WाT 3956-4 \\ APR $101905 B$ B W \\ MART 419745 :}

Neiknotinguges

$A P R-5-200$

\section{QH 366.S43}

Cornell University Llbrary

Theory of evolution : 


\section{Cornell University Library}

The original of this book is in the Cornell University Library.

There are no known copyright restrictions in the United States on the use of the text.

http://www.archive.org/details/cu31924024561015 
Richard Westbrook Lectures of the Wagner Free Institute of Science, Philadeliphia.

\section{THE THEORY OF EVOLUTION}




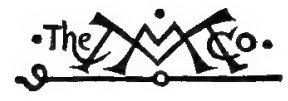

\section{THE MACMILLAN COMPANY}

NEW YORK - BOSTON - CHICAGO - DALLAS ATLANTA - SAN FRANCISCO

\section{MACMILLAN \& CO., LIMTTED IONDON - BOMBAY - CALCUTTA MELBOURNE}

THE MACMILLAN CO. OF CANADA, Ltd. TORONTO 


\section{THE}

\section{THEORY OF EVOLUTION}

WITH SPECIAL REFERENCE TO THE EVIDENCE UPON WHICH IT IS FOUNDED

\section{BY \\ WILLIAM BERRYMAN SCOTT}

PH.D. (heidelberg), hon. D.BC. (harvard \& oxford), Ll.D.

(UNIVERSity OF PENNSYlVANIA), BLAIR PROFEsSOR OF GEOLOGY \& PALAEONTOLOGY IN PRINCETON UNIVERSITY

Arew Uark

THE MACMILLAN COMPANY

1917

All rights reserved

E., 


$$
\text { A.369349 }
$$

Copyrighr, 1917

Bx THE MACMILLAN COMPANY

Set up and electrotyped. Published February, 1917. 


\section{PREFACE}

A new book on evolution, which can lay little claim to novelty of fact or treatment, certainly demands an explanation, if not an apology. My choice of subject for the Westbrook lectures of 1914 was determined by the very general misapprehension in the public mind concerning the present status of the evolutionary theory among men of science. It is widely believed that the theory is an outworn device, which naturalists are beginning to discard and that soon it will have a merely historical interest. This misunderstanding, for such it is, has arisen from the debates among zoölogists and botanists as to the manner in which evolution has actually occurred and the efficient causes which have brought it about, and, further, from the ambiguous way in which the term "Darwinism" is often employed. Frequently, the term is made a synonym of evolution, but it ought properly to be restricted to Darwin's explanation of evolution by natural selection.

It seemed that a useful service might be rendered by making an outline review of the evidence upon which the doctrine of evolution is founded, for the nature and scope of this evidence are but little understood by the educated, though non-scientific public. The interest displayed in these topics by the 
audiences at the Wagner Institute encourages me to hope that a larger and more widely dispersed audience may share the same interest. The annoying barrier of technical language has been evaded so far as possible, but the lack of suitable vernacular terms is such that it is not practicable to escape technicalities altogether. The effort to use ordinary speech and the want of numerous illustrations have caused a certain prolixity of description, which is regrettable, but less so, perhaps, than the alternative of obscurity.

My experience with graduate students of biology has shown me that usually their training has so completely taken for granted the truth of the evolutionary doctrine, that they have but a vague conception of the testimony by which that doctrine is supported. This book may be useful in directing their attention to the character of the evidence and, though, of course, the meagre sketch contained in these lectures is entirely inadequate in itself, it does provide an outline which students can easily fill in from their own reading.

In the winter of 1910-11 an admirable series of popular lectures by several men of high distinction was delivered in the Natural Science Society of Munich, as a tribute to the centennial of Charles Darwin's birth. These lectures were published in 1911 by G. Fischer of Jena with the title Die Abstammungslehre. To this most excellent compendium of the evidences of evolution I am under great ob- 
ligations and I wish that it might soon be translated into English. I take pleasure also in expressing my thanks to my colleagues, Professors Conklin and Smyth and Dr. Mayer for valuable suggestions in the difficulties of treatment and to Dr. W. J. Sinclair for his care in making the figures.

Princeton, N. J., December, 1916. 



\section{CONTENTS}

\section{LECTURE I}

PAGE

Present Status of the Question . . . . . . . . 1

\section{LECTURE II}

Evidences for the Theory-Classification, Domestication and Comparative Anatomy . . . . . 27

\section{IECTURE III}

Evidence from Embryology and Blood Tests . . . 57

\section{LECTURE IV}

Evidence from Palæontology . . . . . . . . 82

\section{LECTURE V}

Evidence from Geographical Distribution . . . 120

\section{LECTURE VI}

Evidence from Experiment-Conclusion . . . . . 149 



\section{THE THEORY OF EVOLUTION}


. 


\section{THE THEORY OF EVOLUTION}

\section{LECTURE I}

\section{PRESENT STATUS OF THE QUESTION}

Among that public which, though educated and intelligent, is yet not professionally scientific, there has been, of late, a widespread belief that naturalists have become very doubtful as to the truth of the theory of evolution and are casting about for some more satisfactory substitute, which shall better explain the infinitely varied and manifold character of the organic world. This belief is an altogether mistaken one, for never before have the students of animals and plants been so nearly unanimous in their acceptance of the theory as they are to-day. It is true that there are still some dissentient voices, as there have been ever since the publication of Darwin's "Origin of Species," but the whole trend of scientific opinion is strongly in favour of the evolutionary hypothesis.

Whatever may be the private opinion of a greater or less number of naturalists on this question, almost the only zoölogist of recognized standing who has taken a pronounced and positive position against the theory, is Professor Fleischmann, of Erlangen. He 
writes: "The more deeply I pursued the alleged evidence for it [the theory] and sought to gain, through special investigations, some essential proof of the genetic relationships of animals, the more clearly I recognized that the theory is a seductive romance, which deceptively pretends to give results and explanations, rather than a doctrine built upon positive foundations." 1 In another passage he speaks of the "collapse of the theory." This opinion of Professor Fleischmann's stands almost entirely alone in modern biological literature, yet is not altogether surprising, for, from the very nature of the case, such complete and indubitable proof as Professor Fleischmann demands is unattainable.

What, then, has led to the belief, mentioned at the outset, that naturalists have so largely grown sceptical and are inclined to abandon the theory? This belief is principally due to the fact that there is no agreement among men of science as to the manner in which evolution operates (modes) or as to its efficient causes (factors) and, further, to the often fierce controversies which long have been and still are held concerning these problems of modes and factors. Some biologists maintain that these questions are unanswerable in the present state of knowledge and have taken up other lines of investigation, but that is very far from being an abandonment of the theory of evolution itself. It is one thing to accept a fact as substantially proved and

${ }^{1}$ Albert Fleischmann: Die Descendenztheorie, Leipzig, 1901, p. iii. 
quite another thing to devise a satisfactory explanation of that fact.

A few quotations from distinguished investigators, who are representatives of different schools of thought, will serve to show just what the most striking divergences of opinion are. Professor E. B. Wilson, in his address as President of the American Association for the Advancement of Science (1914), says: "Biologists turned aside from general theories of evolution and their deductive application to special problems of descent, in order to take up objective experiments on variation and heredity for their own sake. This was not due to any doubts concerning the reality of evolution or to any lack of interest in its problems. It was a policy of masterly inactivity deliberately adopted; for further discussions concerning the causes of evolution had clearly become futile until a more adequate and critical view of existing genetic phenomena had been attained." [Italics mine.]

Professor Gustav Steinmann, of Freiburg, who occupies a very isolated position regarding the actual lines of descent and relationship between the various groups of plants and animals, and whose views on these topics have been very severely criticised, has no hesitation in declaring his unreserved acceptance, of the evolutionary theory. His words are: "The theory of development, as it was revived by Darwin nearly half a century ago, is in its modern form prevailingly unhistorical. True, it has forced beneath its sceptre the methods of investigation of all the 
sciences which deal with the living world and to-day almost completely controls scientific thought. . . . And yet science does not sincerely rejoice in its conquests. Only a few incorrigible and uncritically disposed optimists steadfastly proclaim what glorious progress we have made; otherwise, in scientific as in lay circles, there prevails a widespread feeling of uncertainty and doubt. Not as though the correctness of the principle of descent were seriously questioned; rather does the conviction steadily grow that it is indispensable for the comprehension of living nature, indeed self-evident. [Italics mine.] But never before has it become so notorious as in the last decade, how little there is in this theory that is universally accepted, as appears when the most obvious questions are asked regarding the course of development and its efficient causes. No one can supply simple and satisfactory answers. Should any one ask, by what steps the placental mammals have proceeded from lower quadrupeds, he is informed that some investigators derive them from the reptiles by way of the marsupials, others directly from certain Permian reptiles, while others again push back their origin to the most ancient periods and derive them from entirely unknown ancestors, or, should somebody wish to know why the many remarkable animals and plants of preceding geological periods are no longer living, and what causes led to their extinction, he would receive anything but a clear and unambiguous answer. Who would venture to-day to 


\section{PRESENT STATUS OF THE QUESTION}

report anything but the personal conception of individual investigators, if he were asked for information regarding the hereditary transmission of acquired characters, the significance of natural selection, or many other details of the theory of evolution? For what to one is the corner stone of the theory is to another a factor of quite subordinate importance, while a third regards it as the greatest aberration of the past century." 1 Lastly, may be cited Mr. Bateson, one of the foremost exponents of Mendelism, who rejects Darwinism, one might say, with contumely. "The many converging lines of evidence point so clearly to the central fact of the origin of the forms of life by an evolutionary process that we are compelled to accept this deduction, but as to almost all the essential features, whether of cause or of mode, by which specific diversity has become what we perceive it to be, we have to confess an ignorance nearly total. [Italics mine.] The transformation of masses of population by imperceptible steps guided by selection, is, as most of us now see, so inapplicable to the facts, whether of variation or specificity, that we can only marvel both at the want of penetration displayed by the advocates of such a proposition, and at the forensic skill by which it was made to appear acceptable even for a time." 2

These quotations might be much extended and diversified, but they cover the principal categories

1 Gustav Steinmann: Die Abstammungslehre, Leipzig, 1908, pp. 1, \&. ${ }^{2}$ William Bateson: Problems of Genetics, New Haven, 1913, p. 248. 
of modern biological opinions, excepting that of the strictly Darwinian school. They suffice, however, to show how little support such opinions offer to those who would cast aside the theory of evolution as a worn-out hypothesis. It is clear that the differences of belief are almost wholly concerned with the problems of modes and factors, not with the theory itself. The duality of meaning attached to the term "Darwinism" is largely responsible for the popular misapprehension as to the present status of the theory among naturalists. Darwinism is frequently employed as synonymous with evolution, but this is an inexact usage, and the term should be restricted to Darwin's explanation of the evolutionary process. Owing to this inaccurate use of the word, many people, when they hear that such and such prominent biologists have rejected and attacked Darwinism, jump to the entirely false conclusion that the attack is directed against the theory of development.

The theory of organic evolution made its appearance very early in the history of Greek philosophy and reappeared from time to time in Roman and mediæval writers, because of the charm which the conception of uniformity and continuity in nature exercises over many minds. But these early suggestions were merely speculative; no attempt was made to support the theory by evidence, or to gather a systematic body of observed facts which demanded explanation. Each writer was content to quote from such predecessors as appealed to his fancy or his 
judgment, without undertaking to test the conclusions handed down to him. Indeed, until the sciences of Zoölogy and Botany had been gradually built up and a great body of observed facts had been gathered and arranged in an orderly manner, no other procedure was possible; this did not take place until the end of the 18th and beginning of the 19th century. Even then, however, little real progress was made; scientific opinion was not ripe for such a bold generalization and the teachings of Lamarck attracted few followers, especially as the overwhelming authority of Cuvier was exerted against these teachings.

It is of interest to note that Lamarck (1744-1829) arrived at the evolutionary conception, just as Darwin did nearly half a century later, through a study of the problem of species. Species was first employed as a term in logic and was given a definite application to animals and plants by John Ray (16281705), who indicated by it a group of organisms with marked characteristics in common and freely interbreeding. The concept received a more precise meaning and definition from the great Swedish naturalist Linnæus (1707-1778), who devised the modern scheme of the classification and nomenclature of animals and plants. Linnæus was somewhat inconsistent in his expressions on the subject, but the doctrine which was accepted as his by nearly all of his contemporaries and successors was that species were fixed entities which had been separately created. The Linnæan dogma, which prevailed down to the 
time of Darwin, is that "there are as many species as God created in the beginning." Lamarck, who had accomplished an immense amount of systematic work in zoölogy and botany, felt compelled to deny the Linnæan doctrine and to take up the alternative explanation of evolutionary descent.

Lamarck's best known work is his "Philosophie Zoölogique," which is very abstruse and speculative and contains but little evidence for his conclusions, other than a reference to his wide experience as a systematist, i. e., a student of classification. He maintained that the species was an artificial conception and that nature knew only individuals in graduated steps of relationship. Most of the book is devoted to a consideration of the causes which have led to the transformation of animals and the conclusion is that adaptation to environment is the most efficient factor. This adaptation is to be explained by the fact that the conditions of life determine the manner in which animals make use of their organs; these are developed and perfected by use, but dwindle and are atrophied through disuse. Animals which live in the dark, as in caves or in the abysses of the ocean, are blind, while their organs of feeling are highly developed to take the place of sight. As the environment is subject to constant change, adaptation requires that living beings should be correspondingly, though gradually, transformed.

Modern accounts of Lamarck's views are almost always taken from the "Zoölogical Philosophy," but, 
as Giard has pointed out, a clearer conception may be obtained from an examination of the successive introductory lectures of the courses in zoölogy at the Paris Museum. Giard says: "It was the attentive and minute study of the innumerable species of plants which Lamarck, the botanist, had had to describe and classify in the Flore française and Encyclopédie methodique; it was the necessity of beginning, at the age of fifty, a work of the same kind for the lower animals ... ; it was finally the need of crowning with a synthesis thirty years of analytical labours, which led the great naturalist, till then a partisan of the stability of the species, to demonstrate its variability and to search for the causes of the transformation of types." He then gives an extensive quotation from the introductory lecture of 1806, from which the following passage may be taken:

"All the observations which I have gathered on this important subject, even the difficulty which I know, from my own experience, is now felt in distinguishing species in genera where we are already very rich, a difficulty which is daily increased as the researches of naturalists enlarge our collections, everything has convinced me that our species have but a limited existence and, for the most part, differ from neighbouring ones only by shades which are difficult to express. Those who have observed much and have examined great collections, have been able to convince themselves that, as the circumstances of habitat, of exposure, of climate, of nourishment, of 
manner of life, are changed, the characters of stature, form, proportion of parts, colour, consistency, duration, agility and industry in animals are proportionally changed.

"They could see that in animals the more frequent and sustained use of any organ gradually strengthens and develops that organ, enlarges it and gives it a power in proportion to the duration of that use; while constant disuse of such an organ insensibly weakens it, deteriorates it, progressively diminishes its capacities, tends to destroy it.

"Finally, they could note that everything which nature causes individuals to acquire or to lose through the sustained influence of circumstances to which the race has long been exposed, she transmits by generation to the new individuals which spring from them. These truths are constant and cannot be mistaken save by those who have never observed and followed nature in her operations." 1

Lamarck, as already noted, had but few disciples in his own or immediately succeeding times, largely because of the opposition of Cuvier, who wielded a despotic authority over scientific opinion in France. In Germany also the evolutionary theory fell into complete discredit, but for another reason; in that country the theory had been advocated chiefly by the so-called "Natural Philosophers," whose wild and fantastic speculations finally disgusted soberminded men and turned their labors into more ob-

${ }^{1}$ Alfred Giard: Controverses Transformistes, Paris, 1904, pp. 13, 14. 
jective channels. The Linnæan doctrine of the fixity and immutability of species held the field so exclusively for the next half century, that Darwin tells us that he had never met and conversed with any naturalist who did not hold such a belief.

The way for the great revolution effected by Darwin was prepared indirectly and in a science which seemed to be very remote from the field of controversy, viz., Greology, and the pioneer who opened this new road was Sir Charles Lyell (1797-1875)'. Before Lyell began his great work, the interpretation of the earth's history was under the sway of Cuvier's theory of "Catastrophism." According to this theory, the history of the earth consisted of long periods of tranquil geographical development, interrupted at intervals by utterly indescribable and unimaginable cataclysms, when elemental forces were unchained, devastating the earth, breaking up and displacing the rocks and destroying every living thing; of these periods of destruction, d'Orbigny enumerated 27 . When tranquillity was restored, renewed acts of creation supplied animals and plants for the depopulated earth and thus, as it were, the curtain rose upon a new scene, with a new set of actors, the old having been completely swept away. It was observed that each fresh creation produced animals and plants of a higher type, successively approximating the present order of things. Cuvier was too cautious and too critical to declare dogmatically that there had actually been many successive acts of creation and he 
suggested alternative hypotheses to explain the observed facts. On the other hand, he seems to have himself believed in the creations and his contemporaries and successors accepted that doctrine as his.

Lyell reverted to the neglected teachings of the Scotchman, James Hutton (1728-1797), that the key to the past history of the earth was to be found in the work of agencies which are now in operation. Like Hutton, he would not admit that any process which is not still at work could be called upon to explain events in the past and he even went so far as to make these existing processes the measure and standard of former operations. In the sharpest contrast to Cuvier's Catastrophism, Lyell's theory was that of Uniformitarianism, which insisted upon the uniformity and complete continuity of the earth's history and of the agencies which had wrought such profound changes upon and within the globe. In the early editions of his famous "Principles of Geology," Lyell was evidently on the point of accepting the theory of organic evolution, but later he receded from this position, because he was not satisfied with the evidence for it. Lyell's influence upon geology was rapid and profound in England and Darwin, who became his intimate friend, was conspicuously under that influence, as he himself repeatedly testified. One might almost say that Darwin's work largely consisted in the application of Lyell's principle to the world of living beings. 
Unquestionably, the most important and influential figure in the history of the evolutionary theory is that of Charles Darwin (1809-1882), who effected one of the most remarkable and far-reaching revolutions in all departments of human thought of which we have any record. By a curious coincidence, Darwin and Alfred Russell Wallace (1823-1913) independently reached the same solution of the problem concerning the origin of new species, but, with a fine absence of jealousy and self-seeking, none too common in the history of science, they coöperated in the production of a preliminary paper, which appeared in 1858; this, however, attracted little attention.

The publication of Darwin's "Origin of Species" in 1859 is one of the great landmarks in the history of science and brought about, though gradually, an extraordinary revolution in opinion. That Darwin's work did not share the fate of that of Lamarck and other early evolutionists was due in part to the preparatory labours of Lyell, who had familiarized men's minds with the conception of uniformity, continuity and orderly progress in the development of the earth, but chiefly to Darwin's method of gathering and presenting the evidence. Though greeted at first with a storm of criticism, not unmingled with abuse, the sheer weight of evidence, presented with such transparent simplicity and candour, inevitably forced conviction even upon unwilling minds. But here it is again necessary to 
emphasize the distinction between the two aspects of Darwin's work. His argument, supported by the amazing mass of proof, which had been gathered through twenty laborious years, gradually convinced scientific men that the theory of evolution offered by far the most probable and satisfactory solution of the problems of the living world. On the other hand, Darwin's explanation of the evolutionary process, commonly known as the theory of "Natural Selection," won no such universal acceptance and has been a subject of controversy, more or less acrimonious, from the time of its first promulgation to the present day. On the other hand, it must be recognized that Natural Selection played a very important part in bringing about the general acceptance of evolution, for it was the first suggestion of a reasonable and intelligible factor in producing the transformation of species. Huxley's account of his own attitude of mind is well adapted to explain this. He tells us that before 1858, he had no definite opinions on the subject and this for two reasons: "firstly, that up to that time, the evidence in favour of transmutation was wholly insufficient; and, secondly, that no suggestion respecting the causes of the transmutation assumed, which had been made, was in any way adequate to explain the phenomena." 1 Huxley was never fully satisfied with the doctrine of natural selection, but, nevertheless, that doctrine had a large share ${ }^{2}$ Life and Letters, Vol. II. 
in making him the convinced and thoroughgoing evolutionist that he was.

It is interesting to retrace some of the more significant steps by which Darwin reached his conclusions, a course which he has made easy by his autobiographical sketch. The famous voyage in the naval brig Beagle, which lasted nearly five years (1831-1836) was, he tells us, "by far the most important event in my life and has determined my whole career." Much of this period was spent in long journeys in the interior of South America, and the wealth of observations thus gathered forced upon him the problem of transmutation. There were three classes of facts by which he was deeply impressed. (1) In the surface deposits of the Argentine pampas he found the remains of gigantic extinct animals, differing from, yet fundamentally resembling those which still inhabit the same region. (2) "The manner in which closely allied animals replace one another in proceeding southward over the continent." Such a succession of closely allied forms is what would be expected on the evolutionary theory; a single species in ranging over a very wide area would become modified so as to give rise to several other species, while from the doctrine of special creation no explanation is possible. What had the greatest weight to his mind was afforded by his observations in the Galapagos archipelago, a group of volcanic islands 500 miles west of the Ecuador coast. As a whole, the animals and 
plants of these islands are of distinctly American type, yet most of the species are peculiar to the group and each island has a surprising number of species peculiar to itself. "Reviewing the facts here given, one is astonished at the amount of creative force-if such an expression may be used-displayed on these small, barren, rocky islands; and still more so at its diverse and yet analogous action on points so near each other."

The growth of his belief in evolution is thus described by Darwin in a letter written in 1877: "When I was on board the 'Beagle,' I believed in the permanence of species, but, as far as $I$ can remember, vague doubts occasionally flitted across my mind. On my return home in the autumn of 1836, I immediately began to prepare my journal for publication, and then saw how many facts indicated the common descent of species. . . But I did not become convinced that species were mutable until I think two or three years had elapsed." Even after he had gained his conviction of the mutability of species, he could imagine no adequate cause of the change and, consciously adopting the methods which Lyell had used in Geology, he made a great collection of facts, gathered from breeders, fanciers, gardeners, as well as from his own observations, bearing on the changes and modifications which men had brought about in the various races and breeds of domesticated animals and plants. "I soon perceived that selection was the key-stone of man's success 


\section{PRESENT STATUS OF THE QUESTION}

in making useful races of animals and plants. But how selection could be applied to organisms living in a state of nature remained for some time a mystery to me." The key to this mystery was suggested to him by reading Malthus' famous essay on Population. In his own words: "Being well prepared to appreciate the struggle for existence which everywhere goes on from long continued observation of the habits of animals and plants, it at once struck me that under these circumstances favourable variations would tend to be preserved, and unfavourable ones to be destroyed. The result of this would be the formation of new species. Here then I had a theory by which to work." ,

Time fails to trace farther the stages of growth in Darwin's opinions. All that can be here attempted is a brief outline of the theory which, after nearly twenty strenuous years, he gave to the world in the "Origin of Species," published in 1859. Unlike most other explanations of evolution, Darwin's theory is a chain of reasoning, every link of which is an undisputed fact, the only question being, does the theory afford a sufficient and adequate explanation of the phenomena? The attempts to give a definite and conclusive answer, affirmative or negative, to this question have given rise to the many debates of which we have by no means heard the last word.

$\checkmark(1)$ The first of the undisputed facts upon which Darwin's theory is founded is that of variability. It is 
a matter of the commonest observation that no two individuals of a species are exactly alike and, when a very large number of specimens are studied, the range of variation is often found to be exceedingly wide. Such variations are fluctuating and repeated in every generation.

(2) The second fact is the struggle for existence. Every species in a state of nature produces vastly more young than can possibly survive to maturity; if every egg of the herring should develop to an adult fish and reproduce in its turn, it would not be long before the Atlantic Ocean would fail to contain them. A statistical study of many species leads to the conclusion that, so long as the conditions of life remain the same, the number of individuals of a given species is a substantially constant quantity, subject of course to fluctuations of increase and decrease. Thus, for every young animal or plant that reaches maturity, an old one must die to make place for it. The struggle for existence is not to be thought of as a combat to slay and devour, but as a competition for food, light and the other necessities of life, as well as resistance or escape from the attacks of predatory enemies, parasites, diseases and the like. Not only is there intense competition between members of the same species, but also between allied species with similar habits and needs.

$\sqrt{\text { (3) The third fact is natural selection, or, in Herbert }}$ Spencer's happier phrase, the survival of the fittest. Survival to the age of reproduction is not a matter 
of chance, but those individuals persist which are the most vigorous and any variation from the average of the species which confers an advantage in the struggle will tend to be preserved and to increase in successive generations. Darwin, as he tells us, very early perceived that in making new breeds of domesticated animals and plants, selection of the parents according to the characteristics which it was desired to perpetuate and improve, played the important rôle and he concluded that advantageous variations, by enabling their possessors to survive in the struggle, would furnish the material for the formation of new species, while any disadvantageous variation would be promptly extinguished.

(4) Finally, there is the fact of heredity. It is a commonplace that individuals are like their parents and should the parents have from birth some advantageous peculiarity, this would tend to reappear in the offspring. A repetition of this process from generation to generation would have a cumulative effect, resulting in very extensive changes.

While Darwin always maintained that natural selection was by far the most important and efficient cause in producing transmutation, he admitted the action of other, though minor factors. Thus, he makes frequent appeal to the effects of use and disuse of organs, the agency which Lamarck had regarded as of such primary importance, and he advanced the theory of sexual selection to account for the brilliant colouring and elaborate patterns 
of very many animals, especially of butterflies and birds. Inasmuch, however, as the effects of use and disuse as an evolutionary factor involve the assumption that characters acquired during the lifetime of the parent are or may be transmitted to the offspring, an assumption which is now vigorously denied, modern disciples of Darwin reject this factor and attribute little importance to sexual selection. They accept Weismann's dictum that natural selection is the sole and all-powerful agent of evolution.

Darwin's book, reënforced by his subsequent works, brought about the astonishing revolution in scientific opinion which has already been described, but, while the evolutionary theory thus gained a complete and almost universal victory, Darwin's particular theory, that of natural selection, was not so fortunate. True, it was and still is very widely accepted, but there has always been a large body of opinion which rejected it as vague, inadequate and unsatisfactory and there have been many attempts to supplement it, or to substitute some more convincing explanation for it. Thus, the eminent German botanist Carl von Nägeli (18171891) propounded an elaborate theory of development, in which he attempted to show that natural selection was an insufficient explanation of evolution and that a "principle of perfection" must be assumed, which drives organisms to take on higher and higher forms. He compares the living world 


\section{PRESENT STATUS OF THE QUESTION 21}

to a garden full of shrubs, which are continually sending out new branches, the tips of which represent the plants and animals now existing; they grow by their own internal force, but are kept within limits by the action of natural selection, which plays the part of the gardener with his pruningshears. Were it not for this pruning, the shrubbery would speedily degenerate into a wild and formless thicket.

One of the earliest and most obvious objections made against Darwin's theory was that a slight favourable variation, arising in a few individuals would be speedily swamped by cross-breeding with the vastly more numerous individuals which did not display that variation. To avoid this objection, Moritz Wagner propounded his theory of the "origin of species by separation in space," according to which geographical separation of groups of individuals, by the prevention of interbreeding, produced new forms through a process of divergent development. Everything that we know indicates that geographical separation has been an important factor in bringing about the diversity which characterizes the living world, but few would attribute to this factor the significance which Wagner gave to it.

Professor August Weismann of Freiburg (18341914) was a most influential figure in the biological controversies which raged in the latter part of the nineteenth century, especially by his elaborate the- 
ories of heredity and the constitution of the germplasm, which have been remarkably confirmed by the extensive studies which have grown out of the researches in the exact mechanism of heredity made by Mendel. Weismann was the first writer who strongly questioned the hereditary transmission of characteristics which had been acquired during the lifetime of the parent, maintaining that all new structures must first arise in the germ-plasm. He thus rejected altogether the effects of the use and disuse of organs, which Darwin had admitted and to which Lamarck had attributed the primary rôle in the work of transformation, and regarded natural selection alone as the all-important factor. It would require far more time than is at our disposal to give even an outline sketch of Weismann's theories and it must suffice to point out that his views are still largely in the ascendant and that the great number of naturalists who constitute the so-called "NeoDarwinian School" look upon Weismann as their foremost spokesman.

Palæontologists, whose studies deal with the fossil remains of the ancient plants and animals which once inhabited the earth, but are now altogether extinct, have not, as a rule, been satisfied with the theory of natural selection as an adequate explanation of organic evolution. It was a palæontologist, von Waagen, who, in $186 \%$, first pointed out a distinction, which may yet prove to be the first step toward the formulation of an entirely acceptable 
theory. This distinction was between variations, on the one hand, and mutations, on the other. By variations, Waagen understood the fluctuating differences between contemporary individuals of the same species, differences which are repeated in every generation and are entirely inconstant. Mutations are successive changes, which, however slight they may be, are yet constant in character, and a series of mutations forms successive connected steps of modification in a definite direction. The eminent Dutch botanist de Vries adopted this conception and, with certain changes, erected it into an elaborate theory, which has formed the subject of much controversy. De Vries points out that Darwin did not distinguish clearly between the two kinds of modifications which have, or may have, furnished the starting-points for the various races and breeds of domesticated animals and plants. One kind is the ordinary difference between individuals and the other is the "sport," or sudden and notable change in one or more characteristics, a change which is constant and transmissible to the offspring. An often cited "sport" is the Ancon sheep, a breed which arose from a single short-legged ram, born of normal parents in 1791 on a New Hampshire farm. This ram transmitted his peculiarities to his descendants and soon a new kind of sheep, popular because of their inability to jump fences, was established. Such a sudden, unheralded and transmissible change of structure de Vries calls a mutation and he believes that mutation is the 
normal manner in which new species originate in nature and that the struggle for existence is not so much between individuals as a competition between mutants or incipient species.

Interesting and important as the mutation theory undoubtedly is, it offers no explanation of the phenomena, for the cause of such sudden changes remains a complete mystery. The seat of the change, it can hardly be questioned, must be sought in the germ-plasm of one or both parents, but we have not the least inkling of how such modification is brought about.

Finally, should be mentioned the work of Johann Gregor Mendel (1822-1882) an Austrian monk, who made experiments in crossing different varieties of peas and subjected his results to a mathematical analysis. His paper was published in 1866 and attracted no attention, but long after his death it was rediscovered, his results having been independently and almost simultaneously attained by three botanists, who published them in 1900, de Vries, von Tschermak in Austria and Correns in Germany. It is pathetic to contrast the complete neglect with which Mendel was treated during his lifetime with the honour which is paid to him now. His work has been developed into a new branch of biological science, called "Genetics," an exact analysis of the mechanism of heredity, and will be more fully dealt with in the last lecture of the course. Mendel's name is mentioned here merely to complete the list of those 
who have been the foremost pioneers in clearing the way for the modern conception of evolution.

From the quotations which have been read in the foregoing part of the lecture, it will be only too evident that, while naturalists are all but unanimous in accepting the theory of evolution as an established truth, there is every possible divergence in their views as to the causes of development and diversification. Could a census of opinions be taken among the zoölogists and botanists of the world, it is very probable that a substantial majority of Darwinians would be found. By Darwinians is to be understood those who are convinced that the doctrine of natural selection is the true explanation of organic evolution. Whether or not a majority of all naturalists are to be ranked with the Darwinians, it can hardly be doubted that there are very many more who accept natural selection than there are of those who have adopted any alternative view. Personally, I have never been satisfied that Darwin's explanation is the rightful one; to one who approaches the problem from the study of fossils, the doctrine of natural selection does not appear to offer an adequate explanation of the observed facts. The doctrine, in its application to concrete cases, is vague, elastic, unconvincing and seems to leave the whole process to chance. To be sure, this difficulty is, to a great extent, inherent in the nature of the problem, for direct observation of the long course of evolutionary development is impossible; no one ever saw the birth 
of a species and thus we are shut up to the drawing of inferences from what may be learned by comparison and experiment.

On the other hand, if Darwin's hypothesis be rejected, there is, it must be frankly admitted, no satisfactory alternative to take its place. Granting that de Vries is right in holding that species originate by sudden mutation, the process is not thereby explained and made intelligible and it does not seem likely that such an explanation could ever be found, though it is rash to set a limit to future discovery. In short, while the evolutionary theory is buttressed by such a mass of evidence that nearly all men of science are convinced of its truth, no satisfactory and acceptable explanation of its causation has yet been devised. 'To repeat Prof. E. B. Wilson's words: "Further discussions concerning the causes of evolution had clearly become futile until a more adequate and critical view of existing genetic phenomena had been attained." 


\section{LECTURE II}

EVIDENCES FOR THE THEORY-CLASSIFICATION, DOMESTICATION AND COMPARATIVE ANATOMY

Before attempting to set before you an outline sketch of the evidence which has so firmly convinced zoölogists and botanists that the theory of evolution is true, it is necessary to begin with a warning not to expect too much; that is to say, more complete proof than, in the nature of things, it is possible to obtain. Evolution has been a long, historical process, which has gone on with extreme slowness through unimaginable ages of time, when no man was there to see and observe. Complete demonstration, such as may be given for a physical or chemical law, is therefore not to be expected. Even in so exact a science as astronomy, the attempt to work out historical problems is beset with the gravest difficulties. No astronomer, for example, doubts that the solar system is a unit, which has been developed from some originally continuous body of matter, such as a nebula, but there is no general agreement as to the manner in which this development was brought about. Any solution yet proposed is face to face with unsolved problems. Clearly, therefore, the evidence for organic evolution must be indirect, since direct proof is unattainable, yet it need not be un- 
convincing for that reason, because in science, as in the practical affairs of life, probability must be the guide, whenever certainty is not reached and certainty is very rarely reached, if ever.

Speaking of plants, Dr. D. H. Scott says: "Our ideas of the course of descent must of necessity be diagrammatic; the process, as it actually went on, during ages of inconceivable duration, was doubtless infinitely too complex for the mind to grasp, even were the whole evidence lying open before us. We see an illustration, on a small scale, of the complexity of the problem, in the case of domesticated forms, evolved under the influence of man. Though we know that our cultivated plants, for instance, have been developed from wild species within the human period and often within quite recent years, yet nothing is more difficult to trace, in any given instance, than the true history of a field-crop or garden plant, or even, in many cases, to fix its origin with certainty." 1 Under the infinitely more complex conditions and longer time, in which natural evolution is believed to have taken place, it is no reason for surprise that the evidence should be not only indirect, but also general, even sometimes vague, rather than specific in character. On the other hand, what lends great cogency to this evidence is the fact that several quite distinct and independent lines of proof all converge in a common conclusion. While perhaps no one of these lines is altogether complete or

${ }^{1}$ D. H. Scott: Studies in Fossil Botany, London, 1900, pp. 524-5. 
convincing, yet the harmony of all of them, all pointing in the same direction, greatly strengthens the proof and raises the theory to a very high order of probability, despite the many unanswered questions and unsolved problems. Classification, comparative anatomy, embryology, palæontology, the geographical distribution of animals and plants, all tell the same story. It is because in every department of zoölogy and botany the evolutionary hypothesis offers the simplest, the most rational and the most satisfactory explanation of the observed facts, that naturalists accept it almost unanimously.

In order to explain the character of the living world and what is known of its history, but two alternative hypotheses have been propounded. The first, called the doctrine of Special Creation, holds that each kind of animal and plant was created in its present form and is substantially immutable. This doctrine, formulated by Linnæus, was very widely adopted and held the field until the publication of Darwin's book. The second is the hypothesis of evolution, or "descent with modification," according to which all animals and plants, as we know them, have been developed from primordial germs, leaving open the question as to how life on the earth originated. If any one declines to accept either one of these hypotheses, it only remains to admit that the problem is a complete mystery, for which no solution has been found, the position taken by Fleischmann. In making a choice between these alternatives, it often 
seems to be taken for granted that the burden of proof rests entirely upon the evolutionary theory, but this is a mistake, for there is and can be no evidence for that of special creation. The only thing which could justify us in holding that doctrine would be to find that the facts could be explained in no other way.

It has been objected that the gradations between the various forms of life, to which evolutionists attach so much importance, is in itself no proof of a genetic connection between those forms, and the gradual development of human productions is adduced as showing similar relations without any genetic connections. For example, houses may be traced from their earliest beginning in the rude hut of the savage, through various stages to the most extensive and elaborate modern dwelling, yet no one would suggest that houses were evolved by descent with modification. Here the relationship is ideal, not material, and the development is that of a plan; why should the same thing not be true of the living world? In reply, it may be said that this objection might have some weight, if houses naturally reproduced their kind, as all living things do, and each individual structure were not the work of men's hands. Then, too, in order to hold the evolutionary hypothesis, it is not necessary to deny the ideal relationships between the successive gradations of living beings, or to exclude belief in a creative plan, which has been worked out by the method 
of evolution. This, however, is a metaphysical, rather than a scientific question, and has no immediate bearing upon the evidences for the theory of evolution.

As has already been pointed out, the evidence for the theory consists of several distinct and independent lines of testimony, so to speak, and it will conduce to clearness of treatment, if each of these lines is dealt with separately, though their action and reaction upon one another must not be overlooked. In the first place, we may take up the argument from classification, which is the most obvious one and has the additional historic interest of being the line along which Lamarck and Darwin approached and reached their primary generalizations. It was, in short, the problem of species which led those great naturalists to abandon the current belief in the fixity and immutability of living types and to adopt the hypothesis of development. To repeat, in part, the quotation from Lamarck given in the first lecture: "The difficulty which I know, from my own experience, is now felt in distinguishing species . . . has convinced me that our species have but a limited existence and, for the most part, differ from neighbouring ones only by shades which it is difficult to express." (See ante, p. 9.)

The object of classification is to arrange the extraordinarily manifold assemblages of animals and plants in groups of ascending comprehensiveness, which shall express, so nearly as the present state of 
knowledge permits, the degrees of relationship between them. In this elaborate scheme, which was developed by Linnæus about the middle of the eighteenth century, the unit, so to speak, is the species, the storm-centre of many controversies. Linnæus believed that species were real, objective entities, which it was the business of the naturalist to distinguish, describe and name, and for a very long time the principal occupation of zoölogists and botanists was the discrimination of species, furnishing them with names and arranging them in genera, families, orders and other groups of higher rank. This procedure may best be explained by an example. The European wolf is a species, lupus, which, with other typical wolves, is included in the genus Canis and is therefore designated as Canis lupus, for the name of a species requires that of its genus to identify it and hence the Linnæan scheme of nomenclature is said to be binomial. The true wolves, jackals, foxes, (genus Vulpes) and many other genera of differing dog-like forms are grouped together in the family Canida, which, associated with all the other terrestrial beasts of prey, cats, bears, raccoons, weasels, otters, etc., etc., are included in the sub-order Fissipedia. The latter are joined with the marine forms, seals, sea-lions, walruses, etc., to constitute the order Carnivora. Omitting certain intermediate groups, we find that the order Carnivora belongs in the class Mammalia, or warm-blooded quadrupeds, which, in turn, is a member of the phylum Vertebrata, or 
animals with internal skeleton, which also includes the fishes, amphibians, reptiles and birds.

The principle in accordance with which these groups of an ascending order of comprehensiveness are constructed, is simply the greater or less degree of likeness in structural characteristics. All mammals agree in fundamental features, however much they may differ in size, form, appearance and habits, and thus such different-looking creatures as a whale, a bat, a horse, a mole and a monkey are all referred to the same class. Under the Linnæan conception, which prevailed down to Darwin's time, the relationship between the various species of a genus, or between the genera of a family, the families of an order, etc., was regarded as purely ideal. If each species represented a distinct act of creation and was so fixed as to be incapable of transformation into another species, then obviously no actual genetic relationship, or blood-kinship between different species was possible. According to the evolutionary hypothesis, on the other hand, the relationship is truly genetic and the differences are due to divergent development, acting under different conditions and circumstances, while the deep-seated, fundamental likenesses are explained as inheritances from a common ancestry.

As Lamarck so emphatically pointed out, this distinction of species from one another is often exceedingly difficult and has frequently given rise to great differences of opinion and practice among systema- 
tists, because of the manner in which the different individuals of a species vary among themselves and, in many instances, of the way in which the species of a genus grade into each other. No two individuals, belonging to the same species, are exactly alike in all respects and when a very large number of such individuals are compared, they are found, as a rule, to cover a remarkably wide range of variation, the extremes of which often differ more than do the individuals which are referred to distinct species. The species of a large, thriving and vigorous genus are often so unstable and so connected by intergradations, that there is sometimes a radical difference of opinion as to how many separate species should be recognized. "Nothing is brought out more clearly by ecological studies in New Zealand than the extreme 'plasticity' of many species and structures, and their rapid response to a change of environment. This is so great in numerous instances that the idea of 'normal' loses its meaning." 1

For example, the botanists differ greatly in regard to the American oaks and into how many species they are properly divisible; the same is true of many other groups. To evade this difficulty, at least in part, several groups, subordinate to species, are recognized and named in systematic botany and zoölogy, such as geographical races, varieties, subspecies, etc., each of these minor groups being relatively constant and recognizable, yet not differing sufficiently from ${ }^{1}$ L. Cockayne in Trans. New Zealand Institute, Vol. XLIV, pp. 13, 14. 
the others to require separation as a distinct species. Yet if the natural origin of these minor subdivisions be admitted, there can be no valid reason for denying the natural origin of species, genera and the higher groups of classification, for the difference is one of degree, not of kind, and the intergradation is often so perfect, that it is a matter of personal judgment and experience, whether the systematist shall regard a given group of individuals as a variety, a subspecies, or a species, whence the many differences and conflicts in practice.

If a species, say of birds, having a very wide geographical range, be carefully examined and compared, it very frequently happens that specimens taken from the extreme points of that range differ so notably from one another, that the systematist would not hesitate to separate them as distinct species, were it not that in the intervening area all the intergradations between the extreme forms can be found. The recognition of species is thus often a purely arbitrary procedure, as to which different writers diverge widely in their judgment. All this flux and inconstancy and intergradation between very distinct extremes are hard to comprehend, if we adopt the hypothesis of special creation, while, on the other hand, they are precisely what would be anticipated under the hypothesis of evolution.

A study of the races of domesticated animals and plants, which Darwin ${ }^{1}$ investigated so thoroughly, 1 The Variation of Animals and Plants under Domestication, \& vols., 1868. 
leads to a similar conclusion. Under the conditions of domestication, these creatures have been so profoundly modified that, in many instances, the original, wild progenitor of the race or breed cannot be determined. The various breeds of horses, cattle, sheep, pigeons, fowls, not to mention the garden and field-plants, differ among themselves far more than do many wild species from each other. Were the pointer, terrier and spaniel dogs, the fan-tail, pouter and tumbler pigeons found in a state of nature, no zoölogist would hesitate for a moment to recognize them as well-defined species, yet we know that all the breeds of pigeons have been derived from a single wild form. Dogs are all domesticated wolves, but the history of the various breeds has not been preserved and it is not known whether all the familiar races are descended from a single wild species or from several, or what that wild progenitor or progenitors were. All this diversity has been produced by human agency, acting sometimes with intelligent and conscious purpose, sometimes with no definite end in view, by taking advantage of variability and individual differences. If man can accomplish such results in a relatively short time, it is difficult to see why nature, with illimitable æons at her disposal, should not bring about correspondingly greater transformations. The phenomena of domestication make the dogma of the fixity and immutability of species seem very ill-founded and improbable. This is a very large subject and it has been necessary, on ac- 
count of the limitations of time, to compress into a few sentences, what Darwin has given in two large volumes. To these fascinating volumes may be referred the reader who is interested in following out this line of evidence.

Even under conditions which cannot be called domestication, certain remarkable transformations of animals have been observed. An interesting case of this sort is that of the Porto Santo Rabbit, as described by Darwin. At a date variously given as 1418, 1419 and 1420, the Portuguese navigator Zarco set free a doe and newly born litter of young rabbits upon the small island of Porto Santo, not far from Madeira. From the fact that the doe littered on shipboard, it is evident that she belonged to one of the domestic races, all of which have been derived from the European wild Rabbit (Lepus cuniculus). The absence of any carnivorous creatures, which would have preyed upon the rabbits, or of any other land mammal, which might have competed with them for food, led to a very rapid multiplication, so that in less than 40 years they are described as "innumerable." As a result of four and a half centuries of isolation under these novel conditions, the Porto Santo Rabbit has become so different from any of the domestic races and from its wild progenitor, that Haeckel has described it as a distinct species, Lepus huxleyi. The new form is much smaller than the European wild Rabbit, weighing but little more than half as much as the latter, and differs considerably in 
colour. The fur is redder, with far fewer black-tipped hairs; the throat and belly are gray or lead-coloured, instead of pure white, and the tips of the ears and upper surface of the tail lack the blackish-gray fur so characteristic of the European wild form.

"The two little Porto Santo rabbits, whilst alive in the Zoological Gardens, had a remarkably different appearance from the common kind. They were extraordinarily wild and active, so that many persons exclaimed on seeing them that they were more like large rats than rabbits. They were nocturnal to an unusual degree in their habits, and their wildness was never in the least subdued. . . . Iastly, and this is a highly remarkable fact, $\mathrm{Mr}$. Bartlett could never succeed in getting these two rabbits, which were both males, to associate or breed with the females of several breeds which were repeatedly placed with them.

"If the history of these Porto Santo rabbits had not been known, most naturalists, on observing their much reduced size, their colour, reddish above and gray beneath, their tails and ears not tipped with black, would have ranked them as a distinct species. They would have been strongly confirmed in this view by seeing them alive in the Zoological Gardens, and hearing that they refused to couple with other rabbits. Yet this rabbit, which there can be little doubt would thus have been ranked as a distinct species, has certainly originated since the year 1420 . Finally, from the three cases of the rabbits which 
have run wild in Porto Santo, Jamaica, and the Falkland Islands, we see that these animals do not, under new conditions of life, revert to or retain their aboriginal character, as is so generally asserted to be the case by most authors." 1

Another instance of transformation, in this case very rapid, under "new conditions of life" is that of the Lunar Moth (Saturnia luna) when transported from Texas to Switzerland. In the year 1870, the entomologist Boll brought to Switzerland a number of cocoons of this large and beautiful moth and in May of the following year the full-grown moths emerged from the cocoons and differed in no particular from the ordinary Texas form. From these moths several hundred fertilized eggs were obtained, from which, in the course of a few weeks, small caterpillars were hatched. In Texas the caterpillars of this species feed upon the leaves of hickory and black walnut trees, but, as such leaves were not to be had in Switzerland, those of the European walnut were substituted. The substitution was entirely acceptable to the caterpillars, which ate greedily and formed their cocoons at the end of June, the adult moths emerging early in August. Much to the surprise of all observers, this second generation of moths, the caterpillars of which were fed upon a plant new to them, differed so much in form, colour and markings from the parent Texan species, that any

${ }^{1}$ Darwin, Variation of Animals and Plants under Domestication, Vol. I, pp. 119-20. 
entomologist would have regarded it as a new and distinct species, had its origin not been known. Nevertheless, Dr. Gemminger, a distinguished entomologist, recognized it as a distinct species and named it "Saturnia bolli."

Moritz Wagner, from whom this account is taken, gives the following description of the new form: "At the first glance, the connoisseur is surprised by the striking change of form. In the new species the shape of the body, as of the wings, is somewhat larger and heavier, while the feathery antennæ are slightly narrower and less luxuriant. From the longer hindbody of the new species the carmine-red, longitudinal stripes, which the parent species bears, have completely disappeared. The front wings have a less sinuous form, but are somewhat broader. This change of form is to be more decidedly observed in the tail-like prolongation of the hind wings. Not less striking than the differences of shape are those of colour. In the ancestral species the colour is a yellowish green, while that of the new species is a beautiful lemon-yellow. The carmine-red marginal stripe, with whitish inner border, borne on the anterior wings of Saturnia luna, has quite disappeared in Saturnia bolli and is indicated only by a very narrow, dark yellowish colouring of the outermost margin.

"Most remarkable in this new species is the appearance of a new marking on the anterior wings, which appears as a transverse stripe, with somewhat 
zig-zag outer edge, but is entirely absent from the anterior wings of the parent species." 1

Other similar, if less striking, examples of change might be described, did time permit; all that can be attempted here is to give an outline sketch of the evidence with a few illustrations, chosen from the many that are available. To present anything like an exhaustive display of the evidence would require, not one course of lectures, but many. The instances selected suffice to show that, when placed under new conditions of climate, food-supply, attacks of enemies and the like, animals and plants, whether domesticated or free, may experience very marked changes of size, form and appearance and that species are, in very many cases, if not in all, far from immutable. Often the metamorphosis is so great, that the wild progenitor of many domesticated animals and cultivated plants cannot be determined with any degree of certainty.

The other lines of evidence which are relied upon to prove the theory of evolution are comparative anatomy; embryology, the study of individual development; palæontology, the study of extinct plants and animals which formerly existed on the earth; the geographical distribution of organisms, animal and vegetable; finally, experimental investigation. Each one of these methods of research has its particular advantages, as well as its special limitations and

${ }^{1}$ M. Wagner: Die Entstehung der Arten durch răumliche Sonderung, pp. 309-10. 
drawbacks; it is the harmonious result of all of them, pointing in the same direction, which gives great weight to their combined testimony.

Comparative anatomy, as the name implies, is the comparison of structure and tissues in the whole range of animal life. Such comparison leads to the conclusion that in the animal kingdom there are several distinct types of structure, characterizing the grand divisions of the kingdom. Within any one of these grand divisions may be found almost endless diversities of structure, all of them obviously different modifications of the same fundamental plan. However great the modification, the identity of the plan is clearly to be perceived throughout, just as is the theme of a musical composition, which may be traced through all the variations into which the composer has woven it. A few concrete instances will make clear the application of this principle. Superficially examined, the following structures would seem to have little or nothing in common, but rather to be constructed on totally distinct plans for altogether different purposes: the fore leg of a lizard, the wing of a bird and of a bat, the burrowing shovel of a mole, the flipper of a whale, the fore leg of a horse, the human arm and hand. When, however, all of these structures are carefully dissected and the bones, muscles and nerves are compared, it becomes immediately apparent that the plan of structure is the same throughout, modified to serve different uses, of running, flying, burrowing, swimming and 
grasping. In all of them, the upper arm has a single bone, the humerus, and the forearm two, the ulna and radius; in all there is a wrist, formed of an assemblage of small polygonal bones, followed by the long bones of the hand and, finally, by the fingers. Modification is brought about by the reduction and even the suppression of certain parts, the enlargement of other parts and, very much more rarely, by the addition of new parts. Compare, for example, the human arm and hand with the fore leg of a horse. The human hand is a grasping organ and rotates freely on the arm; there are five digits, one of which, the thumb, is opposable to the others, and each digit is tipped with a flat nail. The wrist-joint is composed of eight bones, arranged in two transverse rows; the two bones of the forearm are complete, entirely separate and movable on each other, the power of rotation of the hand being dependent upon the character of the elbow joint. The upper arm-bone forms a ball and socket joint with the shoulder blade and rotates easily in almost any direction. In the horse, on the contrary, the fore limb is exclusively an organ of locomotion and cannot be used for grasping; as a whole, the limb moves only backward and forward in a plane parallel with that of the backbone and each of the joints is movable only in the same fore-and-aft direction, there being no power of rotating the hand upon the arm, or of the fore limb as a whole upon the shoulder. There is but a single functional digit, the third of the original five, the bones of which are so 
enlarged and strengthened as to support the whole weight of the body; the nail is greatly expanded, to form a hoof, which encloses as in a box the whole
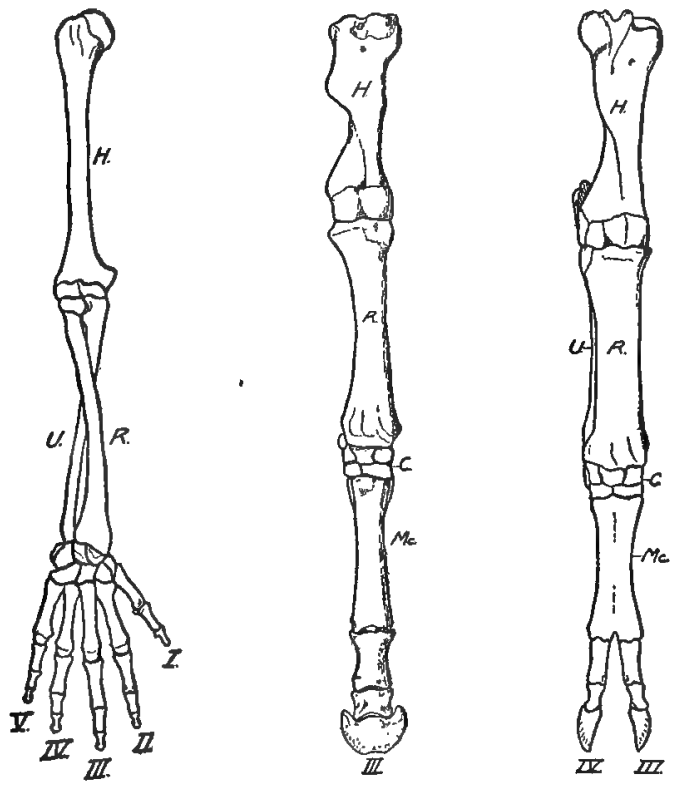

Frg. 1. Right fore limbs of Man (left); Horse (middle); Ox (right). $H .=$ humerus. $R .=$ radius. $U .=$ ulna. $C .=$ carpus. $M c .=$ metacarpals. Digits are numbered with Roman numerals.

terminal joint of the digit. Beside the single functional digit, there are remnants, or rudiments, of two others, the second and fourth of the original series, which are not visible externally and consist only of the long bones of the hand (metacarpals) without free joints or hoofs, and are commonly known as 
"splint-bones." The wrist has seven bones, one of the lower row being suppressed as needless, in correlation with the reduction in the number of digits. One of the forearm bones, the ulna, is very greatly reduced, so that only the two ends remain and these are firmly co-ossified with the radius, which is correspondingly enlarged and bears the whole bodyweight.

The fore leg of the ox, like that of the horse, is exclusively locomotive in function and can move only backward and forward, there being no power of rotation of the hand on the forearm or of the whole leg on the shoulder. In the forearm the enlarged radius carries all the weight and the two ends of the reduced ulna are co-ossified with it. The most striking difference from the horse is to be found in the fact that the foot has two functional digits, the third and fourth, between which the weight is equally divided, and the two hoofs are so shaped as to have a split appearance, which is expressed in the term "cloven-hoofed." While accurately descriptive of the appearance, this term is erroneous if taken to mean that an originally single hoof has been divided. The long bones of the hand, or metacarpals, are completely fused together into a compound "cannon bone" and, in addition to the two functional digits, there are two rudimentary, externally visible ones, the "dew-claws," which are small, nodular hoofs behind the principal ones. In the horse and ox, then, we see two slightly divergent modes of converting 
the primitive, five-toed and mobile anterior limb into structures which are purely locomotive in function.

It is evident that the same elements are present in the human hand and arm as in the fore leg of the horse and ox, but in each case characteristically modified to serve different ends. Man's hand, fortunately for us, is really a very primitive and undifferentiated structure and can be put to a great many different uses. Had it been highly specialized for a single purpose, human progress and civilization would have been impossible, for these have always depended upon the co-ordination of hand, eye and brain. In the horse everything has been sacrificed to speed, making the animal a "cursorial machine," and, to this end, the functional digits have been reduced from five to one, the proportionate lengths of the various segments of the limb adjusted to the best advantage and the feet raised from the ground, so that the horse, as also the ox, walks upon the very tips of the toes. What is ordinarily called the "knee" of a horse is the exact homologue of the human wrist, while the elbow joint is concealed in the muscles of the shoulder.

Again, the flipper of a whale is, to all external appearances, totally different from the human arm and hand, as from the fore leg of the horse, but dissection shows that the plan of structure is the same, identical parts being greatly modified in form and function in accordance with the exclusively marine life of the animal. Except at the shoulder, there is 
no true joint between any of the bones, which arrangement allows but a very limited motion, merely enough for the necessary flexibility of the paddle. The arm-bones are short, massive and simple and, what is extraordinarily rare among mammals, the number of joints in the digits is much increased, to give the needed length and support to the flipper. Clearly, the whale's paddle is of precisely the same type as the fore limb of a land quadruped, but transformed and adapted to a purely marine habit of life.

The comparison of a bat's wing with that of a bird brings to light two quite different modes of adaptation of similar elements to the purposes of flight, and in both groups we find certain differences in the completeness of adaptation. In the bat the bones of the arm are very slender and greatly elongated; the ulna is much reduced, only the upper

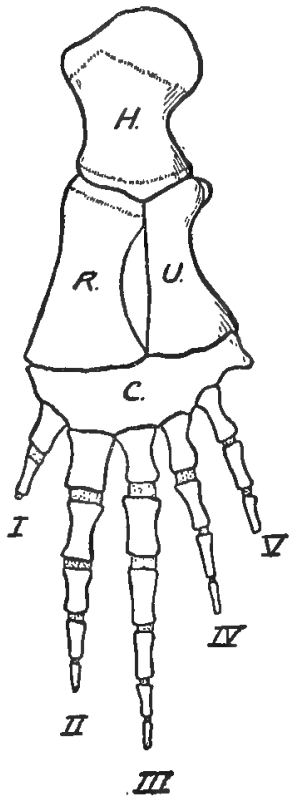

Fig. 2. Bones of left flipper of Greenland Right Whale. Letters as in Fig. 1. (From Allen.)

third remaining and this is co-ossified with the radius. The first digit, or thumb, is divaricated from the others, is not included in the wing-membrane and bears a curved, hook-like claw. The bones of the 
other digits are extremely long and slender and usually the terminal joints, with their claws, have been suppressed, but in the fruit-eating bats, or "flying foxes," the second

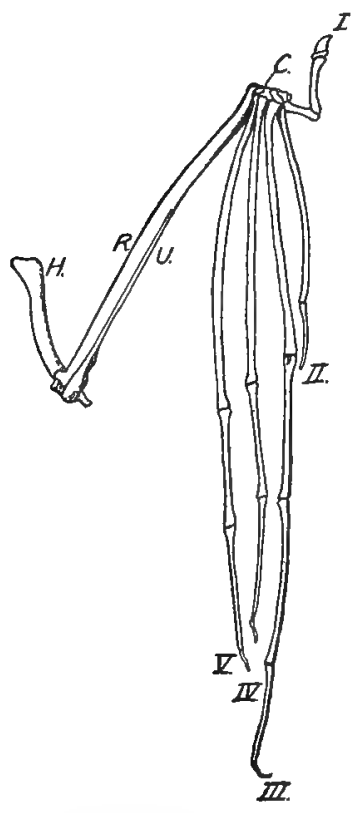

Fig. 3. Skeleton of right wing of Leaf-nosed Bat. Letters as in Fig. 1. digit retains the terminal joint and claw and in certain other families the third digit (but not the second) has the terminal joint, though without a claw. The wing is a fold of skin, which is attached along the outer side of the body and the under side of the arm and forearm and is stretched between the bones of the digits, which support it in much the same fashion as the ribs of an umbrella sustain the cloth. The membrane is also attached to the legs and extends between the two thighs and the short tail.

In the wing of a flying bird the problem of making an organ of strong and steady flight is solved in an entirely different manner. The effective air-plane is formed by large quill-feathers, which are inserted along the outer side of the bones of the arm and hand, so there is no wing-membrane and the stiffness 
of the feathers renders unnecessary any stretching between bony supports. These supports are therefore developed according to another plan. The forearm bones are comparatively short and strong, complete and separate from each other; the structure of the hand varies somewhat in the different groups of birds and it will therefore be simpler to take as a type a particular bird, the common raven. Here, the bones of the wrist are reduced to two, partly by suppression and partly by coossification of the originally more numerous elements. There are three digits, of which the first, or thumb, is free, while the long bones (metacarpals) of the second and third are co-ossified; the fingers are represented

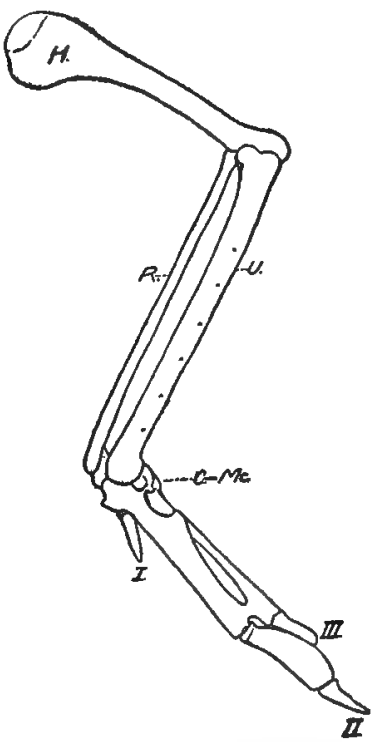

FIG. 4. Skeleton of left wing of the American Raven. Letters as in Fig. 1. (After Shufeldt.) by one or two free joints in each digit. In many groups of birds the first digit has a claw, as, for example, the spur on a swan's wing, and several birds have claws on both the first and second digits.

In the flightless birds, which, there is every reason to believe, are descended from flying ancestors, the 
wing-bones may be like those of the flying birds in form and number, but are altogether too small to be of any functional importance. This is the case in the ostrich, for example, while in the cassowary the digits are reduced to a single one, which is presumably the third. In the penguins, which are incapable of flight, the wing is not useless, but is adapted to a new purpose and has been transformed into a flipper or swimming paddle. This change of function does not involve much modification of the wing-bones, except that those of the hand are much elongated and flattened; the transformation is most marked in the feathers. It might almost be said that these most curious birds have been adapted to flight in a new medium, water instead of air.

Still a third type of wing is exemplified by the remarkable group of extinct flying reptiles known as pterodactyls. In these creatures, some of which attained immense size, the wing was most like that of the bats, being a membrane or fold of skin, naked and without hair, scales or feathers. Only one digit, the fifth, or little finger, was elongated and strengthened to support the wing-membrane along its outer border, while the other digits were free and provided with claws. In all three groups, bats, birds and pterodactyls, a vertical keel grows upon the breastbone (as any one may see in carving the breast of a fowl), in order to furnish a sufficient bony attachment to the powerful and greatly developed breastmuscles, which are the principal muscles of flight. 
The size and prominence of this keel are excellent indications as to the power of prolonged and steady flight.

Many other examples might be given in illustration of the principle that, among the Vertebrates, we are dealing with countless modifications of a single type, with lower and higher grades of organization and adaptation to a great variety of habits of life, terrestrial, burrowing, climbing, swimming, flying, etc., etc. The hypothesis of evolution offers the simplest and most natural explanation of the facts.

Similar considerations apply to the other great types of animal structure. Among the Crustacea, for example, we may take the common lobster, which is one of the most advanced of these animals. There is a large anterior shield, or carapace, which is a single piece and, behind this is a number of movable rings or segments, which compose the abdomen or tail. To each segment is attached a pair of jointed appendages, which are the swimmerets, each of which is divided into external and internal portions. The last pair of the swimmerets is very much expanded and forms with the terminal segment a broad tail-fin. When the lower surface of the lobster is examined, it is seen that the region covered by the carapace is likewise composed of segments, each with its pair of jointed appendages but in this region the segments are immovably fixed together and the appendages are altogether different in appearance from those of the tail. The four 
posterior pairs are walking legs, which correspond to the internal division of the swimmerets. In front of the legs is the pair of great claws, which are composed of the same number of joints, arranged in the same way, only very much larger, heavier and more powerful. In front of the claws come three pairs of appendages called "foot-jaws" (maxillipeds) which are legs with their basal joints forming organs of mastication; the hindmost pair of the foot-jaws differs but little from the walking legs, while in the foremost pair it is difficult to make out the corresponding parts. Next in order come three pairs of jaws, still more modified, then the very long and many jointed feelers (antennx) and the anterior pair of much shorter feelers (antennules). The appendages of the head, body and tail are thus seen to be modifications of a common plan and grade into each other almost imperceptibly.

If representatives of the many families and orders of the Crustacea be compared, it is seen that there is great variety in the number of segments which are united to form the head and trunk, as well as in the form and function of the appendages. The appendages of the same segment, counting from the anterior end, are in one group a pair of jaws, in another foot-jaws and in a third walking legs. The comparison immediately suggests the derivation of all the Crustacea from ancestors in which all the segments, except the head, were similar and were provided with appendages which were similar 
throughout. As this group or that advanced in differentiation certain appendages became specialized for the better performance of particular operations.

In the crabs may be observed a higher grade of organization than in the lobsters, for the crabs, at first sight, appear to have lost the tail entirely. Turning a crab on its back, however, the segmented tail is seen to be folded under the body and lying in a groove on the ventral surface; the appendages of the tail have been almost completely suppressed.

Even more remarkable is the series of modifications brought to light by a comparative study of the mouth-parts among the insects, in which farreaching modifications have been brought about in adaptation to different kinds of food and different habits of life. Fundamentally, the parts are the same throughout, but the transformation is frequently so profound as to obscure this fact. In insects, such as the cockroach, which live upon solid food, there are masticating jaws; in the bumble bee a licking apparatus; in the butterflies and moths a long, tubular proboscis for sucking the nectar from flowers; in the mosquito a most elaborate arrangement for piercing the skin and sucking the blood of its victim. "But always it is the same individual parts, on the same definite segments, which are repeated according to rule as regards number and form, but with a different mode of use; a pair of upper jaws, a first and second pair of lower jaws, but the latter may be long drawn out and rolled up in 
tubular form, and the former may be transformed from jaws into piercing lancets. This arrangement according to a definite rule, despite the differences of form and use, finds its most probable explanation in community of descent." 1

Examples of the same kind, drawn from all the great divisions of the animal kingdom, might be indefinitely multiplied, but such multiplication would serve no useful purpose, even were it feasible within our limits of time. The principle of numerous modifications of a common plan, adapted to a great variety of habits of life is made sufficiently clear by the few instances already given.

The objection has been frequently urged, just as in the case of classification, that this diversification of a single type of structure is no proof of a genetic connection, or community of descent, but that the connection is purely ideal, the manifestation of a creative plan. The answer is the same in both cases; acceptance of the theory of evolution by no means excludes belief in a creative plan, but that theory offers the most satisfactory solution of the problem. Another and perhaps weightier objection is that comparative anatomy gives us no means of connecting animals of fundamentally different types or plans of structure. It is impossible to derive a fish from a lobster, or a starfish from an oyster and thus the different structural types would seem to be separated by impassable barriers. Evolution within

${ }^{1}$ Otto Maas, in Die Abstammungslehre, Jena, 1911, pp. 258-9. 
the type might be admitted, without conceding the possibility of deriving one type from another.

In reply, attention must be called to the fact that comparative anatomy deals only with the animal world as it now exists and that is demonstrably but a very small part of the countless horde of animal forms that formerly inhabited the earth, but have become extinct. An oft-used illustration of the relations between living and extinct organisms is that of a great tree buried in the earth, so that only the outermost twigs are exposed to view. Such twigs would form scattered groups, more or less widely separated from one another, the branches which connect them being buried out of sight. If it were possible to dig away the earth and expose the whole tree, the continuity of all its ramifications would be fully revealed. To a certain extent, this excavation is accomplished by the science of palæontology, which deals with the remains of extinct animals and plants as preserved in the rocks of the earth's crust. Another lecture (No. IV) will be devoted to the testimony of this science to the evolutionary hypothesis. Another illustration may be drawn from a study of modern languages, as it would be if that study were deprived of the help given by books and manuscripts, which register past changes, and confined to an examination of the spoken tongues. This examination would suffice to make clear the interrelationships of most European languages; French, Italian, Portuguese, Spanish, etc., the Romance languages, are 
evidently derived from a common source. Another group of common origin is that of the Teutonic languages, German, Danish, Swedish, Dutch, English, etc., while a third group, that of the Slavonic tongues, is a natural assemblage of related languages, as is that of the Celtic group. A wider comparison indicates that all of these European languages, together with Persian, Hindustani, Lithuanian, etc., form a related group, the Indo-European, in contradistinction to the so-called Semitic and Turanian families. It is an obvious conclusion that all of the Indo-European languages had a common origin at a very ancient date and that this common speech split up into a number of branches, each of which, in turn, became divided into many languages and dialects.

The argument from comparative anatomy in favour of the evolutionary hypothesis would be notably strengthened by a consideration of rudimentary organs, but this line of evidence can best be dealt with in connection with embryology. 


\section{LECTURE III}

\section{EVIDENCE FROM EMBRYOLOGY AND BLOOD TESTS}

Embryology is the study of the development of the individual organsix from its beginning in the egg to the attainment of the adult condition. This individual development is called ontogeny and the question of the relation of ontogeny to the ancestral history of the species, or phylogeny, constitutes one of the main problems of embryology. Around this problem many controversies have raged, controversies which have by no means arrived at a definite solution, even to-day. Thirty years ago the "recapitulation theory" was well-nigh universally accepted, according to which the individual development, or ontogeny, was regarded as an abbreviated repetition of the ancestral history of the species, or phylogeny. Haeckel called this theory the "fundamental biogenetic law" and upon it he established his whole "History of Creation." Nowadays, that "fundamental law" is very seriously questioned and by some high authorities is altogether denied. However, even those who take this extreme position concerning the recapitulation theory see in the facts of embryology one of the strongest supports of the doctrine of evolution. 
It was very early recognized that the recapitulation theory could not be applied with literal exactness, but was subject to certain important exceptions and qualifications.

(1) That the history must have been enormously abbreviated. After three weeks of incubation the tiny speck of protoplasm, which forms a circular mark on the yolk of a hen's egg, is developed into a fully formed chick, ready for hatching and able in large degree to take care of itself. On the other hand, the evolution of birds from their invertebrate ancestors, through the fishes, amphibians, and reptiles, the separation of the gallinaceous stock from other birds and the differentiation of this particular species were extremely slow processes, extending through unnumbered millions of years. Admitting recapitulation to the fullest extent, it is evidently a physical impossibility that it should be a perfect repetition of phylogeny; very much of the long story must of necessity be omitted.

(2) Through all the stages of development the embryo must be rendered able to live and grow and thrive through adaptation to its surroundings and changes in its environment. In some animals development takes place within the body of the mother; in others the embryo is protected by the hard eggshell, as in birds, while the eggs of certain fishes and many invertebrates float freely in the sea and are almost without protection. Such differences in environment necessitate differences in the mode of 
development, while the presence or absence of a large amount of inert food-material, or yolk, exerts a great influence in determining the steps of ontogeny.

(3) Many animals pass through a larval stage of development, in which the immature young leads an independent and self-sustaining existence, during which it is very different in appearance and structure from its adult parents. Familiar instances of this mode of development are to be found in the tadpole, which is the larva of the frog, and the caterpillar the larva of a butterfly. Larvæ are fully subject to the struggle for existence and must adapt themselves to their environment and to changes in that environment, exactly as do adults, if they are to survive. In this way many changes are introduced into the ontogeny which can have no phylogenetic significance. It is found in several known instances, that nearly allied species, living under different conditions, have quite different modes of ontogeny, though their ancestral history must have been substantially identical. In one and the same species of marine worms, for example, which inhabits both the warm Mediterranean and the cold waters of the North Sea, the larva of the northern form is quite distinct from that of the southern. In attempting to interpret the meaning of embryological facts, it is thus necessary to distinguish sharply between those features which are derived from a long inheritance, and are therefore called palingenetic, from those 
which have been secondarily introduced in response to the changing needs of embryonic or larval life. These secondary features are termed cenogenetic.

"If we are compelled to admit that cenogenetic characters are intermingled with palingenetic, then we cannot regard ontogeny as a pure source of evidence regarding phyletic relationships. Ontogeny accordingly becomes a field in which an active imagination has full scope for its dangerous play, but in which positive results are by no means everywhere to be obtained. To attain such results, the palingenetic and cenogenetic phenomena must be sifted apart, an operation which requires more than one critical grain of salt. On what grounds shall this critique be based? assuredly not by way of a vicious circle on the ontogeny again; for if cenogenetic characters are present in one case, who will guarantee that a second case, used for a comparison with the first, does not likewise appear in cenogenetic disguise? If it once be admitted that not everything in development is palingenetic, that not every ontogenetic fact can be accepted at its face value, so to speak, it follows that nothing in ontogeny is immediately available for the critique of embryonic development. The necessary critique must be drawn from another source." 1

These remarks of Gegenbaur's were called forth by the state of wild speculation into which embryo${ }^{1}$ C. Gegenbaur, Morphologisches Jahrbuch, Vol. XV, p. 5. 
logical work had fallen. As there were no generally accepted canons of interpretation for the facts of embryological development, different writers interpreted these facts in the most divergent and contradictory manner, resulting in a chaotic confusion, which led to a strong reaction against the whole method, though there can be little doubt that this reaction has gone too far.

"It must be evident to any candid observer, not only that the embryological method is open to criticism, but that the whole fabric of morphology, so far as it rests upon embryological evidence, stands in urgent need of reconstruction. For twenty years embryological research has been largely dominated by the recapitulation theory; and unquestionably this theory has illuminated many dark places and has solved many a perplexing problem that without its aid might have remained a standing riddle to the pure anatomist. But while fully recognizing the real and substantial fruits of that theory, we should not close our eyes to the undeniable fact that it, like many another fruitful theory, has been pushed beyond its legitimate limits. It is largely to an overweening confidence in the validity of the embryological evidence that we owe the vast number of the elaborate hypothetical phylogenies which confront the modern student in such bewildering confusion. The inquiries of such a student regarding the origin of any of the great principal types of animals involve him in a labyrinth of speculation and hypothesis in 
which he seeks in vain for conclusions of even an approximate certainty." 1

Many other equally vigorous and well-deserved criticisms of the embryological method might be cited, but it should be emphasized that these criticisms are all directed against the application of the method to the solution of definite and concrete problems of descent and relationship. None of them denies and many strongly affirm that embryology affords some of the strongest and most convincing evidence in favor of the evolutionary theory.

Let us examine some of this evidence. To begin with, it should be noted that, in following out the ontogeny or individual development, the observer witnesses the formation of something new, not merely the enlargement and unfolding of a preexisting organism, though the theory of preformation, which was widely accepted in the eighteenth century, looked upon ontogeny precisely in that way, as the growth of a germ which was the miniature of the parent. Such a theory was possible only before the development of microscopic technique had enabled the observer to detect the actual successive steps of change. The egg is a single cell, with the nucleus and all the parts of other undifferentiated cells, though it may be enormously enlarged by the presence of foodyolk. In the hen's egg this food-yolk is quite inert and the activity of development is confined to the minute disc of protoplasm on the outside of the yolk,

${ }^{1}$ E. B. Wilson, in Wood's Hole Biological Lectures, 1894, p. 103. 
while in the frog's egg the yolk is disseminated, though not uniformly, throughout the egg and in the mammalian egg, which is microscopic in size, there is
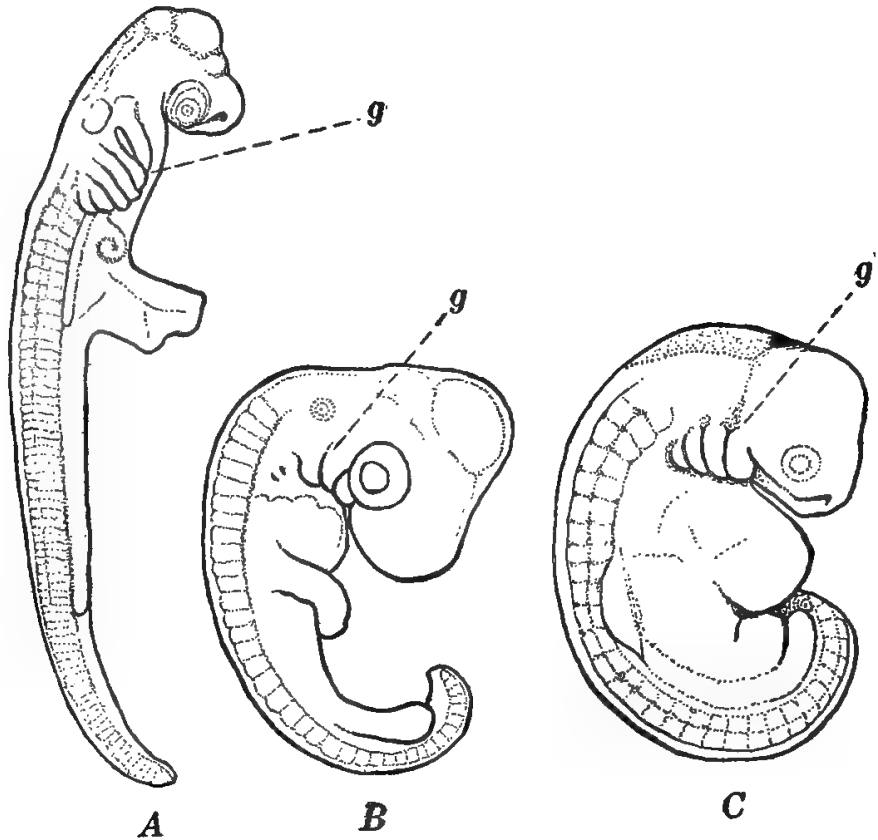

Fig. 5. Embryos in corresponding stage of development of Shark $(A)$, Fowl $(B)$, and Man $(C) . g$, gill-slits.

no yolk. It is a very remarkable fact that all of the vertebrated animals, fishes, amphibians, reptiles, birds and mammals, however different their habits and modes of life, have a mode of ontogeny which is of even more characteristically and unmistakably the same plan than is the type of their adult struc- 
ture, which was described in the last lecture. The egg, or the active portion of it, divides in a definite and regular manner into a very large number of cells, which arrange themselves in definite layers, an outer and an inner, and within these layers cell-aggregates form incipient organs, which, step by step, take on the adult condition. Not only is the plan and type of development essentially similar throughout the whole phylum of the vertebrates, but, in accordance with the recapitulation theory, many structural features which are permanent in lower forms appear in the embryos of higher and more advanced types. In the latter, however, these features are transitory and, in the course of development, they either disappear, or are so modified as to be very different, sometimes unrecognizable, in the adults.

At a certain stage of the ontogeny the embryo of a mammal has gill-pouches like a fish, the skeletal supports of the gill-pouches, the arteries and veins which supply them with blood, the structure of the heart, in short, the entire plan of the circulatory system is fish-like. At a later stage most of the gillpouches have been obliterated, but one is retained and converted into the Eustachian canal, which connects the throat with the middle ear, inside of the ear-drum. Similarly, the embryological evidence shows that the lungs of air-breathers have been derived from the swim-bladder of fishes, a conclusion which had already been reached by comparative anatomy, for in a remarkable group, known as the 
Dipnoi or lung-fishes, the air-bladder is utilized for purposes of respiration.

It has been objected that, while embryology may prove relationship within a single type, it fails to demonstrate any connection between different types, but this is not altogether true. The Tunicata, a curious group of marine animals once referred to the Mollusca, are shown by their ontogeny to be related to the vertebrates and the same is true of certain marine worms (Balanoglossus). Indeed, most modern zoölogists have adopted a scheme of classification, in which the type Chordata includes not only the true vertebrates, but also the Lancelet ( $A m$ phioxus), the tunicates and Balanoglossus; this scheme is founded upon the embryological evidence. Among the invertebrates even more remarkable examples have been observed. Such radically different types as the segmented worms and the shell-fish (Mollusca) are brought into relationship by their ontogeny and their closely similar types of larvæ, as are also, though less distinctly, the brachiopods or lamp-shells, and the Bryozoa. The Horseshoe-crab, or King-crab, so abundant along our Atlantic coast, was long of uncertain affinities; originally referred to the Crustacea, largely because of its marine habits of life, embryology makes much more probable its relationship to the air-breathing scorpions and spiders, a result which will be examined again from another point of view in connection with blood-tests. Even before the publication of Darwin's "Origin of 
Species" one of the great stumbling blocks in the way of the theory of special creation was the existence in a great many animals of rudimentary organs, or such as are so far reduced and atrophied as to be of no service to their possessors. An analogy employed by my lamented friend, Mr. Richard Lydekker, may be advantageously repeated here. Let us suppose that a screw-steamer, with longitudinal shaft leading aft from the engine-room to the stern, where it carries the propeller, should, on close examination, reveal many signs that it had originally been a "side wheeler," or paddle-boat. Recognizable remnants of paddle-boxes, of bearings for a transverse shaft, and the like, are found; what would be the inevitable conclusion? No one would maintain that a naval architect, in possession of his senses, in constructing a screw-steamer would deliberately introduce features which are useful and appropriate only in a paddleboat. The only reasonable explanation would be that the vessel had originally been built as a paddleboat and had subsequently been converted into a screw-steamer and in the conversion it had not been found necessary completely to eradicate all traces of the original construction. Obviously, the same reasoning applies to rudimentary organs. The only satisfactory explanation of such useless remnants is that their possessors are descendants of ancestors in which those organs were fully functional. It seems quite absurd to assume that, in a separately and specially created animal, useless structures, reminis- 
cent of other animals in which the same structures are useful and valuable, should be included, merely to indicate ideal relationships and community of plan.

It was sought to break the force of this very serious objection to the theory of special creation by saying that apparently useless organs may nevertheless have functions which are still unknown to us and may be revealed by future discovery. In certain cases, like that of the thyroid gland in the neck, this contention has been justified, but there are many others to which it does not apply. For example, in the great and varied whale-tribe (order Cetacea) which includes the right, or whalebone, whales, the sperm-whales, the porpoises, dolphins, etc., the forelimbs have been converted into swimming paddles, but the hind limbs appear to have vanished completely, leaving no externally visible trace. Internally, however, recognizable remnants of the hind limb-bones may be found in various stages of reduction, which differ in the different members of the order. In the Greenland Right Whale the hip-bone, thigh-bone and shin-bone are indicated; in the Finwhale only the hip-bones and a minute rudiment of the thigh-bone are to be found; in the toothed whales only an almost unrecognizable remnant of the hipbone is left and in one of the dolphins even that has disappeared. Similarly, the snakes have lost their limbs completely, so far as external appearance is concerned, and in most members of the group no 
trace of limbs is to be found on dissection, but in certain snakes the rudiments of limbs are to be detected. Leaving aside all preconceptions, which is the more probable explanation of such phenomena, the theory of special creation or the theory of evolution?

Even if it were admitted that all rudimentary organs and structures found in the adult have a certain unknown use and value, no one could maintain this with regard to the countless instances of structures which are developed in the embryo, but disappear entirely before birth. It is possible to mention but a very few of such instances out of the great number that have already been observed and recorded, but these few will suffice to illustrate the principle involved.

"Examples of this may be cited from the most widely different groups: in the embryo of insects, especially of beetles, pairs of legs are formed within the egg, not only on the head and thorax, but also on the abdomen, but while those on the head are transformed into mouth-parts, those on the thorax are farther developed in their jointing and musculature to be locomotive legs, those on the abdomen are again resorbed. In many fresh-water worms, the eggs of which are laid in a cocoon, from which they are hatched as a finished, minute, crawling worm, larval organs are nevertheless formed, which recall those of the Trochophore, the larva of the original worms, which swims freely in the sea. However, 
these larval organs ... are never properly functional, since no actually free-swimming larva is developed, but the embryo merely floats in the albuminous fluid of the cocoon.

"A particularly beautiful example is offered by the whales in their embryological development, which has been thoroughly studied by Kükenthal. In the adult condition they show only the anterior extremities, but in the embryo the posterior pair, with their skeletal parts, are formed, but are afterwards completely atrophied. Although they are mammals, in the adult condition they have absolutely no covering of hair, since in their aquatic life another and more effective protection against loss of heat is given by means of a thick layer of blubber; only a few coarse bristles, partly with particular functions, have persisted on a few parts of the body. But in the embryo a dense covering of hair is formed, which is later transformed in a peculiar manner and atrophied. Further, a series of whales have no teeth in the adult condition, but only the wellknown, eel-trap like, horny plates, from which whalebone is produced. Nevertheless, in the embryo there is a dentition of numerous teeth, which are, however, resorbed, without ever piercing the gum." 1

Throughout the great group of the ruminants, which includes the oxen, buffaloes, bison, sheep, goats, antelopes, deer and giraffes, the collar-bone is invariably lacking, since it is superfluous on account ${ }^{1}$ Otto Maas, in Die Abstammungslehre, pp. 273-4. 
of the exclusively locomotive manner in which the fore legs are employed. In the embryo sheep the collar-bone is established and even, to some extent, ossified, but is subsequently resorbed and disappears entirely. No doubt, the collar-bone will be found in many other embryo ruminants, when the proper examination shall have been made, but its demonstrated presence in the foetal sheep is sufficiently striking. In the higher mammals the number of teeth was originally 44, or 11 on each side of both upper and lower jaws, but in most of the modern or existing groups of these higher mammals this number has been very considerably reduced through the suppression of certain teeth. We have every reason to believe that the ancestors of the forms with reduced dentition possessed teeth in full numbers and that there has actually been a loss of teeth in the course of descent. This conclusion is abundantly confirmed by the facts of embryology. Take, for example, the great group of the gnawing mammals, or Rodentia, in which the front teeth or incisors, above and below are reduced to one on each side, except in the rabbits. The incisors are chisel-shaped and are faced with hard enamel, so that the action of the upper teeth upon the lower keeps the cutting edges extremely sharp; these teeth do not form roots, but continue to grow throughout the lifetime of the animal. Between the chisel-like incisors and the grinding teeth, there is a long, toothless gap, which, we assume, was, in the ancestors of the 
rodents, occupied by the second and third incisors, the canine and two or more grinders. This conclusion is justified by the facts of embryology; for instance, in the embryo of the squirrel several of the missing teeth are begun as distinct tooth-germs, but fail to develop, never cut the gum and are resorbed before birth.

All available evidence points to the conclusion that birds are descended from reptiles, a conclusion which is especially strengthened by the facts of palæontology and will be examined more at length in the following lecture. Such a descent explains many otherwise puzzling features in the ontogeny of birds, in which reptilian characteristics appear in transitory fashion and are either modified so as to take on typically bird-like character, or are suppressed altogether. A remarkable example of this is the formation of rudimentary teeth in certain embryonic birds, followed by their resorption and disappearance before hatching.

It can hardly be contended that these rudimentary structures, which are confined to the embryonic stages of development and of which no trace remains in the adult, are so indispensable to the processes of ontogeny, that they were specially created to serve this temporary purpose. For such a contention there is not a particle of evidence and the theory of evolution, which regards these structures as useless remnants, due to inheritance from ancestors in which the structures were functional, 
offers much the most satisfactory solution of the problem that has yet been suggested.

Embryology further shows that evolution is not invariably an advance from lower and simpler to higher and more complex types, but may be by way of degeneration, and degradation. The adoption of a parasitic mode of life is very apt to cause such degradation, and some very remarkable instances of the degeneration of parasites have been observed. An instructive example that may be cited is that of Sacculina, a nondescript creature that is parasitic on certain species of crabs. The parasite is attached to the body of its victim, underneath the tail, by means of root-like fibres which penetrate and ramify throughout the interior of the crab. The root-like fibres absorb nutriment and convey it to the body of the parasite, which is reduced to a mere bag, without appendages, muscles, nervous system, sensory apparatus, digestive tract, or any determinable organs save those of reproduction. The creature has the power of assimilating the nutritive juices which are conveyed to it by the root-like filaments from the body of its host, and the power of reproduction, and it must have some respiratory and excretory capacity, though there are neither gills nor glands. From an examination of the adult parasite alone, it would be quite impossible to classify it and determine the type and class to which it should be referred, but embryology solves the problem. From the egg is hatched a free-swimming larva, which 
has jointed appendages, nervous, muscular and digestive systems and, in short, clearly belongs to that group of the Crustacea which includes the barnacles. This is degeneration carried nearly to the utmost possible extreme and yet the individual development shows the derivation of this otherwise problematical parasite and the steps through which it passed in its deterioration.

It was stated above that several distinguished naturalists altogether reject the recapitulation theory as a means of interpreting the facts of embryology. They do this on the ground that, inasmuch as changes and innovations in form or structure must arise in the germ-plasm, at the very beginning of ontogeny, there is no reason why such changes might not involve the whole course of embryological development. To my mind this $\dot{a}$ priori objection to the recapitulation theory is quite without force in view of the great body of observed facts, but there is no time to enter upon a discussion of such an abstruse and difficult problem. For our present purpose, however, it is important to note that these objectors are staunch evolutionists and find in the community of mode in ontogeny between different classes of organisms one of the strongest arguments in support of the evolutionary doctrine.

Here may be conveniently considered the very interesting and significant blood tests which have been made in the last fifteen years by various physiologists and especially by Dr. George H. F. Nuttall, 
of the University of Cambridge. Though there are several methods of making these tests, the "precipitation method" employed by Dr. Nuttall will be quite sufficient for the ends sought in these lectures. The method and significance of the tests can best be explained by taking as an example human blood, which, of course, has been most extensively and minutely studied, because of its legal importance as well as its scientific interest. Ordinary chemical analysis is unable to determine the differences in blood-composition between various animals, but that there were important differences had long been understood. This was shown by the fact that, in performing the operation for the transfusion of blood, it was not practicable to substitute animal for human blood, since the former might cause serious injury to the patient.

The precipitation method of making blood tests is as follows: Freshly drawn human blood is allowed to coagulate or clot, which it will do in a few minutes, if left standing in a dish, and then the serum is drained away from the clot. Blood-serum is the watery, almost colourless part of the blood, which remains after coagulation. Small quantities of this serum are injected, at intervals of one or two days, into the veins of a rabbit and cause the formation in the rabbit's blood of an anti-body, analogous to the anti-toxin which is produced in the blood of a horse by the injection of diphtheria virus. After the last injection the rabbit is allowed to live for 
several days and is then killed and bled, the blood is left until it clots and the serum drained off and preserved. The serum obtained thus from a rabbit is called "anti-human" serum and is an exceedingly delicate test for human blood, not only when the latter is fresh, but also when it is in the form of old and dried blood-stains, or even when the blood is putrid. Stains, for example, are soaked in a very weak solution of common salt and, if necessary, the blood solution is filtered until it is quite limpid and clear. Into the blood solution a few drops of the anti-human serum are conveyed and, if the stains are of human blood, a white precipitate is formed and thrown down, but if the stains are of the blood of some domestic animal, such as a pig, sheep, or fowl, no such reaction follows. In the same manner as above described, we may prepare anti-pig, antihorse, anti-fowl, etc., etc., sera by injecting the fresh-drawn serum of a pig, horse, fowl, or any other animal into the rabbit, instead of human bloodserum. In some countries, notably in Germany and Austria, this test has already been adopted by the courts of justice and has been found extremely useful in the detection of crime.

Further investigation showed that these blood tests might be employed to determine the degrees of relationship between different animals, for, although a prompt and strong reaction is usually obtained only from the blood of the same species as that from which the original injection into the rabbit 
was taken, the blood of nearly allied species, such as the horse and donkey, for example, gives a weaker and slower precipitation. By using stronger solutions and allowing more time, quite distant relationships may be brought out. Nuttall and his collaborator, Graham-Smith, made many thousands of such experiments bearing upon the problems of relationship and classification and it is of great significance to note that their highly interesting and important results contain few surprises, but, in almost all cases, merely serve to confirm the conclusions previously reached by other methods, such as comparative anatomy and palæontology. It will be instructive to quote some of these results, the quotations being taken from "Blood Immunity and Blood Relationship by G. H. F. Nuttall, including Origirial Researches by G. L. Graham-Smith and T. S. P. Strangeways;" Cambridge, 1904.

"In the absence of palæontological evidence the question of the interrelationship amongst animals is based upon similarities of structure in existing forms. In judging of these similarities, the subjective element may largely enter" (p. 1). "The very interesting observations upon the eye made by Johnson also demonstrate the close relationships between the Old World forms and man, the macula lutea tending to disappear as we descend in the scale of New World monkeys and being absent in the Lemurs. The results which I published upon my tests with precipitins directly supported this evi- 
dence, for the reactions obtained with the bloods of Simiidæ [i. e., Man-like Apes] closely resemble those obtained with human blood, the bloods of Cercopithecidæ [Old World Monkeys] came next, followed by those of Cebidæ and Hapalidæ [New World Monkeys and Marmosets] which gave but slight reactions with anti-human serum, whilst the blood of Lemuroidea gave no indication of blood-relationship." (p. 2). "A perusal of the pages relating to the tests made upon the many bloods I have examined by means of precipitating anti-sera, will very clearly show that this method of investigation permits of our drawing certain definite conclusions. It is a remarkable fact . . . that a common property has persisted in the bloods of certain groups of animals throughout the ages which have elapsed during their evolution from a common ancestor, and this in spite of differences of food and habits of life. The persistence of the chemical blood-relationship between the various groups of animals serves to carry us back into geological times, and I believe we have but begun the work along these lines, and that it will lead to valuable results in the study of various problems of evolution" (pp. 2-4).

The general conclusions on interrelationships, so far as they are of particular interest for our purpose, reached by Nuttall and Graham-Smith as the result of many thousands of blood tests, may be summarized as follows:

(1) If sufficiently strong solutions be used and 
time enough be allowed, a relationship between the bloods of all mammals is made evident.

(2) The degrees of relationship between man, apes and monkeys have already been noted.

(3) Anti-carnivore sera show "a preponderance of large reactions amongst the bloods of Carnivora, as distinguished from other Mammalia; the maximum reactions usually take place amongst the more closely related forms in the sense of descriptive zoology."

(4) Anti-pig serum gives maximum reactions only with the bloods of other species of the same family, moderate reactions with those of ruminants and camels, and moderate or slight reactions with those of whales. Anti-llama serum gives a moderate reaction with the blood of the camel, and the close relationship between the deer family and the great host of antelopes, sheep, goats and oxen is clearly demonstrated.

(5) Anti-whale serum gives maximum reactions only with the bloods of other whales and slight reactions with those of pigs and ruminants.

(6) A close relationship is shown to exist between all Marsupials, with the exception of the Thylacine, or so-called Tasmanian Wolf.

(7) Strong anti-turtle serum gives maximum reactions only with the bloods of turtles and crocodiles, with those of lizards and snakes the results are almost negative. With the egg-albumins of reptiles and birds a moderate reaction is given. 
(8) Anti-lizard serum produces maximum results with the bloods of lizards and reacts well with those of snakes.

(9) These experiments indicate that there is a close relationship between lizards and snakes, on the one hand, turtles and crocodiles, on the other. They further indicate that birds are more nearly allied with the turtle-crocodile series than with the lizardsnake series, results for which palæontogical studies had already prepared us.

(10) "Tests were made by means of anti-sera for the fowl and ostrich upon 792 and 649 bloods respectively. They demonstrate a similarity in blood constitution of all birds, which was in sharp contrast to what had been observed with mammalian bloods, when acted upon by anti-mammalian sera. Differences in the degree of reacticn were observed, but did not permit of drawing any conclusions."

(11) I have already called attention to the fact that the problematical Horseshoe-crab is indicated by its embryology to be related to the air-breathing spiders and scorpions rather than to the marine Crustacea. It is of exceptional interest to learn that embryology is supported by the results of the blood-tests.

It must not be supposed that there is any exact mathematical ratio between the degrees of relationship indicated by the blood tests and those which are shown by anatomical and palæontological evidence. Any supposition of the kind would be imme- 
diately negatived by the contrast between the blood of mammals and that of birds. It could hardly be maintained that an ostrich and a parrot are more nearly allied than a wolf and a hyena and yet that would be the inference from the blood tests. Like all other anatomical and physiological characters, the chemical composition of the blood is subject to change in the course of evolution and these developmental changes do not keep equal pace in all parts of the organism. It is the rule rather than the exception to find that one part of the structure advances much more rapidly than other parts, such as the teeth, the skull, or the feet. The human body is, fortunately for us, of rather a primitive kind, while the development of the brain is far superior to that of any other mammal and this great braindevelopment has necessitated a remodeling of the skull. On the other hand, the skeleton, limbs, hands and feet are but slightly specialized. In the elephant tribe, so far as we can trace them back in time, there has been little change, save in size, in the structure of the body or limbs, while the teeth and skull have passed through a series of remarkable changes. It is for this reason that it is unsafe to found a scheme of classification, which is meant to be a brief expression of relationship, upon a single character, for the result is almost invariably misleading. The results of blood tests must be critically examined and checked by a comparison with the results obtained by other methods of inves- 
tigation, but after every allowance has been made, these tests are very remarkable.

The blood tests have brought very strong confirmation to the theory of evolution and from an entirely unexpected quarter; they come as near to giving a definite demonstration of the theory as we are likely to find, until experimental zoölogy and botany shall have been improved and perfected far beyond their present state. 


\section{LECTURE IV}

\section{EVIDENCE FROM PALÆONTOLOGY}

Palæontology is the science which deals with the fossils of animals and plants entombed in the rocks of the earth's crust. This science has certain preeminent advantages for the investigation of evolutionary problems, because it has to do with the recognizable remains of the actual organisms which formerly inhabited the surface of the earth and which are themselves the links in the chain of development. If there be any truth in the theory of evolution, palæontology ought to be one of its strongest supports and offer some of the most convincing testimony in its favour, and, on the other hand, if it be false, the fossils should be able to expose its fallacies in an overwhelming manner.

Here, again, it is necessary to utter a warning not to expect too much, for this method of inquiry suffers from certain very serious difficulties and disadvantages.

(1) Many types of animals and plants are not capable of preservation in the fossil state, or else are so extremely rare and are found separated by such vast intervals of time, that their remains are of no practical assistance in our inquiry. It is particularly 
unfortunate that many of these almost or entirely missing types are precisely those which would be most useful in the investigation. For any organism to be preserved and discovered, it is almost essential that it should have been fairly common and abundant when living and that is the probable reason why the beginning of so many genealogical lines should be lost in obscurity.

(2) Of the innumerable fossil forms which have been made known, nearly all are but partially preserved, only the hard parts, bones, teeth, shells, etc., remaining, and the interpretation of these incomplete remains is often difficult, sometimes impossible in the present state of knowledge. Exceptions to this almost universal rule are so rare and occur so late in geological time, as to be of little real assistance.

(3) In Darwin's "Origin of Species" is a famous chapter devoted to an examination of "the imperfection of the geological record," in which he points out the accidental and haphazard way in which organisms have been fossilized and the great gaps which occur in the history of life on the earth, so far as that history has been discovered and deciphered. "I look at the geological record as a history of the world imperfectly kept and written in a changing dialect; of this history we possess the last volume alone, relating only to two or three countries. Of this volume only here and there a short chapter has been preserved; and of each page only here and there a few lines. Each word of the slowly changing language, more or 
less different in the successive chapters, may represent the forms of life which are entombed in our successive formations and which falsely appear to us to have been abruptly introduced." 1

An excellent example of the imperfectly recorded facts is afforded by the long and narrow, but very thick belt of rocks, which forms the surface of the Connecticut Valley and runs unbrokenly from the Hudson River across New Jersey, Pennsylvania and Maryland into Virginia; the whole formation is referred to what geologists call the Triassic period. These rocks, which were not laid down in the sea, but on land and in various bodies of fresh water, are remarkably barren of fossils and one may search through great thicknesses and over weary miles without finding a trace of ancient life. In several localities, notably in western Massachusetts, were extensive mud-flats, which have preserved countless foot-prints of the great variety of reptiles then inhabiting North America; in size, these impressions range from the prints made by tiny creatures, no larger than a sparrow, to monsters which left tracks each eighteen inches long. From the diversity in form of the tracks it is obvious that a very large variety of animals must have made them. Yet of all this host, bones of only two or three have been found, in localities scattered from Pennsylvania to Massachusetts and, when it is remembered that these rocks are quarried very extensively for building stone,

${ }^{1}$ Origin of Species, 6th Ed., London, 1872, p. 289. 
the paucity of fossils is all the more evident. It needs no argument to prove that in this case the record is lamentably incomplete and it is typical of a great many others. In a sense, the foot-prints themselves constitute a record, but it is one that we do not know how to decipher.

On the other hand, matters have greatly improved since Darwin wrote his oft-cited Chapter $\mathrm{X}$; many lands then geologically unknown have been explored and many of the missing chapters and paragraphs in the history of life have been brought to light. The most ancient biologically intelligible period of the earth's history is called the Cambrian and, compared with the succeeding periods, the Cambrian has always been poor in fossils, great areas and thicknesses of rocks being entirely barren. No one could doubt that our knowledge of Cambrian life was most incomplete and inadequate. A few years ago Dr. C. D. Walcott, Secretary of the Smithsonian Institution, discovered in the Canadian Rockies a most marvellous series of Cambrian fossils of an incredible delicacy and beauty of preservation, which have thrown a flood of new and unexpected light into very dark places. It is clear that the Cambrian seas swarmed with a great variety and profusion of life, but that in only a few places, so far known to us, were the conditions such that these delicate creatures could be preserved. It is not possible to say how far the difficulty caused by the imperfection of the geological record will be removed by the progress of discovery. 
Even as matters stand to-day, the astonishing fact is that so much has been preserved, rather than that the story is so incomplete. Notwithstanding all the difficulties, the palæontological method remains one of the most valuable means of testing the theory of evolution, because certain chapters in the history of life have been recorded with a minuteness that is really very surprising.

* In the brief time at my disposal it is quite impracticable to make clear all the geological preliminaries which are needed to explain the facts of palæontology. It may seem incredible that a fossil found a thousand feet below the surface is the remains of a creature that once swam in the sea and that it was buried in what was the sea-bottom at the time of its death. Yet such is the fact and the explanation is very simple. I must also ask you to take for granted the possibility of arranging the fossils which are buried in the rocks in the chronological order of their succession. This is no assumption made to bolster up any theory, for, in its main outlines, the scheme of chronology which we now use had been worked out long before the publication of Darwin's revolutionary book, when the theory of special creation had full possession of the field. Any of my hearers who may be interested to learn how this chronological succession of the forms of life has been ascertained, will find the explanation in any of the standard text-books of geology.

This arrangement in the order of succession in time 
is essential to a comprehension of the huge mass of facts which have already been gathered. It is further possible to make an approximate determination of the relative chronology of the rocks and fossils in different regions and continents, a determination which is of the utmost importance, as will appear later. In the following sketch of palæontological evidence, it is not practicable to avoid all mention of the technical terms used in designating the divisions of geological time and so a table of these terms is appended.

Cenozoic era $\left\{\begin{array}{l}\text { Quaternary period }\left\{\begin{array}{l}\text { Recent epoch } \\ \text { Pleistocene epoch } \\ \text { Pliocene epoch } \\ \text { Tiocene epoch } \\ \text { Oligocene epoch } \\ \text { Eocene epoch } \\ \text { Paleocene epoch }\end{array}\right.\end{array}\right.$

Mesozoic era $\left\{\begin{array}{l}\text { Cretaceous period } \\ \text { Jurassic period } \\ \text { Triassic period }\end{array}\right.$

Palæozoic era $\left\{\begin{array}{l}\text { Permian period } \\ \text { Carboniferous period } \\ \text { Devonian period } \\ \text { Silurian period } \\ \text { Ordovician period } \\ \text { Cambrian period }\end{array}\right.$

Pre-Cambrian eras.

N. B. The arrangement of the table is such that the most ancient times are at the bottom and the latest at the top; the epochs of the Mesozoic and Palæozoic eras are omitted as unnecessary.

If, neglecting all details, we survey the great and ever-changing procession of life, as it is recorded in 
the rocks, the immediate impression received is that of constant, though not always uniform advance and progress from the most ancient times, and, the more nearly the present is approached in time, the closer is the approximation to the modern animal and vegetable worlds. This most obvious and striking fact impressed itself upon the earlier palæontologists, like Cuvier and Agassiz, who upheld the theory of special creation and the immutability of species, and they interpreted it as the carrying out of a systematic creative plan, an interpretation which is not at all invalidated by the acceptance of the evolutionary theory.

The latest of the eras, the Cenozoic, in which we are now living, is characterized by a land vegetation consisting chiefly of the flowering plants, such as the trees, bushes and herbs, with which we are all familiar, also palms, lilies and grasses. The conifers, or "evergreens," pines, spruces, firs, etc., also belong to the flowering plants, but to a lower grade, but of the non-flowering or cryptogamic plants, only the ferns, mosses and lichens can be called abundant; the fungi and microscopic plants are left out of account, as so little is known of their history. Certain groups which contain but few species are of interest as being the last survivors of what were once great and dominant assemblages; the Cycads, or erroneously so-called "Sago Palms," are now confined to the warmer parts of the earth and, among the cryptogamic plants, the little ground-pines, or lycopods, and the horse-tails 
are remnants of a more ancient vegetation. Among animals, the most conspicuous groups are the mammals, or warm-blooded quadrupeds, and the birds; the reptiles occupy a very subordinate position and only five orders of them are found, lizards and snakes, turtles and crocodiles, including a single lizard-like creature which is confined to New Zealand. The overwhelming majority of Cenozoic fishes belong to the sub-class of the bony fishes or teleosts, and of the remainder almost all are sharks. But there are, almost exclusively in fresh waters and consisting of very few forms, two groups of very ancient date, the ganoids, and the lung-fishes of the southern hemisphere. Of the vast host of Cenozoic invertebrates it is impossible to make the most hasty survey and nothing more can be attempted than to mention a few of the most conspicuous kinds. There are countless insects, especially of the higher orders, beetles (Coleoptera), moths and butterflies (Lepidoptera), ants, bees, wasps (Hymenoptera) and flies (Diptera). There is a great profusion of marine life, crustaceans, molluscs, star-fishes, sea-urchins, and others innumerable; survivals of formerly abundant groups are the lamp-shells, or brachiopods, and the sea-lilies or crinoids.

While this general statement will serve to give some conception of Cenozoic life as a whole, the periods and epochs of that era are each characterized by stages of constant progress, which may sometimes, when conditions are favourable, 
be followed out in surprising detail. Indeed, the changes within the eras and periods are as marked as those which distinguish these divisions from one another.

The vegetation of the latest part of the Mesozoic era is substantially the same as that of the Cenozoic, the great revolution in plant life taking place within the Cretaceous period, but the characteristic Mesozoic plants were conifers and cycads, the latter in great variety and spread all over the earth, even to the Antarctic continent. Birds are rare and far more primitive than those of the Cenozoic, and the same is true of the mammals, all of which were tiny creatures of very low grade. The conspicuous and all-dominating group was that of the reptiles, so that the Mesozoic is appropriately called the "Age of Reptiles." These creatures swarmed in the sea, on the land and in the air and many attained gigantic size, incomparably the largest land animals that ever lived. The contrast between the Cenozoic and Mesozoic is well summarized by the fact that while in the Cenozoic only five orders of reptiles have been found, in the Mesozoic there were no less than twenty. Like the modern type of vegetation, the bony fishes came in in the Cretaceous, while before that period the fish-fauna was almost entirely composed of ganoids and sharks. Many of the Mesozoic invertebrates were of modern type, but there were several highly characteristic groups. Among the Mollusca the bivalves and gastro- 
pods were less abundant and varied than in the Cenozoic, the beautiful chambered shells called Ammonites were incredibly numerous and diversified. In the successive forms of these shells many striking genealogical series have been made out. The curious Belemnites are almost exclusively Mesozoic.

In all the recorded history of life there was no such radical and far-reaching revolution as that between the Palæozoic and Mesozoic eras. Could a naturalist be transported into the former he would find himself in an unfamiliar world, in which almost every animal and plant that he saw would be strange to him. The land vegetation was made up of gigantic, tree-like cryptogams, especially the lycopods and horse-tails, and the abundant ferns were both in arboreal and herbaceous forms. The flowering plants were represented but scantily and by curious trees allied to the cycads and conifers, but of such plants in the ordinary use of the word, there was no trace, nor was any mammal or bird in existence. The vast majority of Palæozoic fossils belong to marine invertebrates, for, except in the latter part of the era, the only vertebrates were fishes and fish-like forms, sharks, ganoids, lung-fishes and certain bizarre, mailed animals, which were below the fishes in the scale of organization. The seas were swarming with a profusion of invertebrate life, many of which, though referable to types and classes which are still existing, were much more primitive in structure 
than any living representatives of those groups, and groups which now are very rare were then extremely abundant, and many were dominant in the Palæozoic. For example, molluses were less common and brachiopods and sea-lilies vastly more so then than now. Confined to the Palæozoic were the remarkable Trilobites, an extinct sub-class of the Crustacea, while the higher groups of the latter were wanting. Spiders and scorpions were followed by insects belonging to the lower and more primitive divisions, such as cockroaches and dragonflies.

The species of Palæozoic fossils already described are numbered by thousands and the number is constantly growing, as new discoveries are made. Any attempt to survey this vast assemblage is a highly technical problem and cannot be made here. The few salient features which have been selected are enough to show that the farther back in time we explore the history of life, the greater do the differences from the present order of things become and that not in any haphazard way, but by changes in a well-defined serial order. The history of life, both animal and vegetable, is a story of progress and differentiation, of advance continued through millions of years to modern conditions from far-off beginnings, which were of radically different character. In itself, this story is a striking testimony to the theory of evolution and the testimony is much strengthened, when the material at hand permits a 
close study of the genealogy of some restricted group.

It has often been objected that the palæontological record, as we actually have it, is irreconcilable with the evolutionary conception, because of the many cases of the sudden and unheralded appearance of new kinds of organisms, such as the remarkable outburst of modern types of plants and fishes in the upper Cretaceous period. This objection overlooks the phenomena of migration, the importance of which has only lately come to be recognized; the many geographical changes in the connections between the different continents and between the seas, which have demonstrably occurred in the past, have from time to time altered the possibilities and directions of migration. Hence, the appearance in any given area of new forms may either be through the modification of older forms which previously inhabited that area, or by immigration from some other region. It is therefore not to be taken for granted that any group originated in the region where we happen first to find it; quite as frequently it arose in some other region and spread gradually from that. A very instructive illustration of this principle is afforded by the history of the elephants, which appeared suddenly (lower Miocene) in Europe and somewhat later (middle Miocene) in North America. In neither continent has anything been found in any preceding formation, which could plausibly be regarded as ancestral to these ancient and 
primitive elephants, which, to all appearances, might have risen up out of the ground, as Buffon fancied that they actually did. However, on evolutionary principles, they must have had ancestors and the obvious inference was that they had immigrated into the northern continents from some southern land. By a process of elimination, the conclusion was reached that Africa must have been the original home of these animals, a result which has been amply confirmed by discoveries made not long ago in Egypt, which carry the history of the order much farther back in time than had previously been possible.

Another objection which has frequently been brought against the palæontological argument for the theory of evolution is that, while the genealogical series made out within certain families may be admitted as proving development within relatively small groups, the fossil record fails to connect the larger and more widely separated types, thus indicating that evolution, while real enough, is of strictly limited possibilities. This, it will be remembered, is the same objection as has been urged against the argument from embryology, and the answer is in both cases the same. In part, the objection is founded upon an assumption which is not true and is being gradually refuted by the progress of discovery and, where this is not likely to happen, there are obvious reasons why we cannot expect to find the connecting links. The most ancient known 
fossiliferous rocks show that most of the principal types of animal life were already differentiated at the time when those rocks were formed and hence there is little hope of finding the beginnings of those types. It must not be forgotten that there is abundant indirect evidence that life had existed on the earth through unimaginably long ages before the formation of the earliest fossiliferous rocks; that is what Darwin meant when he said that the geological record contained only the last volume of the world's history.

An admirable illustration of the manner in which the evidence of fossils may serve to show the connection between types which are very widely separated in the modern world, is afforded by the vegetation of the Carboniferous period, the last but one of the Palæozoic divisions. This luxuriant vegetation was composed almost entirely of non-flowering or cryptogamic plants and, in addition to a great variety of ferns, giant lycopods and horse-tails, there were two groups of especial interest to evolutionists: (1) the Sphenophyllales, very slender, probably trailing and climbing plants, which are intermediate in structure between the two cryptogamic classes, the lycopods and horse-tails. Doubtless, they were the survivors in Carboniferous times of more ancient plants which were, in turn, the common ancestors of the two classes named. (2) A proverbially impassable gulf yawns between the flowering and the cryptogamic plants and yet the gulf is at least par- 
tially bridged by the Carboniferous group of the Cycadofilices, which, as the name indicates, serve to connect the cycads with the ferns; in appearance of stem and foliage the Cycadofilices most resembled ferns. In view of such facts, it is idle to say, as is still so often said, that the fossils have never afforded transitions between groups which are now radically distinct and widely separated.

Another very interesting and significant transition is that displayed by certain fossil birds, which clearly indicate their derivation from reptiles. The relationship between birds and reptiles is shown by comparative anatomy and embryology and is strongly confirmed by the blood tests which were described in the preceding lecture. To this mass of testimony from three independent lines of inquiry, palæontology adds its quota. At the famous quarries of lithographic stone at Solenhofen, in Bavaria, has been found a marvellously preserved record of the later Jurassic life of Europe and here were discovered two nearly complete skeletons of the most ancient known bird, belonging to the genus Archoopteryx. Though an unmistakable bird, Archoopteryx yet retained many characteristics of its reptilian ancestry, characters which are repeated in no existing bird, or appear only as transitory features in the course of embryological development. There is no horny beak, but the jaws are provided with numerous small teeth, which explains the significance of the 
formation of tooth-germs in certain embryo birds, as was pointed out in Lecture III (see p. 71). The joints of the backbone lack the characteristic features of modern birds, and are much more reptilian in structure. A very remarkable feature is the long, lizard-like tail, composed of many vertebræ, to each of which a pair of quill feathers is attached. The hand is most un-birdlike; its four fingers are all separate and free from one another and are completely developed, with the same number of joints as the corresponding fingers of a lizard, and each one is provided with a claw. Fig. 6. Restoration of Archaopteryx, There are feathers on Jurassic of Bavaria. (After Anthe wings, tail and

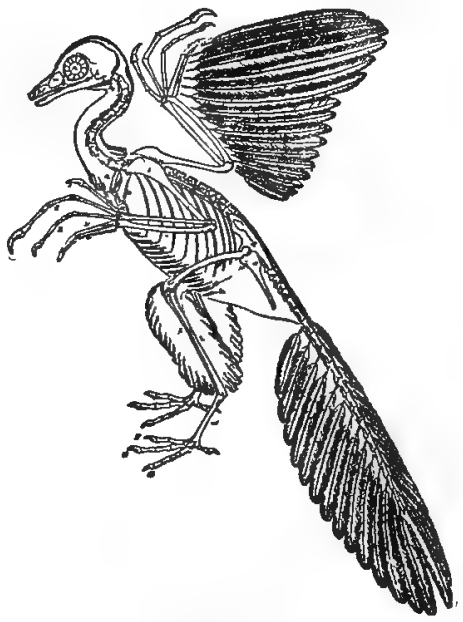
legs, but the head, neck and body are mostly naked. We may well hope that the ancestors of Archoopteryx, fully intermediate between birds and reptiles, will yet be discovered in Triassic rocks.

The ancestry of mammals is still a question of much uncertainty and zoölogists continue to debate whether they were derived from reptiles or amphib- 
ians, a state of affairs which Professor Steinmann regards as so scandalous to science (see p. 4), but there are good reasons for the uncertainty. Mesozoic mammals are very rare and, though they have been found in three continents, the specimens are all so incomplete that they contribute but little to a solution of the problem. Certain reptiles obtained from the Permian rocks of South Africa decidedly suggest that they were closely allied to the long sought ancestors of the mammals, but the gap is still too great for any final decision.

The number of genealogical or phylogenetic series within narrower limits, which has already been made out, would fill many volumes. These genealogies have been determined in a great many different types of animals, both vertebrate and invertebrate, but I shall confine attention to the vertebrates, as it is easier to make these intelligible, and can select only a few of the most conspicuous and best known instances. So long as it is clearly understood that but a small number of illustrative examples are here set forth, it will serve no good purpose to pile up a great number of more or less similar cases. Some of the best preserved and most complete of the phylogenetic series are among the families of mammals, the changes in which may be traced through the successive stages of the Tertiary period. The most complete of all the series so far discovered is that which displays the development of the horses in North America. One cannot but hesitate to tell 
again this oft-told tale, which has been reiterated until it has become a hackneyed commonplace. Friends and foes of evolution are alike given to sneering at it and calling it the "parade horse," the "hobby horse," the "stalking horse," and other opprobrious names, seeming almost to imagine that, if testimony be very often repeated, it loses all validity. Logically, this is on a par with the procedure of the ship's crew in the "Hunting of the Snark," who believed that, by repeating a statement three times, they proved it. On the other hand, no sketch, however slight, which purports to give an outline of the evidences of evolution, can in fairness omit all mention of this remarkable case.

The Recent and Pleistocene horses, including in that term not only the true horses, but also the asses, zebras, etc., have a skeleton which is wonderfully adapted to swift running, while their teeth are highly specialized and elaborated for the masticating of grasses, which are among the most abrasive of plants. The front teeth (incisors) used for cropping, continue to grow for a long period and have on their biting surfaces a deep pit, lined with enamel, which horsemen call the "mark." The grinding teeth are very high-crowned, growing persistently in height, as they are worn down, to an advanced period of life, when the formation of roots puts an end to growth; they have masticating surfaces which are kept rough by the different hardness of the three substances exposed on these surfaces, dentine, 
enamel and cement, which wear unequally. The arrangement of the three tooth-substances is in a highly characteristic and very complex pattern, and the anterior grinding teeth (premolars) are similar in form and size and in the pattern of the masticating surface to the posterior teeth (molars). The facial portion of the skull is very long and the jaws high vertically, to provide room for the very deep tooth-sockets. The eye-socket is completely encircled in bone and displaced backward behind the teeth, which otherwise would invade the socket and compress the eyeball.

The neck is long and its vertebræ are much specialized to secure the greatest freedom of movement in combination with strength. The limbs and especially the feet are elongate and their bones have undergone nearly the utmost possible reduction in number, either by complete suppression and loss, or by co-ossification, such concentration being favourable to rapidity of movement; we find it repeated in other swift runners, such as antelopes and deer. The external bone of the forearm (ulna) is greatly reduced in thickness, the middle portion of its shaft has been lost and its two ends are co-ossified with the enlarged radius, which carries the whole weight imposed upon the fore leg. Similarly, in the hind leg only the shin-bone (tibia) is left in the lower segment, while the fibula seems to have completely disappeared, but if the skeleton of a young colt be examined, it is seen that, while the whole shaft of 
the fibula has been suppressed, its two extreme ends remain and in the adult are indistinguishably fused with the tibia. The feet are very long and have but a single functional toe each, which is greatly enlarged and strengthened to bear the heavy weight. This remaining toe is the median one, or third, of the original five, and the splint-bones are remnants of the second and fourth, but have no joints or hoofs attached to them, and are not visible in the living animal. The horses walk on the very tips of their toes and the curious, box-like hoof, which encloses the terminal joint of the single functional toe, is highly characteristic.

In surveying the history of the changes which lead back from the Recent horses to their far distant ancestors of the lower Eocene, it will be necessary to omit most of the stages, for lack of time, and mention only the most obvious. Passing back to the lower Pliocene and upper Miocene, we find that the horses of those times, while unmistakably equine, differed in certain very significant ways from their modern descendants. They are decidedly smaller and of more slender and deer-like proportions; their grinding teeth are hardly more than half as high proportionately and with masticating surfaces of similar, but less complicated pattern. The feet are three-toed, the lateral toes (second and fourth) having a full complement of joints and carrying hoofs, but were more dew-claws, not reaching the ground, and could have been of service only in soft 
mud. A small, nodular rudiment of the fifth toe is also present. The horses of the middle and lower
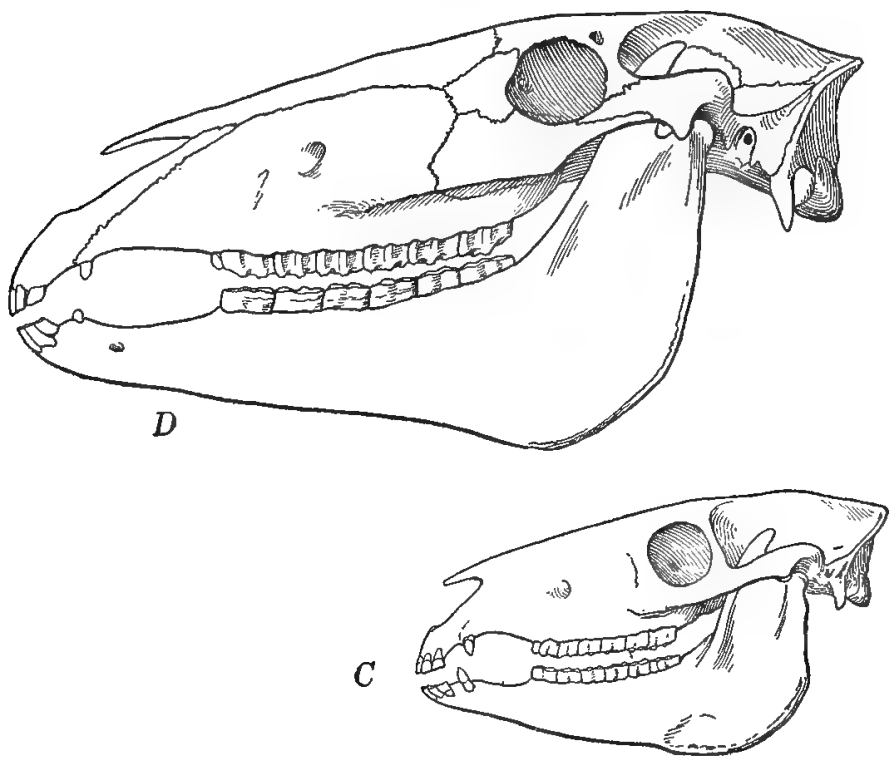

A

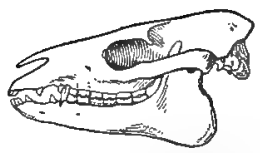

B

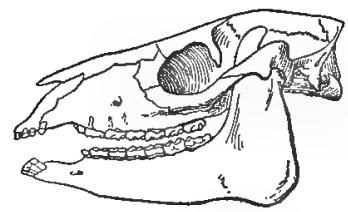

Fig. 7. Four stages in the evolution of the equine skull. A, Eohippus, lower Eocene. B, Mesohippus, lower Oligocene. C, Protohippus, upper Miocene. $\quad$ D, Equus, Pleistocene and Recent.

Miocene display the transition between the highcrowned, cement-covered grinding teeth and those 
with low crowns, which were incapable of growth after they had cut the gum, and have no cement on the crown, but only on the roots.

It is very interesting to note that this adoption of a high-crowned, persistently growing type of grinding teeth was by no means confined to the horses, but was repeated in several other families of hoofed animals and gnawers (Rodentia), and came about during the Miocene epoch. This transformation of the teeth indicates a change from the habit of browsing upon leaves and other soft vegetable substances to grazing, or feeding upon the hard, abrasive grasses, and it is highly suggestive that this coincided with, or quickly followed the spread of grassy plains, which afforded a new and abundant supply of nutritious food.

Again omitting intermediate stages and taking another long backward step, we come to the horses of the lower Oligocene, in which are notable changes in all parts of the skeleton, as well as a distinct reduction in size, for these animals are no larger than sheep. The teeth are low-crowned and devoid of cement, save on the roots, and the sharp-edged incisors have no mark. The facial portion of the skull is shorter and the eye-socket farther forward, placed over the teeth, and is partially open behind; the jaws are shallow and slender, as there is no need of providing for very deep sockets. The neck is only moderately elongate and its vertebræ are much less specialized. In the forearm the ulna is already much reduced in 
thickness, but is complete and separate from the radius, and in the lower hind leg, the fibula is separate and has a very slender shaft, but it is entire and uninterrupted. The feet are still three-toed, but the lateral toes are longer and more useful in carrying weight.

Once more omitting many intermediate forms, we may examine the most ancient known horses, those of the lower Eocene, which were little creatures, not exceeding a fox in size. The grinding teeth have a very simple and primitive pattern, though the beginnings of the complicated horse-pattern may be discerned in them; the premolars are all smaller and simpler than the molars. The neck and limbs and especially the feet are relatively short; there are four functional toes in the front foot and three in the hind, but the latter also has splint-like rudiments of the first and fifth, plainly indicating derivation from a five-toed foot.

Here the line breaks off and cannot at present be traced farther back, the preceding Paleocene of North America having yielded nothing that can be regarded as ancestral to this family. The lower Eocene horses in Europe are of the same type and there also they appeared unheralded by any predecessors in the Paleocene. The obvious conclusion from these facts is that the family arose in some region, as yet unidentified, but which not improbably was central Asia, and thence migrated into Europe and North America; the latter continent was made 


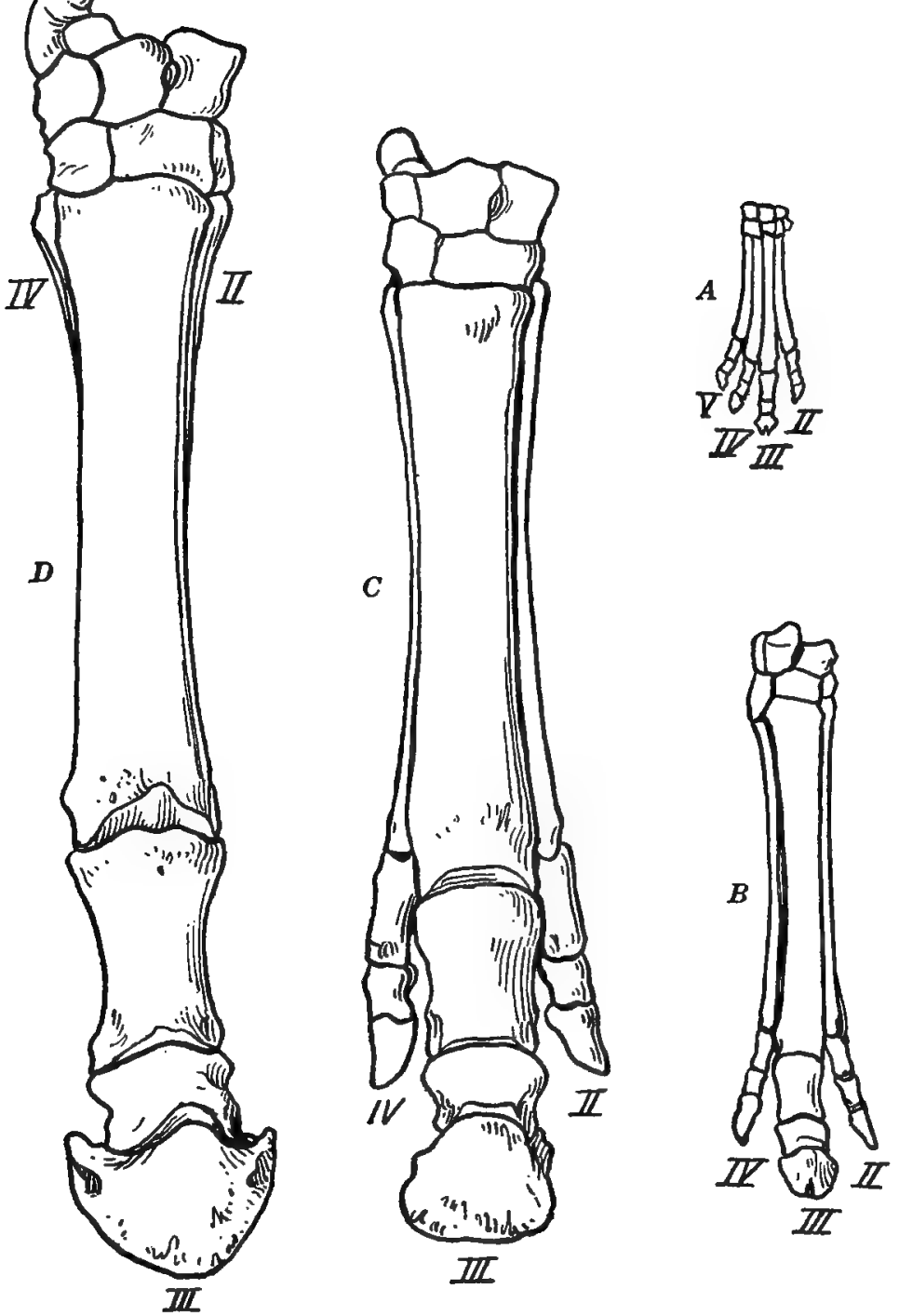

Fig. 8. Four stages in the evolution of the equine fore foot. A, Eohippus, lower Eocene. $B$, Mesohippus, lower Oligocene. C, Protohippus, upper Miocene. D, Equus, Pleistocene and Recent. 
accessible by a junction with northeastern Asia, where now are Bering Strait and Sea.

Though the equine family did not originate in North America, its principal development took place here and went on unbrokenly through the long ages of the Tertiary period. After they had arrived at a high stage of advance and differentiation, the horses spread to other continents and eventually reached all of them except Australia. Invading South America in the late Miocene or early Pliocene, after the two continents had been joined by the upheaval of the Isthmus of Panama, they there gave rise to a number of peculiar and characteristic forms. In the Pleistocene epoch great herds of horses, belonging to no less than ten distinct species, ranged through the forests and over the plains of North America, extending from the Atlantic to the Pacific and from Alaska through Mexico. In size, they varied from a Shetland pony to species exceeding the largest modern draught-horses in stature. Then, for some unknown reason, they died out completely all over the western hemisphere, a fate which was by no means confined to the horses or to the Americas; the close of the Pleistocene witnessed over three-fifths of the landsurface of the globe, the extinction of a multitude of the largest and most conspicuous mammals, but the causes of such a tremendous mortality can only be conjectured.

In addition to the main line of equine descent, leading up to the modern horses, there were several 
side-branches of the equine stock, which, after a longer or shorter duration, died out without leaving descendants. One such branch was that of the browsing horses, which were abundant through the Miocene and early Pliocene of North America; they retained the low-crowned teeth and the three-toed foot until the end. The peculiar South American forms were likewise side-branches, given off from the main stem at a later date; one of these was a small mountain horse, with very short feet, especially adapted to climbing, like several of the existing mountain antelopes. A very early branch, which probably originated in Asia, diverged so widely from the equine series that it is included in a different family, is that of the Palæotheres, which was abundant in the Eocene of Europe, but did not extend its range to the western hemisphere.

We have thus traced the horses back to little animals, whose structure is but remotely equine and which are in all respects so unlike the modern species, that hardly any palæontologist would be bold enough to connect them, were it not for the many intermediate stages, which join these extremes in almost unbroken continuity. No more illuminating example of evolutionary development can be found among the geological records of mammalian life than the history of the horses, just because well-preserved specimens, exemplifying all the important steps of change, have been discovered. In turn, this was probably due to the fact that, from the beginning to the end of their 
separate history, the horses have been individually abundant and thus have had a much better chance of

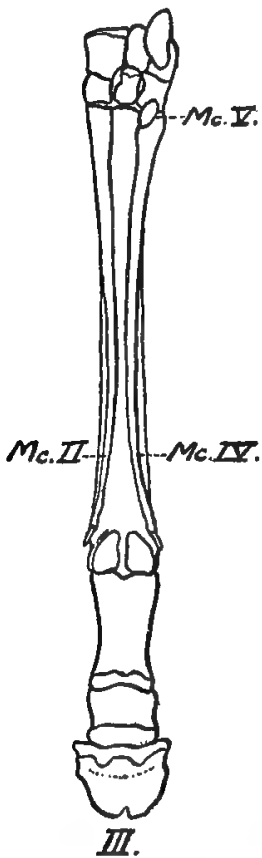

Frg. 9. Fore foot of Pliohippus, Pliocene, hinder view, showing the very long splint-bones (Mc. II and IV) and rudiment of fifth digit (Mc. V) (from Troxell).

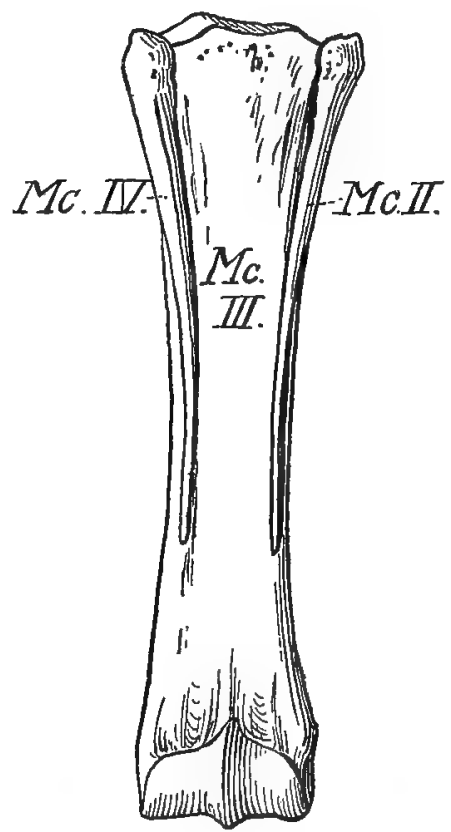

Frg. 10. Fore foot of Horse (Equus) posterior view, showing short splint-bones. Wrist- and toe-bones omitted.

being preserved as fossils than those of their contemporaries which were less common. But there are several other families whose history is only less com- 
pletely known than that of the horses and which illustrate similar principles. In several instances we are embarrassed with riches, finding it difficult, or even impracticable, to select from the many possibilities the forms which are actually and properly referable to a given series. Indeed, there is every reason to believe that, did we possess well-preserved specimens of every mammal that ever lived on the earth, we should be entirely unable to find a clue that would guide us through the complex maze.

A family that has been traced from the Pleistocene to the Eocene of North America is that of the tapirs, but, for the most part, by the aid of rare, fragmentary and therefore unsatisfactory materials. This, however, is of less consequence in the case of the tapirs, for they are a very conservative family and have undergone relatively little change. There has been a moderate increase in size and bulk in the successive stages, a few changes in the teeth and skull may be noted, especially the modifications of the latter caused by the development of a proboscis, but otherwise the bony structure of an Eocene tapir differs but little from that of its modern descendants. In the Pleistocene, tapirs extended from Pennsylvania to Argentina and to eastern and southern Asia, but they had vanished from Europe, where they had lived in the Miocene and Pliocene. Thus, at one time or another, they ranged all over the northern hemisphere; the significance of this fact will appear in the next lecture. 
Another family, the history of which is far more fully recorded, but much more difficult to decipher and understand, is that of the rhinoceroses. The difficulty arises from the number of divergent branches and parallel series which developed within the family and the local forms which arose in the various regions to which they migrated, for, with the exception of South America and Australia, every continent has had its rhinoceroses. Strange to say, the available evidence points to North America as the region of their origin, though the proof of this is not entirely conclusive. At all events, the family has been traced farther back in time here than in any other region. At a very early stage, the family divided into three strongly divergent branches, two of which were short-lived, lasting only from the middle Eocene through the lower Oligocene, while the third, that of the true rhinoceroses, has persisted to the present day, but is confined to the warmer parts of Africa and southern Asia. The brief series of the cursorial rhinoceroses was exclusively North American and differed from the other branches of the family in being quite defenceless, having neither horns nor tusks, and entirely dependent upon speed for their safety. They were lightly built and slender, long-necked, long-legged and narrow-footed, with three-toed feet before and behind. There is much about these curious animals that suggests relationship to the horses, but the likeness is superficial and due to cursorial habits, for every tooth and every 
bone in the skeleton declares its affinities with the rhinoceroses.

The second branch, though of American origin, spread to the Old World and has been found in France. The short, low and very broad skull had no horns, but large tusks provided effective weapons of defence. In marked contrast to the cursorial type, these animals were presumably aquatic in habit and though rather low, were very massive in build and had four toes in the front-foot; aside from the head, they must have been quite hippopotamus-like in appearance.

The third branch, the true rhinoceroses, has had a far more complicated history, because of the number of distinct series within the group, which passed through parallel courses of development; Professor Osborn recognizes no less than seven of these series in the Old and New Worlds. The terminal members of three series are the modern African, Indian and Sumatran species. While the structure of the true rhinoceroses underwent very considerable changes in that part of their history of which the record has been discovered, the changes are much less radical than those which took place in the horses in the same length of time and, for the most part, they affected the skull and dentition. The true rhinoceroses are characterized by the peculiar development of the front teeth (incisors and canines); in the modern African species these teeth have been entirely suppressed, but in the Indian and Sumatran and the 
great majority of the extinct species, the peculiarity above mentioned may be observed. The upper jaw has but one incisor on each side and no canine; the remaining incisor is chisel-shaped, with a sharp cutting edge; in the lower jaw are two incisors on each side, but no canine. The first lower incisor is very small and can be of little or no real use, but the second is a fairly large tusk, which points directly forward and the Indian species, at least, uses them effectively as weapons. All of the existing species, as well as most of the fossil forms, are provided with solid horns, which have no bony core; with an exception, to be noted below, the horns are not paired, but, if more than one is present, they are placed one behind the other in the middle line of the skull. The skull is much modified to form a strong support for the horns and its upper profile is convex in front, concave behind. The neck is short, the body very large, the legs and feet short and very heavy, with three toes in each foot. It is quite impossible to take up here the many series of the true rhinoceroses; all that can be done is to indicate very briefly the changes that have been noted in the group as a whole. Going back at once to the most ancient known forms which can be positively identified as true rhinoceroses, we find in the lowest Oligocene of North America very interesting species which help to connect the rhinoceroses with other families of their order (Perissodactyla). In these far-off animals the first upper incisor had already assumed its trenchant shape, 
but is smaller than in later forms, and is followed by two other incisors and a canine. The lower jaw also has three incisors on each side, but has lost the canine. The skull is without horns and the skeleton is much lighter and more tapir-like in its proportions and the whole animal decidedly smaller than the existing rhinoceroses; the front foot has four toes, but the external one (the fifth of the original five), is already much reduced in size and evidently dwindling away. From the Oligocene to the Pliocene, inclusive, North America had an abundance of rhinoceroses, both horned and hornless, but finally they disappeared from the continent entirely.

In the uppermost part of the lower Oligocene occur rhinoceroses which have the beginnings of a transverse pair of horns on the nose; in the upper Oligocene these have increased to full size and this gives us the exceptional series of paired-horn rhinoceroses referred to above. In the lower Miocene the series was represented by its terminal member, a very small animal, of which immense herds lived on the Great Plains. Near Agate, Nebraska, is a bed, perhaps an ancient quicksand, which contains the bones of this little rhinoceros in incredible quantities.

The story of the rhinoceroses, their development and their wanderings, is a fascinating one, but, unfortunately, only this bald sketch can be given, from which the most interesting details have been omitted. Their testimony, so far as it goes, is just the same as in the other genealogical series, gradual differentia- 
tion, with diversification and adaptation to different climates, food-plants and habits of life.

There remains one family of mammals with which it is necessary to deal and that is the camel tribe. This family has two well-defined subdivisions, the camels of the Old World and the llamas, guanacos, etc., of South America. For a very long time, the family was entirely confined to North America and did not reach its present homes until the Pliocene epoch of the Tertiary period. The skeleton of a Patagonian Guanaco may be taken as the startingpoint of our inquiry. In this animal the third incisor and the canine are retained in the upper jaw, all the incisors and the canine in the lower. The anterior two grinding teeth have been lost and the others are moderately high-crowned. The skull is broad and capacious behind, narrow and tapering in front. The neck is long and its vertebræ very curiously modified. The limbs are long and slender and have undergone nearly the same modifications as in the horses; the ulna is greatly reduced, interrupted in the middle and its separated portions are fused with the radius. In the hind leg the shaft of the fibula has been completely suppressed; the upper end fuses with the tibia, while the lower remains as a small separate bone, wedged in between the tibia and the heel-bone. The feet are very long and slender, with two toes in each; the long bones of the foot are coossified to form a "cannon-bone," the very young skeleton showing that this co-ossification does ac- 


\section{EVIDENCE FROM PALAONTOLOGY}
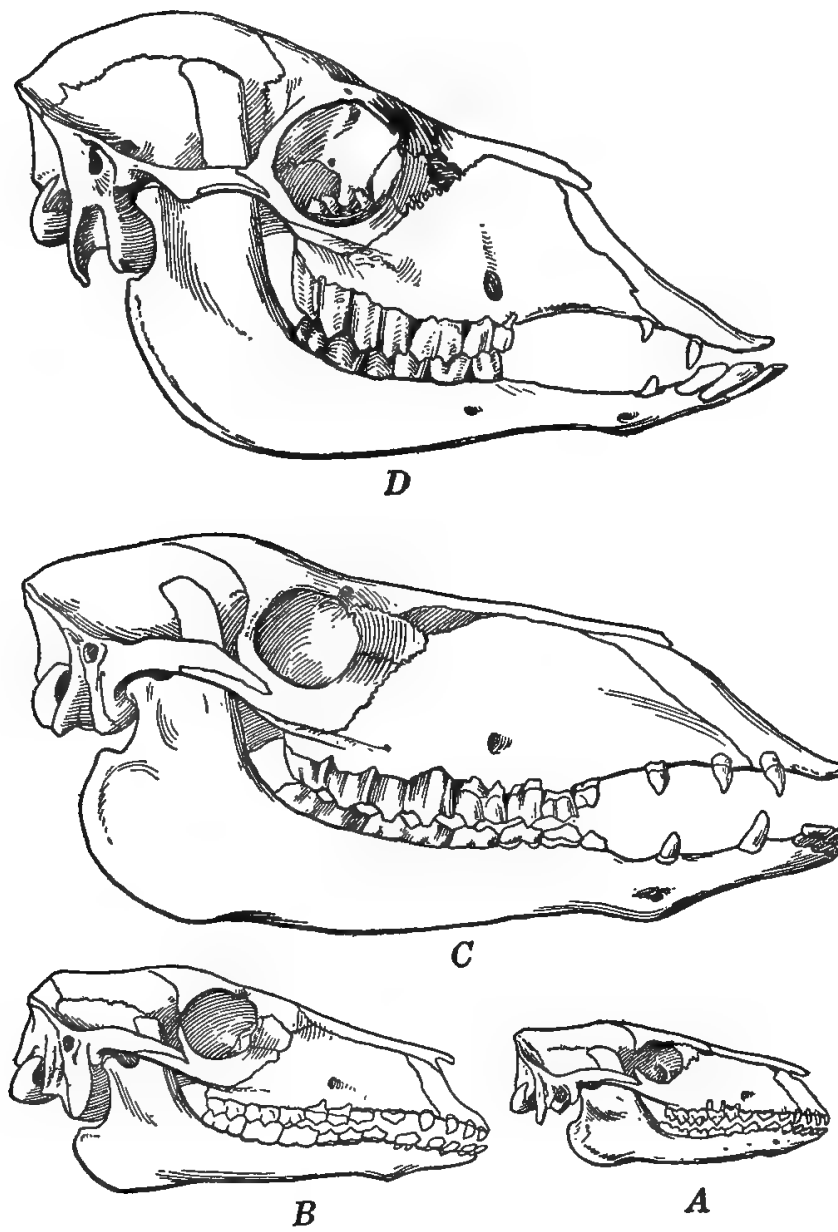

FIg. 11. Four stages in the evolution of the cameline skull. $A$, Protylopus, upper Eocene. $B$, Poëbrotherium, lower Oligocene. C, Pro: camelus, upper Miocene. $D$, Guanaco, Recent. 
tually take place. The toes proper are free, giving the "cloven hoof," but the hoofs are very small and the weight is carried upon a soft thick pad.

Were there time enough to do so, we might trace the development of this family backward, step by step, through all the many stages between the Pleistocene and the upper Eocene in quite as unbroken sequence and in as full detail as can be done for the horses. We must, however, pass over all the intermediate steps and consider the ancestral camels of the upper Eocene. These were very little animals, hardly larger than a jack rabbit, which had the full complement of teeth, 44 in total number and all with very low crowns. The limbs and especially the feet, are relatively short, the ulna is complete and separate, as is also the fibula; there are four toes in each foot, though the lateral pair of the hind foot are extremely slender, and there is no co-ossification to form cannon-bones. The hoofs are well developed, in form like those of an antelope, so that there can have been no pad. For the present, the line cannot be carried back of the upper Eocene, the probable ancestors from the middle and lower Eocene being, as yet, represented only by fragmentary specimens.

In addition to this main stem of cameline descent, which resulted in the modern species, there were two short-lived side branches which should be mentioned. One, ending in the lower Miocene, was the series descriptively called "gazelle-camels," small 
animals with very long and slender legs, evidently swift runners. The other series, the so-called "giraffe-camels," terminated in the upper Miocene; these were browsers and display an increasing stature, especially in the length of the neck and fore limbs. They adapted themselves to the growing aridity of the western plains.

Finally, may be mentioned an example from the reptiles. The pre-eminently Mesozoic group of reptiles known as the Dinosaurs has been made quite familiar to the public by our great museums, notably the American Museum in New York, the National Museum in Washington, and the Carnegie Museum in Pittsburgh. In the latter part of the Cretaceous period, North America had a remarkable family of Dinosaurs, harmless, plant-eating and quadrupedal monsters. Though inoffensive, they were well provided for defence, having three long and sharp horns, one on the nose, like that of a rhinoceros, and one over each eye. The neck was protected by an enormous frill of solid bone, growing out from the skull and reaching back to the shoulders. The family may be traced far back through the Cretaceous, the animals becoming smaller and the horns shorter as we go back in time, and the neck-shield becoming a mere outline framework. When sufficient well-preserved material, leading through long periods of time, can be obtained, the result is always suggestive of a gradual development. 

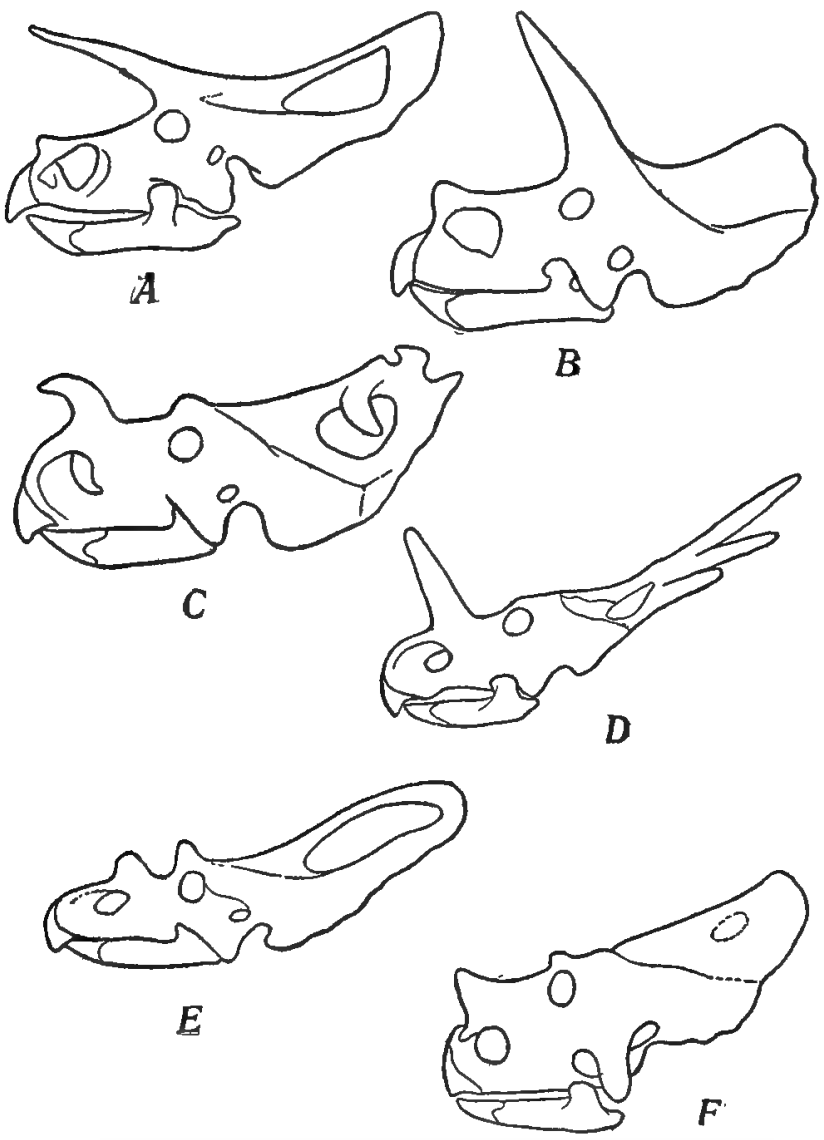

Frg. 13. Skulls of Horned Dinosaurs. A, Torosaurus. B, Triceratops. C, Monoclonius. D, Styracosaurus. E. Ceratops. F, Brachyceratops. These do not form a single genealogical series, merely several stages in the development of the skull. (From Matthew, in part). 


\section{LECTURE V}

\section{EVIDENCE FROM GEOGRAPHICAL DISTRIBUTION}

The geographical distribution of animals and plants over the surface of the globe was a subject of interest and importance even in pre-Darwinian days and great attention was paid to it as to so much statistical information. Under the then prevailing theory of special creation and the immutability of species, no explanation of the facts could be expected or even looked for; organisms were created and placed where we find them and that, if true, was an ultimate fact, of which no explanation was possible. As was pointed out in the first lecture, Darwin tells us in his autobiography that it was the facts of distribution which he observed in South America and, above all, in the Galapagos Islands, that first turned his thoughts in the channel of his great work, because these facts seemed to demand an evolutionary explanation.

Every one knows that different animals and plants are to be found in different parts of the world; the polar bears and musk-oxen occur in the treeless wastes of the Arctic lands, lions and tigers, elephants and rhinoceroses and tall palms must be sought in warm countries and, on hasty consideration, it might 
seem that distribution were wholly a matter of climate. But this explanation fails on closer examination. The tropical parts of Australia, Africa and South America have very similar climates and yet it would be difficult to select three regions of the earth which are more radically distinct from the zoölogical point of view. The fact that a given animal or plant does not occur in a particular region, is no conclusive proof that it is not fitted to live there. The rabbits introduced into Australia have multiplied to such an extent that they have become a very serious pest, as have the European Gypsy and Brown-tail Moths in Massachusetts. The acclimatization of the Indian Mongoose in Jamaica has upset the whole zoölogical equilibrium of the island, while domesticated horses and cattle, running wild, grew into vast herds, which overspread the plains of North and South America. European weeds are among the most difficult and annoying enemies with which the American farmer has to contend, and the American cactus, incautiously brought into South Africa, has become a nuisance and taken possession of large areas. Cactuses and the Agave (or Century Plant, also American) have taken so kindly to the Mediterranean lands, that many artists have painted them in scenes of classical antiquity, which to the botanical geographer is amusing. These and many similar facts sufficiently show that the introduction of a new animal or plant may be a very serious undertaking, fraught with great possibilities 
of mischief and, further, how excellent are the reasons for the modern legislation which forbids the importation of live animals into the United States, except by permission of the Secretary of Agriculture. No one can tell in advance what plague he may be bringing in.

These facts also prove definitely that animals and plants may flourish in many regions beside their native homes and that the absence of any organism is not to be explained by assuming its unfitness. Such considerations might easily lead us to conclude that the whole subject of distribution was a meaningless hodge-podge of uncorrelated facts, which defied explanation and, yet, if there be any truth in the theory of evolution, it must afford an explanation, or else its claims upon our acceptance will be very greatly weakened. The fundamental postulate of the theory is the unbroken continuity of life from its first appearance on the earth and therefore the present arrangement of living things must be the outcome of an unimaginably long series of past changes, not only those produced by the evolutionary process, but also the countless changes of climate and geography which have continually altered the possibility of migration in this or that direction. The great extinctions, which have from time to time devastated whole regions, have also played a part in bringing about the present order of things. At the end of the Pleistocene epoch, immediately preceding our own, North America lost a host of large mam- 
mals, the bones of which are preserved in such. natural museums as the wonderful asphalt pits near Los Angeles: horses, tapirs, llamas, elephants and mastodons, giant ground-sloths, huge wolves, lions, the terrible sabre-tooth tigers, and countless others. Here is a zoölogical revolution, which equally affected the northern part of the Old World.

We have very clear proof that the form, size and mutual connections of the various continents have undergone a long succession of changes. In the cases where two continents, now connected, were formerly separated by the sea, the proof of this separation almost always remains in the form of marine deposits, including the fossils of marine animals. In this manner the ancient disjunction of North and South America, the separation of the Spanish peninsula from Europe, of north Africa from the remainder of the continent and of India from Asia, may be readily demonstrated. On the other hand, in the case of those lands which were formerly connected, but now are separated by the sea, the direct proof is wanting, because the connection is covered by the sea, but soundings generally indicate it, for most of the former connections which, for one reason or other, we presume to have existed, are marked out by areas of shoal water in very sharp contrast to the profound depths of the oceanic abysses. Such former connections are indicated between Alaska and northeastern Asia, Great Britain and the continent of Europe; Spain and 
Morocco; Italy, Sicily, Malta and Tunis; the Greek islands and the mainland; Japan, Formosa, Borneo, Java, etc., and Asia, and many others. The evidences of climatic changes, though of an entirely different kind, are equally clear.

In brief, the distribution of existing animals and plants constitutes a series of historical problems, the solution of which is to be sought in the facts of geology and palæontology. On evolutionary principles, we ought to find that, the longer time any two regions have been separated, the greater is the difference between the animals and plants of those regions, and this is precisely what we do find. So well established is this principle, that we may invert it and use it to distinguish those separations which are earlier from those which are later in geological date, in cases where direct geological evidence is unattainable. The separation of Great Britain from the continent must have taken place very recently, geologically speaking, because there is no important difference between their animals or plants, while the separation of Madagascar from Africa must have been effected at a much earlier time because of the radical differences between the faunas of island and continent. Of course, such instances cannot fairly be used as arguments in favour of evolution, because they assume the truth of the thing to be proved, except in so far as the evolutionary explanation is the only one that will account for the facts.

Before attempting to explain any of the problems 
of distribution, it will be necessary to consider the factors which determine distribution under present conditions and, in order to keep the whole great subject within manageable limits, we must confine our attention to a few groups of organisms. For our purposes by far the most suitable examples are those furnished by the mammals, All the evidence at our disposal goes to show that every species originated in some one particular area and has spread from that starting-point as far as circumstances would permit. This is called the "doctrine of specific centres." In the case of more comprehensive groups also, there is no reason to believe that, among the higher animals, at least, the same genus, family, order, class, etc., ever arose twice independently in disconnected land areas. This being the case, the possession of identical, or closely similar, animals by two regions now separated is strong evidence that these regions were once joined and at no very distant date. The spread of new forms from their centres of origin may be quick or slow, as circumstances are or are not favourable; very rapid spread was shown by the horses which, set free about 1537, on the abandonment of the first settlement of Buenos Aires, within forty-three years appeared on the Straits of Magellan, nearly a thousand miles away.

The nature of the barriers which limit the spread of any species differs with the kinds of organisms, but for land mammals the most important are wide 
arms of the sea; no such animal can pass the English Channel or Bering Strait. Next in importance is climate and especially temperature, though humidity also plays an effective part. As we have seen, similarity of climate is, of itself, entirely powerless to bring about similarity of animals, but as a passive barrier, climatic differences are most effective in limiting the spread of organisms, many of which are utterly unable to pass an isothermal line. In minor degree, large rivers, mountain-chains and the other great topographic features frequently act as barriers. Still another kind of barrier is pre-occupation by some other species, it may be a competing species which leaves no place in the economy of nature which the newcomer can fill, or it may be an enemy or infectious disease which destroys the immigrants as fast as they can arrive. The Tse-tse flies of Africa close the area of their range against the entrance of most of the domestic animals by infecting them with a fatal disease.

Many attempts have been made to divide the lands of the globe into zoölogical regions, which shall express the degrees of likeness and difference in their animal inhabitants. This cannot be satisfactorily done by using the same scheme for all kinds of organisms, for the geological dates of the origin and dispersal of the various types of land animals are so far apart in time, that each found such very different geographical arrangements, and frequently also climatic conditions, that the possi- 
bilities of migration had been greatly changed. For the mammals a very satisfactory working arrangement has been gradually reached, which is well justified by the data of geology and palæontology. This plan first of all divides the continents into two groups of very unequal size, (1) Australia and its adjoining islands, Tasmania, New Guinea, etc., (2) the rest of the world. This division recognizes the fact that Australia is, zoölogically speaking, by far the most isolated region of the earth; aside from the bats and a few mice, its mammals are Monotremes and Marsupials. Of the monotreme egglaying mammals Australia has all existing species and of the marsupials all except the opossums of the western hemisphere, with the addition in South America of one interesting genus, the survivor of a group that was abundant in the Tertiary of that continent.

Neglecting Australia, the other continents likewise fall into two very unequal groups, (1) South America, including Central America and the West Indies, and (2) the other continents. South America is, after Australia, much the most peculiar part of the globe, a fact which is explained by its geological history. The remaining continents, North America, Europe, Asia and Africa, with great local differences among themselves, have a certain unmistakable similarity in their mammals. The local differences are expressed by dividing this vast land-area into a number of regions, with the curious and unexpected 
result that, except Europe, none of the continents falls into a single region. North America, for example, contains more or less of three regions, Asia and Africa each two. This striking lack of coincidence between geographical and zoölogical boundaries is, at first sight, so anomalous as to make the whole scheme appear very doubtful, but, here again, past geographical and present climatic conditions offer an adequate explanation of the anomaly.

Finer distinctions are expressed by dividing the regions into subregions, provinces, faunas, etc., but it will not be necessary to consider these subdivisions here. The following table, which omits Australia, gives the arrangement of geographical realms and regions which is now very generally adopted by students of the mammals, past and present.

I. Reatm of Neogate.

1. Neotropical Region, South and Central America; lowlands of Mexico; southern tips of Florida and Lower California; West Indies.
II. Realm OF
Arctogara.
1. Malagasy Region, Madagascar.
2. Ethiopian Region, Africa south of the Sahara.
3. Oriental Region, Southern peninsulas of Asia; Malay Archipelago.
4. Holarctic Region, N. Africa; Europe; Asia north of the Oriental Region, Japan; boreal N. America.
5. Sonoran Region, Remainder of N. America.

A kind of distribution which has seemed very diffcult to explain is that known as "discontinuous," where the areas inhabited by a given group, large or small, are separated by a very wide intervening 
space from which it is absent. Two or three examples, of which history affords the solution, may be cited. At the present time the family of the tapirs is found in the Oriental region and in South America, with almost half the circumference of the earth between them. In the latter part of the Tertiary period the tapirs ranged all over the northern hemisphere,-but became extinct in Europe before the Pleistocene; at the close of the latter epoch they vanished from eastern Asia and from North America, persisting in southern Asia and in Central and South America to the present day. We have no means of telling why they became extinct in the areas from which they vanished, but the significant fact remains that the vast stretch of land between their modern homes was formerly covered by them. According to the doctrine of special creation this fact explains nothing, because the American species are different from the Asiatic, but this is the almost inevitable result, if evolution be true. The extremes of such a wide ranging genus would, in the great majority of cases, diverge to such an extent that it would be necessary to refer them to distinct species.

A second case is very similar. The camel family is divided into two well-defined genera, the true camels, which are native to Asia, and the guanacos, llamas, etc., of South America. This family, during much the longest part of its history, was exclusively North American in distribution, but in the Pliocene epoch true camels had appeared in India and llamas had 
extended their range to Argentina. The explanation of the discontinuity is the same as in the tapirs, the former occupation of the intervening lands by the family in question and their eventual extinction in those lands.

A third case is rather different. On the tops of the White Mountains in New Hampshire grows an assemblage of plants, to find which in the lowlands, one must go hundreds of miles northward to Labrador. The probable reason for this strange distribution is given by the glacial phenomena of the Pleistocene; when the ice had buried the northern part of the continent, Arctic animals and plants were driven far to the South, the walrus coming down to the coast of Georgia and the musk-ox to Kentucky and Oklahoma. With the amelioration of the climate and retreat of the ice, the Arctic plants and animals once more went northward and ascended the mountains, as these were freed from the ice. When present climatic conditions had been attained, the Arctic forms had disappeared from the foot of the mountains, but remained on their cold summits as colonies of the great Arctic invasion. The same thing happened in Europe, where Arctic plants still flourish in the high Alps. Thus, in all cases where the history of the animals or plants involved can be obtained, the explanation of discontinuous distribution is the same,-former occupation of the intervening area.

The striking contrast between North and South America is expressed in the scheme of classification; 
North America is a zoölogical patchwork, consisting of one entire region, the Sonoran, a large area of a second, the Holarctic, and small portions of the third, the Neotropical, while, on the other hand, the southern continent is all included in the Neotropical region. This contrast is explained by the different geological history of the two continents. During the earlier and longer moiety of the Tertiary period North and South America were separated by a broad sea which swept over the Isthmus of Panama and most of Central America and throughout this time of separation the northern and southern continents developed faunas which were most radically different. The student who is familiar with the Tertiary mammals of the northern hemisphere, American, European and Asiatic, finds himself in a new and strange world, when he takes up those of South America. On the other hand, North America was repeatedly joined to the Old World and as often severed from it, chiefly by way of Alaska and northeastern Asia, but probably also by a land-bridge from Greenland to Scandinavia. It is almost always easy to distinguish the times of separation from those of union, for the former are marked by a rapid divergence from the Old World forms, while the latter, because of the intermigration of mammals, always possess a certain number of families and genera which are common to both hemispheres. The latest of these invasions from Asia took place in the Pleistocene and brought in a crowd of Old World mammals, bears and wol- 
verenes, sheep, antelopes, bison, the wapiti (erroneously called "elk") the moose, the caribous and many others, and these continue to inhabit the northern half of the continent and have given to it that old World stamp which is recognized by including this boreal area in the great Holarctic region. Many species, which are now extinct, accompanied this Pleistocene invasion, the most conspicuous of which was the Siberian mammoth, or hairy elephant, which ranged from the south of France to Kamche. ${ }^{+} \mathrm{ka}$ and, on the American side, from Alaska to New England. Systematic naturalists still debate the question as to whether these immigrants have sufficiently changed since their arrival in America to deserve to rank as species distinct from their Old World relatives. Whether the American and European bison, the Scandinavian and American moose, the wapiti of America, that of Asia and the European red stag, the caribou and the reindeer, are valid species or merely geographical races of the same species, need not be discussed here. Whichever view we take, the Old World character of the northern half of our continent is not affected.

Between this "boreal zone" and the Sonoran region, there is a "transition zone" where the two faunas mingle. The Sonoran region, which, roughly speaking, includes the United States, except the high mountain ranges, which carry the northern fauna far to the South, and the plateau of Mexico, is the characteristically North American region. Its 
deer are all different from the northern genera of the family, which came in during the Pleistocene; they too were ultimately derived from the Old World, but at a very much earlier date, probably as far back as the lower Miocene epoch. This Sonoran fauna was greatly impoverished by the Pleistocene extinctions, which put an end to so many of the ancient American groups, but it retains a large number of characteristic forms, chiefly rodents and carnivores, or beasts of prey.

Besides the immigration from the eastern hemisphere, there were successive waves of invaders from the Neotropical region; the earliest one of which we have found a trace arrived in the Miocene and the latest in the Pleistocene, when North America had several characteristic Neotropical forms, the most striking of which were the giant ground sloths, and the huge, armoured, armadillo-like glyptodonts, both now extinct. Of this southern invasion little now remains; the Canada porcupine is certainly one survivor from the invasion and probably, though not certainly, the opossum is another. The influence of climate upon present distribution is very well shown in Mexico; the high table-land, with its moderate and relatively dry climate, is Sonoran, while the hot, lowlying coast-lands are Neotropical.

When the existing mammals of South America are reviewed, they are plainly separable into two categories. In the first are included those which are evidently indigenous and are, for the most part, very unlike those of any other continent. The monkeys 
and marmosets are but remotely related to the monkeys and apes of the Old World; the horde of most curious creatures which we call ant-eaters, sloths and armadillos, are altogether peculiar to the Neotropical region; the extremely large and varied assemblage of porcupine-like rodents are either peculiar or, in a few cases, related to those of Africa. The many species of opossums are related, though not very closely, to the marsupials of Australia. Australia excepted, no other continent has so many different kinds of mammals peculiar to itself as South America, and the birds are almost equally characteristic. The second category contains those mammals which are nearly related, often belonging to the same genera, to those which now live, or formerly lived, as shown by the fossils, in North America. This section includes all the beasts of prey, the wolves, large and small cats, weasels, otters, skunks, raccoons; all the hoofed animals, the tapirs, peccaries (native swine) llamas, deer (all of which belong to the Sonoran group), the rats and mice, squirrels and rabbits.

This twofold division immediately suggests that the mammals belonging to the second category are immigrants from the North and the suggestion is very strongly confirmed by the testimony of the fossils. The geology of the Isthmian region proves that South America was formerly cut off from the northern continent and if we examine the fossil remains of the mammals which lived there during 
that time of isolation, we find, as already stated, that they are totally distinct from their contemporaries of the north. The rocks of Patagonia and Argentina have proved to be quite as marvellous a museum of vanished mammalian life as those of the western United States and they tell the story of origins and migrations with the greatest clearness. The older Miocene rocks of Patagonia have already yielded to the zealous collector a great host of beautifully preserved mammalian remains, among which cannot be found a single one that was ancestral to any of the mammals of the second category, which, on other grounds, we concluded to have been derived from the north. On the other hand, we find the ancestors of nearly all the peculiarly South American forms, except those which, there is reason to believe, never ranged so far south as Patagonia. There was a great abundance of hoofed animals, but they all belonged to orders which have long been extinct, and there were many beasts of prey, large and small, but they were not true Carnivora, but rather resembled the predaceous marsupials of Australia. South America suffered even more from the Pleistocene extinctions than did North America and lost not only many indigenous orders, such as the ground sloths and glyptodonts, of which there was an incredible variety, and the native hoofed animals, but also several of the immigrants as well, such as the mastodons, horses and antelopes, the great sabre-tooth tigers and short-faced bears. 
There is a remarkable contrast between the fates that befell the northern invaders of the Neotropical region, and the southern invaders of the Sonoran region. The former, in most cases, conquered a permanent footing in South America and their descendants, more or less modified, are living there now, while the latter could not maintain themselves and only one, or at most two, has survived to the present time. The reason for this very striking difference is probably to be found in the fact that the northern animals were of higher type and more advanced grade than the southern. North America was a part of the vast land-area of Arctogæa, a condition much more favourable to the development of the higher forms than was the insular state of South America. Such a conclusion might seem to be contradicted by Central America, which is Neotropical not Sonoran, but here the dominant factor is obviously climatic, as is shown by the conditions in Mexico. The native and immigrant mammals of North America are Arctic and Temperate and most of them are not adapted to life in the Tropics, yet in spite of this, many have permanently established themselves in South America, while the southern immigrants failed to keep their footing in the north. The zoölogical realms and regions which were established only to express the present order of things, thus prove themselves to be an expression of past changes. Even were nothing known of the geology and palæontology of the western hemisphere, but 
merely the existing distribution of its mammals, it would be entirely possible to deduce from that distribution the main outlines of the history which geology reveals. The geological dates could not be so definitely fixed, but the principal events and the order in which they occurred could be made out, assuming the truth of the evolutionary theory. The very fact that such an assumption is necessary, if the deductions are to harmonize with the facts revealed by geology and palæontology, is strong evidence that the assumption is true. On the theory of special creation and the immutability of species, the facts are meaningless. We find that a certain proportion of South American forms is extremely peculiar, having no close allies in any other continent, and a certain proportion is of mammals clearly related to those which dwell in Arctogæa. But the latter all belong to peculiar species and many of them to peculiar genera, which, on this theory means that they were separately created and therefore that their relationships with North American and other Arctogæan forms are purely ideal. It is highly significant that the history, so far as it has been recovered and deciphered, is seen to lead gradually through a long series of changes to the present order, which is so plainly the inevitable outcome of those changes, provided only that evolution be accepted.

It may well be asked why no such interchange of mammals between the Americas is going on now, but the question cannot be definitely answered. It is 
probable, however, that a state of equilibrium has been reached after the readjustments made necessary by the last geographical and climatic changes. On the other hand, a slow movement may actually be in progress, as is suggested by the geographical races of the Virginia Deer from Mexico to Guiana. Central America contains a considerable number of Sonoran mammals, which have not yet passed the Isthmus, but might perhaps eventually have done so, had not the construction of the canal intervened.

The elevation of Central America and the Isthmus cut off the waters of the Caribbean Sea from those of the Pacific and the separation led to divergent development of marine organisms in the divided waters. A careful comparative study has been made of the sea-fishes on the two sides of the Isthmus, with the result that nearly all the species are different, while the genera and families are, for the most part, the same. The amount of difference is what might have been expected $a$ priori on the evolutionary hypothesis and, indeed, the ichthyologists had approximated the true date of the separation before the geological evidence had been found.

There is no time to go into the highly complex history of the vast aggregation of land in the Old World, further than to point out that as late as the Pleistocene epoch, when primitive men were already living in Europe, that continent underwent a remarkable series of climatic and geographical changes. At the time of greatest elevation, the Adriatic and 
Egean Seas were land; the junction of Italy and Spain with Africa cut the Mediterranean into two land-locked basins; the North Sea was land and the British Islands were joined to each other and to the continent. This, taken in connection with the barrier made by the Desert of Sahara, explains why North Africa belongs now to the great Holarctic region and not to the Ethiopian, which covers the continent south of the desert.

I do not wish to give the impression that all the problems of distribution have been solved and all the difficulties removed, for such an impression would be far from the truth. What can fairly be said is that the main outline has been satisfactorily explained on the evolutionary theory and no other theory even pretends to account for the facts. Just in proportion to the completeness with which the past history of any mammalian group is known, is it easy to account for its present distribution. In the same way, the more fully the geographical and biological history of any continent has been ascertained, the more readily can the arrangement and relationships of its animals and plants be understood. It is largely because the history is incomplete, that difficulties still remain.

It is often very puzzling to explain why groups that range together in the region of their origin should behave so differently when new land-connections are established and new regions invaded; of this there are very many instances. The mas- 
todons and the true elephants lived together all over North America, but only the mastodons entered South America. A possible explanation of this may be that the species of elephants were cold-country animals which had come in from the north and were unable to cross the Tropics, but no such considerations will apply to the Siberian rhinoceros and mammoth. Both were well protected against the cold and both extended their range in the Pleistocene from southwestern France to Kamchatka; the mammoth passed over to Alaska and crossed North America to New England, but the rhinoceros has never been found on the American side. Deer migrated repeatedly from the Old World to the New, but the giraffes, which were once very numerous and varied in all the Mediterranean lands, did not accompany them. Wolves, foxes, cats, bears migrated back and forth, but America never had any hyenas or civets and the raccoon family has always been American, though not quite exclusively so. The large, spotted cats, called jaguars, do not extend north of Texas or south of the Argentine Republic, yet the very nearly allied pumas range from Pennsylvania far into Patagonia. These are closely allied species and yet their adaptability to climate is very different. Deer and antelopes both invaded South America, presumably together, yet the deer maintained themselves, while the antelopes failed to do so. Then, too, there is much mystery about the extinction of species and larger groups; in a general way 
we can understand why this should have happened, but, in a given case, it is not possible to do more than conjecture the reasons.

Another series of observations and deductions, which depend for their cogency little or not at all upon the data of geology and palæontology, is that afforded by the phenomena of the distribution of animals and plants on islands. Darwin's attention was strongly arrested by what he observed in the Galapagos, and A. R. Wallace, who, it will be remembered, independently reached the same conclusions as Darwin, was led to his results largely by his studies in the East Indian islands. To the end of his life Wallace was fascinated by this topic and his two delightful books, "The Malay Archipelago" and "Island Life," testify to his unfailing interest in its problems. The problems of insular life are much simpler and more comprehensible than those of continental distribution; they are like experiments performed upon a small scale and with relatively few factors involved.

From the point of view of animal and plant distribution there are two clearly distinguished classes of islands: (1) Continental and (2) Oceanic. Continental islands are, as their name implies, detached fragments of a continent, with which they were at one time joined; their geological structure is that of the continent and usually they are not far from the parent continent and are surrounded by shoal water. It should be explained that the line between shallow 
and deep water is commonly taken as the 100 -fathom depth; this is not an arbitrary selection, but the reasons for the choice cannot be discussed here. Several of the best known of the continental islands, such as Great Britain and Ireland, Borneo, Sumatra, Java, Madagascar, have been mentioned in this lecture. Their animals and plants are those of a continent and the degree of difference from the neighbouring mainland is an indication of the date of disjunction. In a few cases continental islands rise from great depths of water, as is true of the Greater Antilles, and some are far from any land, like New Zealand and the Seychelles. Oceanic islands, on the other hand, are all either volcanic and have been built up from the sea-floor by the material ejected in the eruptions of submarine volcanoes, or they are coral reefs. As a rule they rise from the profoundest depths of the sea and are far removed from any land and they appear never to have formed part of any continent. Examples of this class are the Azores, Madeira, the Canaries, Cape Verdes, Hawaiian Islands and the thousands which dot the South Pacific.

The two classes of islands differ as radically in their animals as they do in structure. The continental islands may and frequently do contain everything that an equal area of the parent mainland had at the time of separation, though in this respect there is naturally a difference between large and small islands. Sometimes it is difficult to un- 
derstand why a large continental island should be so poor in mammals. The contrast between the large islands of the East and West Indies is very remarkable; Borneo, Sumatra and Java are extremely rich in mammals, while Cuba, Haiti and Porto Rico have very few. The oceanic islands have peculiarly limited faunas; on the theory of special creation, we should expect to find in them as large a variety of animals as their area, their vegetation and their climate would enable them to support. On the theory of evolution, they must have received only such plants and animals as could be carried to them by the wind, or currents of the sea, carried on driftwood or floating trees, or transported by birds. When an oceanic island is very far from the nearest land, the accession of a new animal or plant must be a very rare event.

That islands are actually, not merely hypothetically, stocked in this manner is clearly shown by the case of Krakatoa, a volcanic island not far from Java. The great eruption of 1883 blew a great part of the island out of existence and buried the remainder so deeply under volcanic débris, that every living thing perished. In a surprisingly short time the island was re-vegetated and abundant insect life arrived, all borne by the winds and the sea from Java and Sumatra. Professor Selenka writes of a visit to Krakatoa: "Under the shade of a Casuarina, amidst cocoa-nut palms and thickets as high as my head, I found here, to my astonishment, an active 
animal life of spiders, flies, bugs, beetles, butterflies; even lizards more than two feet long animated the peaceful picture." In this instance, however, the distance from land was not very great, or else the restocking would have required a very much longer time.

The oceanic islands have no land mammals, except bats, which like birds are often carried immense distances by strong gales. That this lack of mammals is due to the impossibility of reaching the islands and not to any unfitness to support the mammals is made clear by the artificially introduced rabbits, rats, mice, pigs, goats and cattle, which have, on many such islands, thriven and multiplied exceedingly. They also lack Amphibia, for frogs and toads, newts and salamanders, their eggs and larvæ, cannot long endure immersion in sea-water; real fresh-water fishes, crayfishes and shells, as distinguished from those which readily enter rivers from the sea, are likewise wanting. Birds and insects are brought by the winds, reptiles, especially lizards, and snails are carried on driftwood, and it is only such groups that occur in the oceanic islands.

The observations which Darwin made in the Galapagos, a volcanic group about 500 miles from the coast of Ecuador, will serve as a type of what may be learned from the life of oceanic islands. Leaving out of account the sea-birds, which can traverse the widest expanses of sea, the birds, reptiles and plants of the Galapagos for the most part 
belong to peculiar species, but all are of South American type and have their nearest relatives in that continent. Each of the larger islands of the group has species peculiar to itself, but almost all the species distributed on the various islands belong to the same or nearly allied genera, and thus together form a homogeneous and closed group. The explanation which Darwin gave to the phenomena still remains the most satisfactory that has been offered. The distance from the mainland is so great, that for any bird or lizard to reach the islands must always have been a rare event, but a few species did arrive and were thus practically cut off from their relatives of the continent. Communication between the different islands is likewise rare and so each became the seat of a little colony which gradually changed from its former condition to form races, varieties and eventually species. Thus, the evolutionary theory accounts for the facts in a simple and adequate manner, while the rival theory offers no explanation. The Cape Verde Islands, off the west coast of Africa are a volcanic group quite like the Galapagos, but their animals are of African type modified through isolation and the Galapagos kind of distribution is not the exception, but the rule under similar conditions.

Whether new species, say of birds, will arise in an oceanic island, depends on the frequency with which mainland birds can visit it and thus by constant crossing maintain the continental character- 
istics. Such islands as Bermuda and Madeira are annually visited by birds from the adjoining continents and they have hardly any peculiar forms, while St. Helena and the Hawaiian group have almost all their birds and reptiles peculiar to themselves and so far changed, that it is difficult to make out their geographical relationships. If species are immutable, why should this factor of inaccessibility have any influence upon the peculiarity of the species found in a given island? Another curious series of facts is displayed by the family of birds known as the Rails, which are distributed all over the world except the polar regions. The family includes fiftyfive genera, twenty-five of which inhabit islands and of these ten have lost the power of flight. A genus, with only one or two species, will be confined to a single island, while the genera of the continents have more numerous species and all of them can $\mathrm{fly}$. It is an obvious inference that the loss of flight and the separation as distinct genus and species must have taken place after the original progenitors had reached a given oceanic island, for the birds could not have crossed wide seas by swimming, nor could the flightless ones have arrived in any other way.

"If we briefly resume these surveys of island faunas, the result for our problem is as follows: The islands must have received their animals in some fashion from the mainland, the continental islands when they were a part of it, the oceanic not till after their appearance above the surface of the 
sea. This may be directly proved for young oceanic islands. Now, since we have all stages from the youngest to the oldest islands and see how the degree of specialization of the animals increases in just such a graduated way, and how their number and kind are different in correspondence with the distance of the island and the animals' power of dispersal and how they everywhere display a relationship with those of the nearest lands, the conclusion is cogent that even on the most ancient islands the animals were not created, but immigrated after the islands had been formed. If this be admitted, the further conclusion cannot be escaped, that the greater or less difference of the insular forms from those of their former home must be ascribed to a mutability and capacity of change on the part of the animals." 1

As in the case of all the topics dealt with in the preceding lectures, I cannot but lament the inadequacy of treatment which is made necessary by the demands of brevity. Nobody would pretend for a moment that we understand all the phenomena of distribution and can account for every seemingly anomalous fact, or that all difficulties have been removed. We are attempting to reconstruct a long history of past changes, and under such circumstances, partial success is all that can be hoped for. But if, in looking over the vast array of data that have been gathered illustrating distribution and

${ }^{1}$ A. Brauer, in Die Abstammungslehre, pp. 161-q. 
comparing these with the results of geology and palæontology which bear upon the same problems, we ask whether the theory of evolution or that of special creation offers the most satisfactory explanation, an unprejudiced judge would not long hesitate in giving his decision in favour of evolution. 


\section{LECTURE VI}

\section{EVIDENCE FROM EXPERIMENT-CONCLUSION}

Experiment is the method used in physics and chemistry, to determine the laws of matter and force; such experiments can be repeated at will and any competent person can obtain the same results. It is highly desirable that the experimental method should be applied in biology, because of the exactitude which can thus be secured, affording an invaluable complement to the results of observation. Darwin always insisted upon the indispensable character of experiments and performed a great many himself. One might have anticipated that the problems of evolution could be thus attacked with success and subjected to the tests of a precise analysis. But such hopes have left out of account the difficulties inherent in the application of the method; human life is very brief and experiments, to be conclusive, must often be continued without interruption through a very long series of generations. Then, too, it is impracticable to make conditions in the laboratory sufficiently like those in the open to give definite answers to many questions.

In a sense, the long continued improvement of domesticated animals and plants by careful breed- 
ing and selection has been by a great series of experiments, but, unfortunately, the conditions under which these were carried out are too inexact and the records, which are usually lacking altogether, are, even when preserved, too vague to be of much service in a modern investigation. Domestication, as was pointed out at some length in a previous lecture (p. 36), shows how surprisingly animals and plants may be changed by human agency, but tells us little of what we are now seeking to learn.

The changes which are experimentally produced must be transmissible to the offspring, if they are to have any evolutionary significance. Plants, in particular, are very susceptible to extensive modification through external influences, such as the chemical constitution of the soil, heat, light, moisture, elevation above sea-level, and the like, and these modifications will continue as long as the external conditions remain the same, but disappear when the plants are once more placed under the original circumstances. The French botanist Bouvier took shoots or layers from several kinds of common plants and set out, from the same individual, some shoots in the lowlands, others high up in the mountains. The differences in the results were remarkable; the mountain plants had more vigorous roots, but the part above ground was much smaller, with more delicate stem and leaves; the flowers were fewer in number, but individually larger and more intensely coloured. When taken back to the lowlands, the plants re- 
turned to their original type. The same species of Ranunculus may be grown on land or in the water, with totally different forms of leaf in the two media. The land individuals have broad, tripartite leaves, with serrate edges, while in the water plants the leaves are subdivided into long, thread-like filaments and the whole appearance of the plant is that of a different species. "In all these cases, the plant has not inherited a definite form from its parents, but, within the limits of the hereditary fundamental plan of structure, it has received certain possibilities of development, which did not appear in the parents. Which of these possibilities shall be realized in the development of the individual, is determined by external conditions." 1

This must not to be taken to mean that it is not possible to produce hereditable modifications in plants, the contrary is true, but merely that very striking changes may be of no lasting importance because they are not transmissible.

Of late years, a host of experiments have been performed upon animals, the larger number of them with the object of determining whether new characters, acquired during the lifetime of the parents, can, under any circumstances, be transmitted to the offspring. This is one of the most hotly disputed questions of modern biology and our whole conception of the efficient factors which have brought about evolution hinges upon the answer to this question.

${ }^{1}$ Karl Giesenhagen, in Die Abstammungslehre, pp. 307-8. 
The same experiments are interpreted in diametrically opposite senses by different writers according to their predisposition and general point of view. At the present time, it is probable that a very considerable majority of zoölogists and botanists, especially in this country, are inclined to deny the hereditary transmission of characters acquired in the post-embryonic life of the parents, but the problem is still far from definite solution. Important as this problem is in any attempt to explain evolution and the manner in which it has been effected, it has no bearing upon the question which $\mathbf{I}$ have been endeavouring to answer in these lectures, as to the probable truth of the evolutionary theory. That theory is held quite as strongly by those who deny as by those who affirm the transmission of acquired characters. Whatever interpretation be put upon the significance of the experiments, presently to be mentioned, as to the problem of acquired characters, they do, at all events, show that hereditarily transmissible modifications may be artificially produced in both animals and plants.

We are again, as in every one of the preceding lectures, confronted by the difficulty of making an instructive and convincing selection from a great and ever growing mass of facts, but it is impossible to present more than a few typical examples. Among the older experiments may be mentioned those made by Schmankewitsch upon the brine-shrimp. By increasing the proportion of salt dissolved in the 
water, the little creatures passed, in the course of several generations, into quite a different form, identical with what had previously been regarded as a distinct species. On the other hand, by diminishing the quantity of salt, and keeping many successive generations in progressively freshened water, the brine-shrimp gradually assumed the characters of quite a distinct genus, which lives in fresh water. A very important distinction between these results and those obtained by Bouvier with plants, is that in the latter case the change was effected immediately and went no farther in succeeding generations, but could be at once reversed by restoring the plant to its original place of growth. With the brine-shrimps, on the contrary, the changes were gradual and cumulative, many generations being required to bring them to full development.

By keeping water-fleas in the dark, Kapterew caused them to grow blind, the eyes losing their regular outline, and their black pigment began to wander over the head and body. At first this deterioration appeared sporadically, but after a year and a quarter all the individuals were similarly affected and the blindness appeared to be hereditary.

Many experiments have been made by Weismann, Standfuss, Fischer, Schröder, Pictet and others upon the caterpillars and cocoons of moths and butterflies, changing their food-plants, in some cases, and in others hatching the full-grown insects from cocoons which had been exposed to abnormal conditions of 
temperature. Some very striking changes were produced in this manner and the remarkable case of the Lunar Moth, taken from Texas to Switzerland, has already been described in another connection. (See p. 39.) Cocoons of one species of butterfly and one moth, when exposed to a low temperature, considerably below the freezing point, yielded mature insects which, especially in the males, were darker in colour and had a different wing-pattern from those which were hatched at normal temperatures. The second generation, derived from these modified parents, but hatched from cocoons exposed to the normal temperature of the season, had a considerable number of insects which resembled their dark parents, while others had reverted to the ordinary condition of the species. In another moth a very decided darkening of the wings and a change of pattern was produced by the opposite method of keeping the cocoons in an atmosphere much hotter than that of the hatching season out of doors. Here also a considerable number of moths in the second generation inherited the characters of their modified parents, though they themselves had been hatched at the normal temperature. The larvæ of a beetle, which feed upon a smooth-leaved willow, were transferred to another species with densely hairy leaves. The descendants freely chose the hairy leaves, when both kinds were accessible and the number so choosing increased with each successive generation, the effect being cumulative. 
A very remarkable series of experiments upon the Colorado Potato-beetle were made by Professor Tower, of Chicago, under conditions of the greatest exactitude and rigorous control, as much so as in any chemical or physical laboratory; the results are famous throughout the biological world. In these experiments the larvæ and the beetles were subjected to varying conditions of heat and moisture and at different stages of their development, and thus several distinct races were established, differing in size, colour, markings and, in one case, in breeding habits; the new characters are hereditary and transmitted from generation to generation. A remarkable feature of these experiments was the discovery that the beetles had a sensitive period in their development, when they are particularly susceptible to the influence of changes in the environment. When larvæ in their sensitive period are exposed to altered conditions, the adult beetles display corresponding changes, but these are not hereditary and do not reappear in the next generation. When, however, the beetles, at the time when the eggs are maturing and getting ready for fertilization, are so exposed, the beetles themselves show no visible change, but the offspring do and these modifications are hereditary. Tower interprets this as being the action of external conditions directly upon the reproductive cells, or "germplasm," but this interpretation is disputed by others.

Kammerer has made numbers of experiments on amphibians and has succeeded in producing hered- 
itary modifications in several of them, of which a few may be mentioned here. A salamander, black with yellow spots, which lives in damp woods, is viviparous and produces sixty to seventy gill-bearing larvæ, which are deposited in water and develop there for several months, leaving the water for the land at the time of metamorphosis, when the larvæ become adult, air-breathing salamanders. If captive animals are deprived of water in which to deposit their young, a very few are produced, but these are not larvæ, but little salamanders like their parents. When this second generation breeds, if it is allowed access to water, it will once more produce larvæ, but very large ones, which leave the water in a few days, instead of remaining in it for several months. If adult salamanders of this species are kept for years on yellow soil, the yellow spots and blotches greatly enlarge, encroaching on the black ground, and the effects of this treatment are much increased in the second generation, showing a cumulative action. The larvæ of a toad were, by means of darkness, cold water, and other unnatural conditions, made to delay their metamorphosis and became sexually mature and able to breed while in the tadpole stage. These tadpoles attained great size and their offspring did not advance beyond the stage in which the hindlegs are developed, remaining in that condition for years and showing no tendency to metamorphosis. Other experimenters have failed to repeat these results, which are strongly questioned. 
All of these experiments, and many more that might be cited, would seem to prove that it is possible to effect lasting and hereditary modifications in animals by abrupt changes in their environment, and the same result has been obtained with plants. By injecting various substances into the young seedcapsule, when the germs are becoming ready for fertilization by the pollen, MacDougal effected some very remarkable changes, which were hereditary through four or more generations and remained stable, the plants exhibiting no tendency to return to the parent type. Gager also produced hereditary modifications in plants by exposing the seed-capsule before fertilization to the action of radium, but these results are not yet conclusive.

Thus, the experimental proof goes to show that the species of animals and plants are not fixed and immutable entities, but are capable of extensive modification even in the short time which is at the command of the experimenter.

In the first lecture it was stated that the experiments of the Austrian monk, Johann Gregor Mendel, published in 1866, had attracted no attention, because they were too far ahead of their time and their farreaching significance was not perceived. Rediscovered in 1900, Mendel's results have been enormously extended and have led to the development of the new science of Genetics. This is an extremely complex subject, which would require more than one course of lectures for its elucidation, not merely the 
fraction of a single lecture, in which only a hasty and most inadequate sketch can be attempted. On the other hand, it is not possible to omit all mention of Mendel's work from a review of the modern state of opinion on the subject of evolution, for this work has thrown great light upon the mechanism of heredity and, as has been repeatedly insisted, heredity is an all-important part of evolution.

Mendel crossed two varieties of peas, one of which constantly had white flowers and the other violet flowers. The first generation of hybrid plants all had violet blossoms, which Mendel explained by saying that in this particular cross the violet colour was "dominant" over the white, which was "recessive." The second generation of the hybrids, however, showed a change, only three-fourths of the plants had violet blossoms and one-fourth had white; the latter, in all subsequent generations, gave only white flowers; the plants had "reverted" to the original white parent. Of the violet-flowered plants in the next and all following generations, one-third remained constantly violet and two-thirds split in the next generation into three-fourths violet and onefourth white. From the mere inspection of a violetflowered plant, it was impossible to say whether it would give rise only to violet offspring, or to those which were partly violet and partly white. These and thousands of other experiments indicate that an organism is a mosaic of "unit characters," which are transmitted independently of one another to the 
offspring, and that in each generation of hybrids a process of segregation goes on, by which a definite proportion of plants is separated out from the mass of cross-bred individuals and returns to the character of one or other original parent. When this segregation has once been effected, all the subsequent progeny is constant to type; the descendants of the segregated white flowers are invariably white.

The process is made simpler and more intelligible, when the somewhat confusing effects of dominance are absent, as they are in the Jalap, or Wonder of Peru, experimented on by Correns. If the whiteflowered race of this plant is crossed with the redflowered race, all the plants of the first hybrid generation have uniformly pink flowers, because neither color is dominant over the other and the two seem to blend, though they do not actually do so. When the second generation is produced, either by selffertilization or by crossing the hybrids with each other, one-fourth of this second generation is red, one-fourth white and one-half pink, and each succeeding generation acts in the same way.

This behaviour is explained by assuming that every unit character is represented in the reproductive cells, or germ, by something which causes the development of that character in the full-grown plant and this something is called the "factor" for the character. If we symbolize the factor for the red colour by $\mathbf{R}$ and that for the white by $W$, then the germs of the red-flowering race contain the fac- 
tor $\mathbf{R}$ and those of the white-flowering race the factor W. The female hybrids produce egg-cells, one-half of which contain $\mathbf{R}$ and one-half $\mathbf{W}$; likewise the male hybrids produce pollen-cells, one-half of which contain $\mathbf{R}$ and one-half $\mathbf{W}$. Fertilization consists in the fusion of the nucleus of the male cell with that of the female cell, as has been very often directly observed in all kinds of animals and plants which have the sexual method of reproduction. After fertilization the germ, which is now ready to begin its development, contains factors derived from both parents and, according to the mathematical laws of probability and combination, there would be four combinations: RR, WR, $\mathbf{R W}$, and WW. The factor from the male parent is put first, so that the combination $\mathrm{RW}$ means that the red factor is derived from the male and the white factor from the female; in WR this is reversed, though, in practice, the result is usually the same in either case. In the Jalap, where neither white nor red is dominant, both $\mathbf{R W}$ and WR give the pink flowers and, obviously in the proportion of one-half the entire number of plants in the second hybrid generation. The germs having the factors $R R$ give the segregated red flowers and, as there is no W, it is plain that all the descendants of the $\mathbf{R R}$ seeds, generation after generation, if crossing is avoided, will produce only red flowers. For the same reason, the WW germs and all their pure-bred descendants can give only white flowers. If the unit-characters do not actually blend and become inseparable, it is 
easy to see why segregation must occur in each generation of the hybrids.

The complexity of the calculation rises very rapidly, when, instead of experimenting with only a single pair of alternative characters, as in the cases previously cited, combinations of several such pairs are effected. Mendel himself used as many as seven pairs, combined in many different ways. Yet, if regard be paid only to the behaviour of a single pair of alternatives, it makes no difference how many other unit-characters are associated in the combination, as they all act independently. When the behaviour of all the characters is analyzed, it is found that the mathematical laws of probability and combination are followed as closely as when but a single pair is dealt with. Indeed, the correspondence between the calculated and the experimental results is highly remarkable.

Mendel's own experiments were made with plants, but the same laws of heredity apply to animals. Lang experimented with the garden-snail of Europe, one race of which has a yellow, unstriped shell and another has the shell with spiral stripes of black. Crossing these, the unstriped yellow proved to be dominant, all the individuals of the first hybrid generation having shells of that kind. In the second generation segregation began and in just the same proportion as in the violet and white peas; one-fourth of the shells were striped, three-fourths unstriped. All the descendants of the former were constantly 
striped, but the yellow forms again split in the next generation. Inasmuch as the sexual method of reproduction was independently acquired in both the vegetable and the animal kingdoms, not inherited from an ancestor common to both, this agreement indicates that the Mendelian laws of inheritance are of universal validity, save under such circumstances as will be mentioned later.

The Mendelian laws further explain how new races may arise through the sudden loss of one or more factors by mutation. The common housemouse in its wild state has a characteristic gray colour, but there are several fancy breeds of mice, white, brown, black and blotched, all of which were derived from the wild form. Many experiments in the cross-breeding of these domesticated varieties with one another and with their wild ancestor, in all sorts of combinations, have shown that the varieties have arisen through the suppression of factors. Many factors are involved in these cross-breedings, but, simplifying the matter to the utmost, they may be reduced to four. (1) A colour-factor, which must be present if any colour at all is to be developed in the hairs of the coat. (2) A factor which determines that the colour shall be distributed over the whole body. (3) A pigment-factor, which conditions the occurrence of black in the hairs, which, without it, would be brown. (4) A distribution-factor, which controls the arrangement of black and brown in each hair, so that the combined effect is the characteristic 
mouse-colour. If this last factor should be eliminated, the result would be the production of black mice, an explanation which is strongly supported by crossing black mice with the normal animal and making a mathematical analysis of the proportionate numbers of hybrid forms. If the pigmentfactor, which determines the formation of the black colour, should disappear in black mice, brown animals would be produced and, if the factor controlling the distribution of colour should be lost, then blotched mice would appear. Finally, the suppression of the general colour-factor would lead to the development of white or albino mice. We may thus witness the formation of new varieties through the loss of factors, but the addition of new factors has not yet been observed, unless the additional toe in Castle's four-toed race of guinea pigs should be so interpreted.

Interesting and profoundly important as are the results of the Mendelian investigations, it must be admitted that, so far, they have rendered but little assistance in making the evolutionary processes more intelligible and, instead of removing difficulties, they have rather increased them. That the Mendelian laws of inheritance are immensely valuable to breeders, is not to be questioned, but it remains to be determined just how far they are operative in nature and what bearing they have upon the problems of evolution. The experimenter can, if he so desires, preserve all of his plants or animals 
through many successive generations, deriving thousands of individuals from a single pair of progenitors, but, under natural conditions, matters are very different. A single plant may produce thousands of seeds in a season, though but a very few, or, perhaps only one, can arrive at maturity and reproduce in its turn. Unless it possesses some very notable advantage, the determination of which individual seedling shall survive, is far more likely to be conditioned by the spot where it happened to germinate, with reference to light, moisture, etc., than by its germinal constitution. It is difficult to see how the laws of proportionate segregation can have any effect under such conditions. Some students of genetics go so far as to maintain that all evolutionary changes are made by the elimination of factors, and others that species are immutable, except as new combinations are formed through hybridization.

It is quite possible that the Mendelian laws are those of ordinary, conservative inheritance, by means of which species are maintained in their normal condition, and yet may not be applicable, when new characters arise through the action of the environment. This is suggested by Tower's experiments on potato-beetles, cited above. He says: "In what way is the constitution of the germ cell modified so that the organism shows in subsequent generations a permanent change in its coloration? It has been pointed out to me by Professor Morgan 
that in those experiments the behavior of the first generation is difficult of interpretation. In these experiments the male cells and the female cells, and sometimes both, have been subjected to conditions of experiment at a susceptible stage.

"Morgan has raised the question, why do individuals, developed from eggs which have been subjected to conditions of experiment and fertilized with normal sperm, not give a subsequent hybrid behavior? No hybrid splitting has ever been found in any of my experiments, or in those of MacDougal or Gager. The resulting modification reproduces itself true to type, and does not give subsequent splittings suggestive of the combination of different factors or unit-characters. If there are unit-characters, it is logical to expect that in experiments of this kind the experiment would modify the unitcharacter in the germ-plasm, and that this modified unit-character would then behave, when crossed with its normal homologue, exactly as hybrids do in other cultures. The total lack of this behavior in my experiments, and those of MacDougal, Gager, and others, might be considered good evidence that there are no such things as unit-characters, nor in the germ cells any potentiality capable of individual removal or behavior. Any such deduction, however, is unwarranted and contrary to known facts, and, furthermore, these modified characters themselves show that after establishment [italics mine] they are alternative and capable in many instances of re- 
placement and recombination in full conformity with established principles of heredity behavior." 1

These and many similar questions must be left to future investigations for reply; it is, in any event, a great advance that we should be able to approach these problems by means of exact experiment and mathematical analysis.

This concludes our sketch of the various lines of testimony which have been adduced in favour of the theory of evolution and I can readily imagine that some of you, at least, are saying to yourselves: "Is that all? I don't think that amounts to much!" For such lack of conviction, if such there be, there are obvious reasons. It has been necessary, because of the very brief time at our disposal, only six hours all told, to make a very limited selection out of the great mass of evidence that might otherwise have been brought forward. However candidly and skilfully the selection may be made, it cannot produce the same impression, as when the whole body of testimony can be presented, a principle which is well understood in the courts of justice. I have said very little with regard to plants, picking out only a few conspicuous examples, yet the evidence in their case is the same as for animals, fuller and clearer in some respects, less so in others. Professor Giesenhagen sums up for plant evolution thus: "The evidence disclosed by palæontology shows us that

${ }^{1}$ Wm. Laurence Tower, in Heredity and Eugenics, Chicago, 1912, pp. $222-3$. 
the species of plants which inhabit the earth to-day have proceeded from the different plant-forms of the earth's earlier epochs. Experimental investigation and observation upon heredity in existing organisms prove that the specific characters of plants are changeable, that especially by hybridization and mutation new species of plants may arise from those already present. The comparative study of structure and course of development in plants justifies us in concluding that the species of plants, under the continually acting influence of the external conditions of life, lose certain possibilities of development and gain new possibilities and may thereby undergo a genealogical development." 1

I must again remind you that what we are endeavouring to prove is a great historical process, which has gone on through vast and unnumbered æons of time, when no observer was present to record the forward steps in the magnificent procession of life. The details of evolutionary change must have been of an unimaginable complexity and, of necessity, the evidence for that change must be chiefly indirect and circumstantial, to appreciate the full force of which requires a certain degree of technical training. The Indian hunter swiftly follows a trail which is invisible to the white man's eye, and the experienced detective finds clues where the average man sees nothing of importance, so only one who has gained some first-hand knowledge of

${ }^{1}$ Karl Giesenhagen, in Die Abstammungslehre, p 320. 
living things is in a position to estimate the strength and the weakness of such testimony as has passed before us. That does not for a moment imply that we are here dealing with esoteric mysteries which the laity are unable to comprehend and must accept on faith. The detective's work must convince the jury and in this case, the jury is the body of intelligent, non-professional opinion. I merely wish to point out that such an exposition as I have been able to make, in elementary and non-technical fashion, is less convincing than the whole body of known facts is to those who are familiar with it.

From the very nature of the case, complete demonstration is impossible; we can only determine which one of alternative explanations is most in harmony with observation and best explains all the facts, which one is therefore the most probable. What gives great weight to the evidence in support of the evolutionary theory is the harmonious concurrence of so many independent lines of testimony. Whether we deal with classification, or the results of domestication, with comparative anatomy, embryology, blood tests, palæontology, geographical distribution, or experimental investigation, we find in every instance that the simplest, most satisfactory and least forced interpretation is that which is offered by the theory of evolution. The probability rises in geometrical ratio with each additional, independent class of evidence.

The pathway of science is strewn with the wrecks 
of hypotheses and theories, which have served their purpose and have been worn out and discarded. How are we to distinguish between those theories which will be permanent and those which are doomed to decay and oblivion? A theory is only an attempt to explain and interpret a body of facts and, for a time, this may be equally well done by a true theory and a false one; both may seem equally plausible and promising. It is the advance of discovery, bringing to light many new facts, which were neither known nor anticipated when the rival theories were first propounded, that puts the theories to the severest test. From this point of view, the doctrine of evolution has stood the test remarkably well. Darwin's book put new life into all departments of biology; every one, friends and foes alike, was eager to find proofs which should establish or overthrow this new and innovating belief, so that all lines of inquiry were pushed forward with renewed activity and enthusiasm. This zealous labour has resulted in the accumulation of a mass of data such as Darwin never dreamed of. The existence of the marvellous treasures which have been disinterred from the rocks of western North America was hardly suspected when the "Origin of Species" appeared, yet it is there that were found some of the most complete genealogical series yet made known. Though Darwin himself was one of the pioneers in the discovery of South American fossil mammals, it was not until after his death that the immense 
wealth of the southern continent was brought to light. The long isolation of South America made it the arena of a vast experiment in evolution, which may be followed in the most gratifying manner and which has solved some of the most puzzling problems of modern distribution. South Africa, Russia, China and the Malay Archipelago have also yielded to the explorer much of which Darwin knew nothing, but which he would have cordially welcomed as strongly supporting his belief. It is the same in other fields of research, new and unexpected discoveries are continually being made, but evolution still affords the best explanation of them. A remarkable instance of this is the blood tests, of which an account was given in the third lecture. Here was a totally new field, the existence of which was altogether unsuspected, yet, when the field was opened, it afforded some of the most cogent evidence in favour of the evolutionary conception that has anywhere been found. Not that new difficulties and perplexities have not arisen, but in spite of these, the probability of the theory remains unshaken after more than half a century of unceasingly active investigation carried on all over the world. The doctrine seems stronger now and is upheld by a greater proportion of naturalists than when it made its early conquests of opinion.

Another searching test of a theory is when it can be made the basis of prediction or deduction. That an astronomer should be able accurately to predict 
an eclipse is strong proof that the theory of lunar and terrestrial motions, from which he makes his calculations, is sound. From irregularities in the motion of Uranus, the outermost planet then visible, the astronomers predicted the discovery of another planet beyond, and the prediction was verified when Neptune was discovered with the telescope. This was rightly accepted as convincing proof that the theory of the solar system and of planetary motions, from which these distinguished men had worked, was true. Similarly, predictions and deductions have been made and subsequently verified concerning "missing links" in genealogical series. I myself had the great pleasure of finding in the rocks of northern Utah a fossil animal with a type of dentition which no man had ever seen, but which had been predicted some time before by Dr. Max Schlosser of Munich. That such predictions can be and have been successfully made, is very strong evidence that the theory of evolution, which is assumed as the basis of deduction, is well founded.

Admitting fully all that has been said, we must yet beware of erecting evolution into a sacred dogma which no one shall dare to criticise or doubt. Huxley has rightly said that "Science commits suicide when she adopts a creed," and it is a duty to keep the mind ever open for new and revolutionary discoveries, which may change the aspect and significance of all previously acquired knowledge. While I believe that the evolutionary conception of nature is one 
of our permanent possessions and that it will in the future continue to direct and condition all lines of intellectual inquiry and advance, I can understand that half a century hence the question may possibly have assumed a very different aspect. Once more quoting from Professor Giesenhagen: "As soon as direct experience brings to light unambiguous negative examples, which can in no way be harmonized with our conclusions from analogy and induction, we must be ready to make a corresponding change in our doctrines and bring them into harmony with the newly recognized truth, for infallibility in matters of science is given to no man. Up till now, however, no such negative examples are known." 1

' K. Giesenhagen, loc. cit. 


\section{INDEX}

N. B. Entries in quotation marks are titles of books. Technical names of genera and species are in italics; names of authors in small capitals.

Acquired characters, 20, 151

Adriatic Sea, 138

Egean Sea, 139

Africa, 94, 98, 110, 121, 123, 124,

$126,127,128,134,139,145,170$

Agassiz, 88

Agate, Neb., 113

Agave, 121

Alaska, 106, 123, 131, 132, 140

Alps, 130

Americas, 137

Ammonites, 91

Amphibia, 33, 144, 155

Amphioxus, 65

Ancon sheep, 23

ANDRE 4,97

Antarctic continent, 90

Ant-eaters, 134

Antelopes, 132, 135, 140

blood of, 78

mountain, 107

Anti-body, 74

Anti-toxin, 74

Antilles, 142

Ants, 89

Apes, blood of, 77

Old World, 134

Archoopteryx, 96, 97
Arctic animals and plants, 130 lands, 120

Arctogea, 128, 136, 137

Argentina, 109, 130, 135

Armadillos, 134

Asia, 104, 106, 107, 109, 110, 123,

$124,127,128,129,131,132$

Asphalt pits, 123

Asses, 99

Australia, 106, 110, 121, 127, 128, 134,135

Austria, 24

Azores, 148

Balanoglossus, 65

Barriers, 125

Bahtilett, 38

Bat, 33

wing of, 42,47

Bateson, 5

Bats, 127, 144

Bavaria, 96

Beagle, H. M. S., 15, 16

Bears, 32, 131, 14.0

polar, 120

short-faced, 135

Bees, 89

Beetle, larvæ of, 154 
Beetles, Cenozoic, 89 embryo, 68

Belemnites, 91

Bering Sea, 106, 186 Strait, 106, 126

Bermuda, birds of, 146

Binomial nomenclature, 38

Biogenetic law, 57

Bird, wing of, 42,48

Birds, 33, 144 absence of from Palæozoic, 91 blood of, 79, 80

Cenozoic, 89 derivation from reptiles, 96 descent of, $7 \mathbf{1}$ fossil, 96

Mesozoic, 90 ontogeny of, 71

Bison, 182

Bivalves, 90

"Blood Immunity and Blood Relationship," 76

Blood tests, 73, 170

BouI, 39

Boreal zone, 132

Borneo, 124, 142, 143

Bouvier, 150, 153

Brachiopoda, Cenozoic, 89

ontogeny of, 65

Palæozoic, 92

Brachyceratops, 119

BraUer, 147

Brine-shrimp, 152

British Islands, 139

Bryozoa, 65

Buenos Aires, 125

Bufron, 94

Bumble bee, 53

Butterflies, 153
Butterflies, Cenozoic, 89 larva, 59

mouth-parts of, 53

Cactus, 121

California, Lower, 128

Cambrian fossils, 85 period, 85,87

Camels, 114 blood of, 78 distribution of, 129 evolution of, 114 true, 189

Canadian Rockies, 85

Canidæ, 32

Canis lupus, 32

Cannon-bone, 45, 114

Cape Verde Ids., 142, 145

Carboniferous period, 87, 95, 96

Caribbean Sea, 138

Caribou, 132

Carnivora, 32, 133, 135 blood of, 78

Carpus, 44

Cassowary, 50

Cagthe, 163

Casuarina, 143

Catastrophism, 11, 18

Caterpillar, 59, 153

Cats, 32, 134, 140

Cattle, 36, 144 wild, 121

Cebidæ, 77

Cenogenetic, 60

Cenozoic era, 87 life, 88

Central America, 127, 128, 189, 131, 136, 138 
Century plant, 121

Ceratops, 119

Cercopithecidæ, 77

Cetacea, 67

China, 170

Chordata, 65

Civets, 140

Class, 32, 125

Classification, 31

Cloven-hoofed, 45

Cockayne, 34

Cockroach, mouth-parts of, 53

Cockroaches, Palæozoic, 92

Cocoons, 153

Coleoptera, 89

Comparative anatomy, 48

Conifers, 90

Connecticut valley, 84

Continental islands, 141

Correns, 24, 159

Crabs, 53

Crayfishes, 144

Creative plan, 30, 88

Cretaceous period, 87, 118 vegetation, 90

Crinoids, 89

Crocodiles, blood of, 78, 79

Cenozoic, 89

Crustacea, 51, 52

Cenozoic, 89

Palrozoic, 92

Cryptogams, 91

Cuba, 143

Cuvier, 7, 10, 11, 88

Cycadofilices, 96

Cycads, Cenozoic, 88

Mesozoic, 90

Palæozoic, 91
DARWIN, 1, 3, 7, 8, 11, 18, 13, 14, $15,16,17,19,20,21,22,23,25$, $26,29,31,33,35,37,39,65,83$, $85,86,95,120,141,144,145$, $149,169,170$

Darwinians, 6, 25

Darwinism, 5, 6

Deer, 140

blood of, 78

Sonoran, 133

South American, 198

Virginia, 138

Degeneration, 72

Devonian period, 87

Dinosaurs, 118

Dipnoi, 65

Distribution, discontinuous, 128 geographical, 120

Dogs, 36

Dolphins, 67

Domesticated animals and plants, 35

Domestication, 35, 150

Dominant characters, 158

Dragon-flies, 92

East Indies, 141 mammals of, 143

Eastern hemisphere, 133

Egg, 62, 64

Egg-albumins, 78

Egypt, 94

Elephant, hairy, 132

Elephants, 80, 120, 123

history of, 93

true, 140

Elk, 132

Embryology, 57

English Channel, 126 
Eocene epoch, 87, 104, 105, 109, Formosa, 124 110,117

Eohippus, 102, 105

Equine family, 106

Equus, 102, 105, 108

Ethiopian region, 128, 139

Europe, 93, 104, 109, 123, 127, $128,129,130,131,132,138$

Eustachian Canal, 64

Experiment, 149

Extinction, 122, 140

Pleistocene, 106, 139, 135

Factor, 159, 162, 163, 165

Family, 32, 125

Fan-tail, 36

Faunas, island, 146

Ferns, 96

Cenozoic, 88

Palæozoic, 91

Fertilization, 160

Fibula, 100, 104, 114, 116

Fin-whale, 67

Fischer, 153

Fishes, 33

Cenozoic, 89

Cretaceous, 90, 93

fresh-water, 144

Mesozoic, 90

of Panama, 138

Palæozoic, 91

Fish-like forms, 91

Fissipedia, 32

Fleischmann, 1, 2, 29

Florida, 128

Flies, 89

Flowering plants, 91

Flying foxes, 48

Foot-prints, fossil, 84

Fossils, 85, 92, 123

Fowl, blood of, 79 embryo of, 63

Fowls, 36

Foxes, 32, 140

France, 10, 111, 132, 140

Frog, egg of, 63

larva of, 59

Frogs, 144

GAGer, 157, 165

Galapagos Ids., 15, 120, 144, 145

Ganoids, Cenozoic, 89

Mesozoic, 90

Palæozoic, 91

Gastropods, 90

Gazelle-camels, 116

Gegenbadr, 60

Gemminger, 40

Genetics, 24, 157

Genus, 32, 125

Geological record, imperfection of, 83

Georgia, 130

Germany, 10, 24

Giard, 9, 10

Giesenhagen, 151, 166, 167, 172

Gill-pouches, embryonic, 64

Giraffe-camels, 118

Giraffes, 140

Glyptodonts, 133, 135

Gnawers, 70, 103

Goats, 144

blood of, 78

Graham-Smith, 76, 77

Grasses, 88, 103

Great Britain, 123, 124, 142

Plains, 113 
Greek islands, 124

Greenland, 131

Ground-pines, 88

Ground-sloths, 123, 133, 135

Guanaco, 114, 115, 117, 189

Guiana, 138

Guinea pigs, 163

H开CKEL, 37, 57

Haiti, 143

Hapalidæ, 77

Hawaiian Ids., 142, 146

Hen, egg of, 62

Heredity, 19

“History of Creation," 57

Holarctic region, 128, 131, 132, 139

Hoofed animals, 103, 134, 135

Horse, 33, 46

blood of, 76

fore leg of, $42,43,44,45,46$

mountain, 107

Horses, 36, 123, 135

browsing, 107

evolution of, 98

Eocene, 104

Miocene, 101, 102

Oligocene, 103

Pleistocene, 99, 106

Pliocene, 101

Recent, 99

South American, 106, 107

spread of 125

wild, 121

Horse-shoe crab, blood of, 79 ontogeny of, 65

Horse-tails, 95

Cenozoic, 88

Palæozoic, 91

Houses, development of, 30
Humerus, 43

Hutron, 12

HUXLEY, 14, 171

Hybridization, 164, 167

Hyenas, 140

Hymenoptera, 89

Immutability of species, 11, 29, 31, $36,88,120,137$

India, 123, 129

Insects, 144

Cenozoic, 89

embryo, 68

mouth-parts of, 53

Palæozoic, 98

Invertebrates, Cenozoic, 89

Mesozoic, 90

Palæozoic, 91

Ireland, 148

"Island Life," 141

Islands, animals and plants of, 141 continental, 141 oceanic, 141, 144

Italy, 124, 139

Jackals, 32

Jaguar, 140

Jalap, 159, 160

Jamaica, 39, 121

Japan, 124, 128

Java, 124, 142, 143

Jurassic period, 87, 96, 97

Kamchatka, 132, 140

KAMMEReR, 155

KAPTEREW, 153

Kentucky, 130

Krakatoa, 143

KÜKENTHAL, 69 
Labrador, 130

LAMARCK, 7, 8, 9, 10, 13, 19, 22, 31, 33

Lamp-shells, 65, 89

Lancelet, 65

I.ANG, 161

Languages, 55

Larvæ, 59

Lemurs, blood of, $\mathbf{7 7}$ eye of, 76

Lepidoptera, 89

Lepus cunioulus, 37 huxley, 37

Lichens, 88

Lilies, 88

LINNAUS, 7, 11, 29, 32, 33

Lions, 120, 123

Lizard, fore leg of, 42

Lizards, 144 blood of, 78, 79

Cenozoic, 89

Llama, 114, 123, 129, 134

Lobster, 51

Los Angeles, 123

Lung-fishes, 65, 89

Lungs, derivation of, 64

Lycopods, 95

Cenozoic, 88

Palæozoic, 91

LYDEKKER, 66

LYELL, 11, 12, 13, 16

MAAs, 54

MacDodgal, 157, 165

Macula lutea, 76

Madagascar, 124, 128, 142

Madeira, 142

birds of, 146

Malagasy region, 128
Malay Archipelago, 128, 170

"Malay Archipelago, The," 141

Malta, 124

Malthus, 17

Mammalia, 32, 33

Mammals, absent from Palæozoic, 91

ancestry of, 4, 97

blood of, 78, 80

Cenozoic, 89

Mesozoic, 90, 98

Tertiary, 98, 131

Mammoth, Siberian, 132, 140

Man, arm and hand of, 42, 43, 44,46

blood of, 74

body of, 80

embryo of, 63

eye of, 76

Pleistocene, 138

Marmosets, 134

blood of, 77

Marsupials, 187

Australian, 134, 135

blood of, 78

Maryland, 84

Massachusetts, 84, 121

Mastodons, 183, 135, 139

Mediterranean lands, 121, 140

Sea, 59, 139

MENDEI, 22, 24, 157, 158, 161

Mendelian laws, 162, 163, 164

Mendelism, 5

Mesohippus, 102, 105

Mesozoic era, 87, 90, 98, 118

Metacarpal, 44, 45

Mexico, 106, 128, 132, 133, 136, 138

Mice, 187, 134, 144

albino, 163 
Mice, fancy, 168

Migration, 93

Miocene epoch, 87, 93, 101, 102, $106,107,109,113,116,133,135$

Missing links, 171

Mole, 33

fore leg of, 42

Mollusca, Cenozoic, 89

Mesozoic, 90

ontogeny of, 65

Palæozoic, 92

Mongoose, 121

Monkey, 33

Monkeys, blood of, 77

eye of, 76

Old World, 76, 77, 134

South American, 76, 77, 133

Moose, 132

Morgan, 164, 165

Morocco, 124

Mosquito, 53

Mosses, 88

Monoclonius, 119

Monotremes, 127

Moth, Brown-tail, 121

Gypsy, 181

Lunar, 39, 154

Moths, 153

Cenozoic, 89

mouth-parts of, 53

Mouse, 162

Musk-ox, 120, 130

Mutation, 162, 167

Theory, 23

Mutations, 23

NÄGELI, 20

Natural Philosophers, 10

Selection, 14, 18, 20, 25
Nebraska, 113

Neo-Darwinian school, \&2

Neogæa, 128

Neotropical region, 128, 131, 133, 134,136

Neptune, 171

New England, 140

Guinea, 127

Hampshire, 130

Jersey, 84

World, 111, 140

Zealand, 34, 89, 142

Newts, 144

North America, 93, 104, 107, $109,110,112,114,121,122$, $123,127,128,129,131,132$, $133,134,135,136,137,140$, 169

horses of, 98, 106

North Sea, 59, 139

Northern hemisphere, 129, 131

NotTaLL, 73, 74, 76, 77

Oaks, American, 34

Oceanic islands, 141, 144

Oklahoma, 130

Old World, 111, 114, 123, 131, 132, $133,134,138,140$

Oligocene epoch, 87, 108, 103, 105, $110,112,113,115,117$

Ontogeny, 57, 68

Opossum, 127, 133, 134

OrBIGNY, A. D', 11

Order, 32, 125

Ordovician period, 87

Oriental region, 128, 129

"Origin of Species," 1, 17, 65, 83, 169

Osborn, 111 
Ostrich, blood of, 79 wing of, 50

Otters, 32, 134

$0 x$, blood of, 78 fore leg of, 44, 45, 46

Pacific, islands of South, 142

Palæontology, 55, 82

Palæotheres, 107

Palæozoic era, 87 life, 91

Paleocene epoch, 87, 104

Palingenetic, 59, 60

Palms, 88, 120 cocoa-nut, 143

Pampas, 15

Panama, Isthmus of, 131, 134, 138 marine fishes of, 138

Parasites, 78

Patagonia, 135

Peas, 158

Peccaries, 134

Penguins, 50

Pennsylvania, 84, 109

Perissodactyla, 112

Permian period, 87, 98

"Philosophie Zoölogique," 8

Phylogeny, 57

Phylum, 32

Pictet, 153

Pigeons, 36

Pigs, 144

Plants, Carboniferous, 95

Cenozoic, 88

Cretaceous, 93

evolution of, 166

modification of, 150

of White Mts., 130

origin of cultivated, 28
Pleistocene epoch, 87, 99, 106, 109, $116,122,189,130,131,132$, $133,138,140$

Pliocene epoch, 87, 101, 106, 107, $108,109,113,129$

Pliohippus, 108

Poëbrotherium, 115, 117

Pointer, 36

Porcupine, Canada, 133

Porto Rico, 143

Porto Santo, 37, 39

Potato-beetle, 155, 164

Pouter, 36

Pre-Cambrian eras, 87

Preformation, 62

Procamelus, 115, 117

Protohippus, 102, 105

Protylopus, 115, 117

Province, zoỏlogical, 128

Pterodactyls, 50

Quadrupeds, 32, 89

Quaternary period, 87

Rabbit, European wild, 37

Falkland Id., 39

Jamaica, 39

Porto Santo, 37

Rabbits, 121, 134, 144

Raccoons, 32, 134, 140

Races, geographical, 34

Radius, 43, 44, 45, 100, 104, 114

Rails, 146

Ranunculus, 151

Rats, 134, 144

Raven, 49

RAY, 7

Realm, zoölogical, 136

Recapitulation theory, 57, 61, 64, 73 
Recent epoch, 87, 99, 101

Recessive characters, 158

Record, geological, 95 palæontological, 93

Region, zoölogical, 126, 127, 136

Reindeer, 138

Reptiles, 33, 144

age of, 90

Cenozoic, 89, 90

Mesozoic, 90

Permian, 98

Rhinoceros, African, 111

Indian, 111, 112

Siberian, 140

Sumatran, 111

Rhinoceroses, 120

aquatic, 110, 111

cursorial, 110

evolution of, 110

paired-horn, 113

true, 110, 111

Rodentia, see Rodents.

Rodents, 103, 133

rudimentary teeth in, 70

porcupine-like, 134

Rudimentary organs, 56, 66

Rudiments, 44:

Ruminants, blood of, 78

ontogeny of, 69

Russia, 170

Sabre-tooth tigers, 123, 135

Sacculina, 72

Sago palms, 88

Sahara, 128, 139

St. Helena, birds and reptiles of, 146

Salamander, 144, 156
Saturnia bolli, 40 luna, 39, 40

Scandinavia, 131, 132

Schlossar, 171

Scemankewitsch, 152

SCHRÖDER, 153

Scorpions, 65, 79, 92

Sсотт, 28

Sea-lilies, Cenozoic, 89

Palæozoic, 92

Sea-lions, 32

Seals, 32

Segregation, 159

Selenka, 143

Sera, anti-carnivore, 78

Serum, 74

anti-fowl, 75

anti-horse, 75

anti-human, 75, 77

anti-lizard, 79

anti-llama, 78

anti-pig, 75, 78

anti-turtle, 78

Sexual selection, 19

Seychelles, 142

Shark, embryo of, 63

Sharks, Cenozoic, 89

Mesozoic, 90

Palæozoic, 91

Sheep, 36, 132

blood of, 78

embryo of, 70

Shells, fresh-water, 144

Sicily, 124

Silurian period, 87

Simiidæ, 77

Skunks, 134

Sloths, 134

Snail, garden, 161 
Snails, 144

Snakes, blood of, 78, 79

Cenozoic, 89

limbs of, 67

Solenhofen, 96

Sonoran region, 128, 131, 132, 133, $134,136,138$

South America, 15, 110, 114, 120, $121,123,127,128,129,130$, $131,133,134,135,136,137$, $140,145,169,170$

birds of, 134

horses of, 106

mammals of, 130, 133

Tertiary mammals, 131, 169

Spain, 123, 139

Spaniel, 36

Special creation, $7,29,30,35,66$,

$67,86,88,120,129,137,148$

Specific centres, 125

SPENCER, 18

Sphenophyllales, 95

Spiders, 65, 79, 144

Palæozoic, $9 z$

Splint-bones, 45

Sports, 23

Squirrels, 134

rudimentary teeth of, 71

Stag, red, 132

STANDFUSS, 153

StetnmanN, 3, 98

Straits of Magellan, 125

Strangeways, 76

Struggle for existence, 18, 24

Styracosaurus, 119

Sub-order, 32

Subregion, 128

Subspecies, 34

Sumatra, 142, 143
Survival of the fittest, 18

Switzerland, 39, 154

Tadpole, 59, 156

Tapirs, 123, 134 distribution of, 129, 130 evolution, 109

Tasmania, 127

Tasmanian Wolf, blood of, 78

Teleosts, 89

Terrier, 36

Tertiary period, $87,98,106,127$. 189,131

Texas, 39, 154

Thylacine, blood of, 78

Tigers, 180

Toad, larvæ of, 156

Toads, 144

Torosaurus, 119

Tower, 155, 164, 166

Transitional zone, 132

Triassic period, 84, 87, 97

Triceratops, 119.

Trilobites, 92

Trochophore, 68

Troxeid, 108

Tschermak, 24

Tse-ste flies, 126

Tumbler, 36

Tunicata, 65

Tunis, 124

Turtles, blood of, 78,79

Cenozoic, 89

Type of structure, 42, 54, 55

Ulna, 43, 45, 100, 103, 114, 116

Uniformitarianism, 12

Unit characters, 158,165

United States, 132, 135 
Uranus, 171

Utah, 171

Variability, 17

Variations, 23

Varieties, 34

Vegetation, Carboniferous, 95

Cenozoic, 88

Mesozoic, 90

Palæozoic, 91

Vertebrata, 32

Vertebrates, ontogeny of, 63

Palæozoic, 91

Virginia, 84

VRIEs, H. DE, 23, 24, 26

Vulpes, 38

WAAGEN, 22, 23

WAGNER, 21, 40, 41

WALCOTT, 85

WALLACE, 13, 141

Walrus, 32, 130

Wapiti, 132

Wasps, 89

Water-fleas, 183
Weasels, 32, 134

Weeds, European, 121

Weismann, 20, 21, 22, 153

West Indies, 12\%, 128

mammals of, 143

Western hemisphere, 127, 136

Whale, 33

flipper of, 4, 46,47

Greenland Right, 47, 67

Whales, blood of, 78 development of, 69 limbs of, 67 toothed, 67

White Mts., 130

Wilson, 3, 26, 62

Wolf, 32

Wolverenes, 131

Wolves, 32, 123, 134, 140

Wonder of Peru, 159

Worms, embryo of, 68 ontogeny of, 59,65

Wrist-joint, 43

ZARCO, 37

Zebres, 99

Printed in the United States of America 



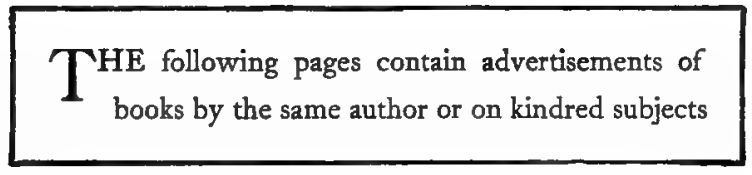





\section{A History of Land Mammals in the Western Hemisphere}

With many illustrations made from paintings by W. B. Horsfall and others

Decorated cloth, $8 v 0, \$ 5.00$

For nearly half a century a constant and ever-widening stream of discovery has brought to light a multitude of the animal forms which successively inhabited North and South America, but long ago vanished from the earth. This wonderful mammalian history has been slowly and laboriously deciphered by many workers, and the results of their investigations are scattered widely through the scientifie journals of nearly every European language and are thus inaccessible to the general educated public. It is highly desirable to bring together the more significant of these results in a form which shall be intelligible to the reader who is interested in the progress of science, but cannot make use of technical papers. After a discussion of the methods of investigation, a sketch is given of the geographical history of the western hemisphere and of the mammalian groups which successively inhabited it. This is followed by a series of chapters dealing with the evolution of those land mammals whose history is known, and finally are described the inferences as to the operation of the evolutionary process which may be drawn from the study of these histories. The numerous illustrations by Mr. Bruce Horsfall and Mr. Charles Knight make the marvellous tale of development clear with a minimum of technical description.

\section{THE MACMILLAN COMPANY \\ Publishers 64-66 Fifth Avenue New York}




\section{An Introduction to Geology}

Cloth, illustrated, $12 m o, 816$ pages, $\$ 2.60$

This is intended to serve as an Introduction to the science of Geology, for both students who desire to pursue the subject exhaustively, and those who wish merely to obtain an outline of the methods and principal results of the science. This is not one of the text-books which always pronounce a definite and final opinion. The author holds that in no science are there more open questions than in Geology, in none are changes of view more frequent, and in none is it more important to emphasize the distinction between fact and inference, between observation and hypothesis. The student is here encouraged to weigh evidence and balance probabilities and to suspend judgment when the testimony is insufficient to justify decision. The author is an advocate of the new geology, and his book presents all the latest advances in science. After an introductory chapter and a survey of the rock-forming minerals, the author takes up in turn Dynamical Geology, Structural Geology, Geomorphology and Historical Geology. An appendix contains a classification of all plants and animals possessing importance as fossils. Over three hundred illustrations largely from photographs and numerous plates enhance the practical value of the book.

\section{THE MACMILLAN COMPANY Publishers 64-66 Fifth Avenue New York}




\title{
Genetics. An Introduction to the Study of Heredity
}

\author{
By HERBERT EUGENE WALTER \\ Associate Professor of Biology, Brown University \\ Cloth, $12 m o, \$ 1.50$
}

In his "Genetics" Professor Walter summarizes the more recent phases of the study of heredity and gives to the non-technical readers a clear introduction to questions that are at present agitating the biological world.

Professor Walter's conception of sexual reproduction is that it is a device for doubling the possible variations in the offspring, by the mingling of two strains of germ plasm. The weight of probability, he concludes, is decidedly against the time-honored belief in the inheritance of acquired characters. Professor Walter also predicts that the key to this whole problem will be furnished by the chemist, and that the final analysis of the matter of the "heritage carriers" will be seen to be chemical rather than morphological in nature. In the practical application of this theory to human conservation or eugenies, it would follow that the only control that a man has over the inheritance of his children is in selecting his wife. Professor Walter holds, if only modifications of the germ plasm can count in inheritance, and if these modifications come wholly from the combination of two germ plasms, then the only method of hereditary influence is in this selection.

"I find that it is a very useful study for an introduction to the subject. Professor Walter has certainly made one of the clearest statements of the matters involved that I have seen, and has made a book which students will find very useful because he keeps everything in such entirely simple and clear outlines, and at the same time he has brought the book up to date." -Professor Loomis of Amherst College.

"I am much pleased with it and congratulate you upon securing so excellent a treatment. It is one of the most readable scientific books I have, and goes unerringly to the fundamentals of our most recent advances in the experimental study of heredity as well as those of the older studies."-Professor George H. ShuLL, Cold Spring Harbor, Long Island, N. Y.

"There was a decided need for just such a work. The book strikes me as most excellently done."-Professor H. S. Jennings, Johns Hopkins University.

\section{THE MACMILLAN COMPANY \\ Publishers 64-66 Fifth Avenue New York}




\section{The Germ-Cell Cycle in Animals}

BY ROBERT W. HEGNER

Assistant Professor of Zoölogy in the University of Michigan, author of "An Introduction to Zoölogy" and "College Zoölogy." New York, 1914.

346 pages, ill., $12 m o, \$ 1.75$

An excellent survey of a subject which is extremely important to all biologists and a book available for use as a supplementary text in courses on Cellular Biology, Evolution, Heredity, and Genetics. The term "Germ-Cell Cycle" is meant to include all those phenomena concerned with the origin and history of the germ cells from one generation to the next generation. Contrary to the usual custom, the period of the germ-cell cycle which is emphasized in this book is not the maturation of the germ cells, but the segregation of the germ cells in the developing egg and the visible substances (keimbahn-determinants) concerned in this process. While the author's treatment is technical, he has presented the data available in such a clear way as to make them intelligible to those who have not been able to follow in detail the progress of cytology during the past few years.

\section{THE MACMILLAN COMPANY Publishers 64-66 Fifth Avenue New York}











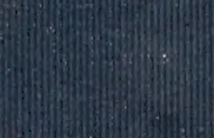